\title{
CARACTERIZAÇÃO GENÉTICA E FISIOLÓGICA DE Crinipellis perniciosa
}

\author{
TAÍS GUIMARÃES LANA
}

Tese apresentada à Escola Superior de Agricultura "Luiz de Queiroz", Universidade de São Paulo, para obtenção do título de Doutor em Agronomia, Área de Concentração: Microbiologia Agrícola.

\author{
PIR A C I C A B A \\ Estado de São Paulo - Brasil
}

Fevereiro - 2004 


\title{
CARACTERIZAÇÃO GENÉTICA E FISIOLÓGICA DE Crinipellis perniciosa
}

\author{
TAÍS GUIMARÃES LANA
}

Bióloga

Orientadora: Profa. Dra. REGINA TERESA ROSIM MONTEIRO

Tese apresentada à Escola Superior de Agricultura "Luiz de Queiroz", Universidade de São Paulo, para obtenção do título de Doutor em Agronomia, Área de Concentração: Microbiologia Agrícola.

\author{
PIR A C I C A B A \\ Estado de São Paulo - Brasil \\ Fevereiro - 2004
}


Dados Internacionais de Catalogação na Publicação (CIP) DIVISÃO DE BIBLIOTECA E DOCUMENTAÇÃO - ESALQ/USP

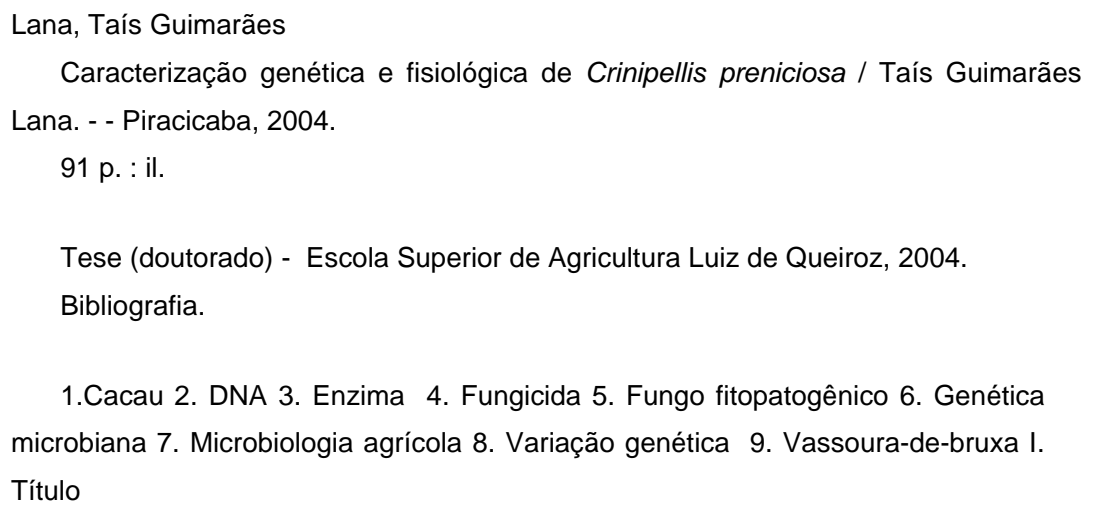

CDD 633.74 
À minha querida mãe Imaculada

Ao meu amado e saudoso pai Sebastião

\section{DEDICO}




\section{AGRADECIMENTOS}

- A Deus, por tudo que tem me proporcionado, pois todas as coisas foram feitas por Ele, e sem Ele nada seria possível;

- À Profa. Dra. Regina Teresa Rosim Monteiro pela orientação e apoio;

- Ao Prof. Dr. João Lúcio de Azevedo pela amizade, oportunidade e confiança;

- Ao Wellington L. Araújo pelo carinho, confiança, incentivo, paciência e apoio indispensável em todas etapas desse trabalho;

- À Profa. Dra. Aline Aparecida Pizzirani-Kleiner pela amizade e oportunidade de utilizar o Laboratório de Genética de Microrganismos "Prof. João Lúcio de Azevedo";

- Ao Ricardo Yara (Pipa) pela grande ajuda prestada em diferentes etapas do trabalho;

- Ao Rodrigo Mendes pela indispensável ajuda nas análises estatísticas;

- À Adalgisa Torres, Ágata Cristiane, Cristina Maki, Maria Clara Pestana, Fernando Barcelos, Júlia Sobral, Luciana Cursino e Mayra Martins e pela amizade;

- À Joelma e ao técnico José Antônio (Zezo) pela amizade e agradável convivência;

- Aos demais colegas de laboratório, pelo agradável convívio;

- À Almirante Cacau na pessoa do Dr. Allan Pomela por ceder gentilmente as instalações da Almirante Cacau para realização de parte dos experimento;

- À CAPES pelo apoio financeiro;

- Aos professores do curso de Microbiologia Agrícola;

- Às secretárias Sara e Giovana pela ajuda. 


\section{SUMÁRIO}

LISTA DE FIGURAS ……................................................................... viii

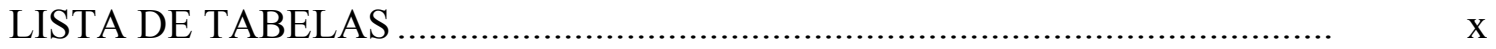

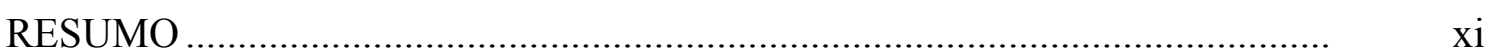

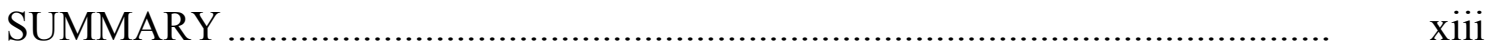

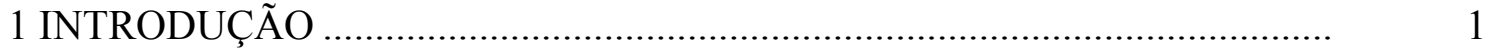

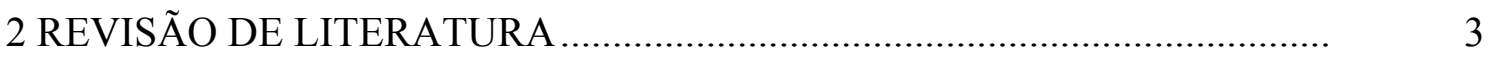

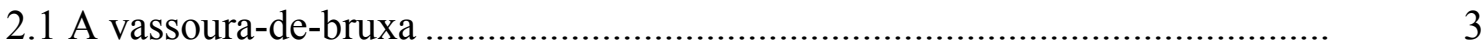

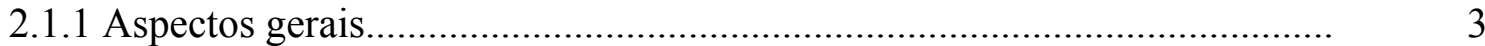

2.1.2 O Fungo Crinipellis perniciosa ...............................................................

2.1.3 Controle da doença..................................................................................

2.2 Variabilidade genética detectada por RAPD (Random Amplied

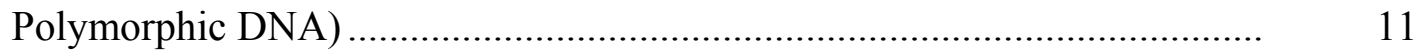

2.3 Variabilidade genética por sequenciamento do rDNA (DNA ribossômico)... 13

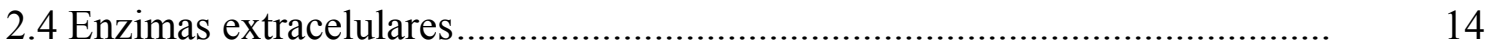

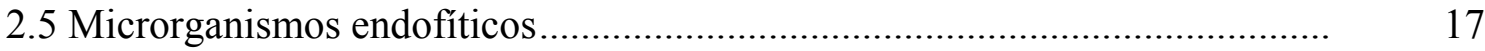

3 MATERIAL E MÉTODOS _.................................................................... 20

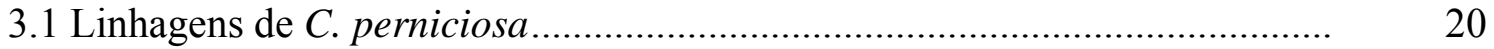

3.2 Meios de cultura e soluções ............................................................................ 20

3.2.1 Meio Batata Dextrose Ágar (BDA) .......................................................... 20

3.2.2 Meio BDA enriquecido ....................................................................... 22

3.2.3 Meio Mínimo (Pontecorvo et al., 1953).................................................... 22

3.2.4 Meio Mínimo modificado para produção de pectinases ................................ 22

3.2.5 Meio Ágar-Água …................................................................................. 23

3.2.6 Substrato para produção de basidiocarpos ...................................................... 23 


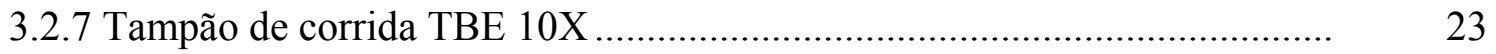

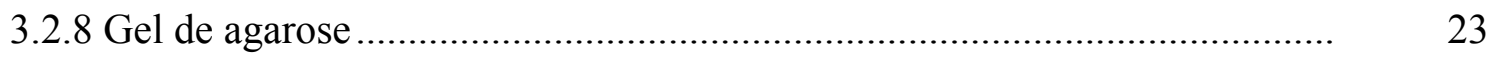

3.2.9 Solução de brometo de etídio (Sambrook et al., 1989) ............................... 24

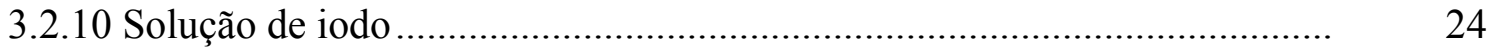

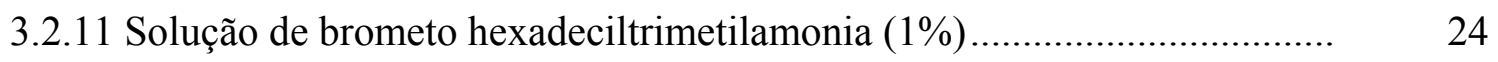

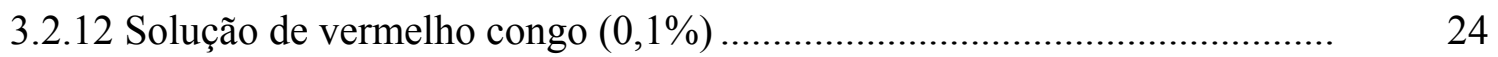

3.2.13Solução para coleta de esporos .............................................................. 24

3.3 Isolamento de C. perniciosa de cacau........................................................... 25

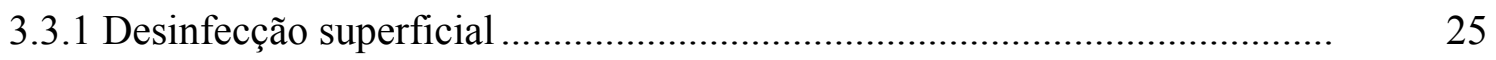

3.3.2 Seleção de isolados de C. perniciosa.........................................................

3.4 Caracterização e análise da variabilidade genética de C. perniciosa por RAPD

e seqüenciameto de regiões ITS ............................................................ 25

3.4.1 Extração de DNA total ............................................................................ 26

3.4.2 Quantificação do DNA........................................................................... 26

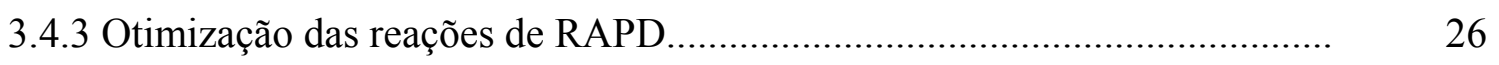

3.4.4 Análise da variabilidade por RAPD ...................................................... 26

3.4.5 Sequenciamento do rDNA de C. perniciosa ............................................ 28

3.5 Produção de enzimas extracelulares............................................................ 28

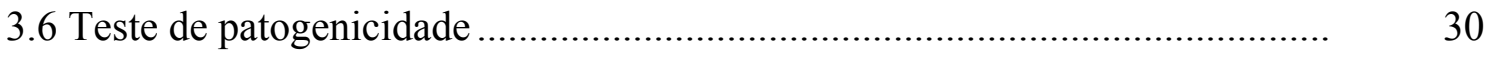

3.7 Avaliação in vitro da resistência/susceptibilidade de C. perniciosa a diferentes

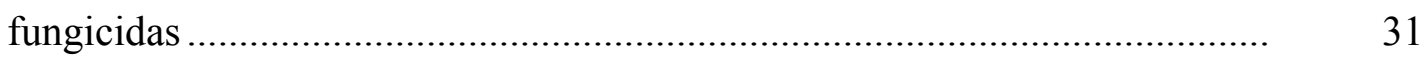

4 RESULTADOS E DISCUSSÃO .......................................................... 32

4.1Isolamento de C. perniciosa endofítico provenientes de T. cacao ................... 32

4.2 Análise de variabilidade genética por meio de marcadores RAPD ................ 35

4.2.1 Padronização da técnica de RAPD e seleção de oligonucleotídeos ............. 35

4.2.2 Variabilidade genética por meio de marcadores RAPD ............................. 37

4.3 Análise do rDNA de C. perniciosa......................................................... 40

4.4 Produção de enzimas extracelulares................................................................ 44

4.5 Análise de patogenicidade................................................................ 50

4.6 Efeito de fungicidas sobre o crescimento micelial in vitro de C. perniciosa.. $\quad 52$ 


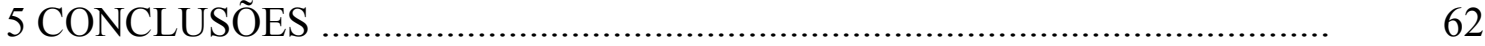

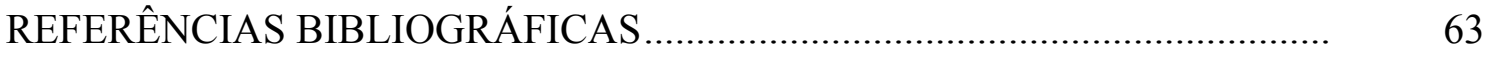

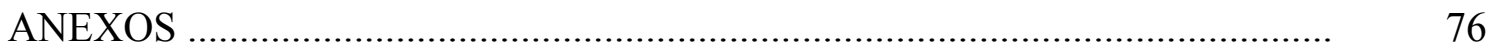




\section{LISTA DE FIGURAS}

Página

1 Aspecto morfológico de hifas de C. perniciosa. A seta indica a presença

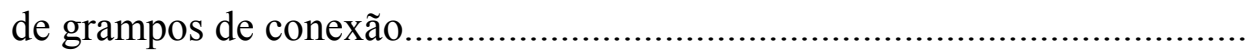

2 Aspectos morfológicos de diferentes linhagens de $C$.

perniciosa

3 Amplificação de DNA de C. perniciosa com o iniciador OPX17, para verificar a condição ótima de reação, em função da concentração de íons $\mathrm{Mg}^{++}$e Taq polimerase ..................................................................... 36

4 Gel de eletroforese mostrando padrões de RAPD obtidos de 35 isolados de C. perniciosa usando o primer OPX 17............................................. 39

5 Dendrograma de similaridade genética baseada em padrões de RAPD de

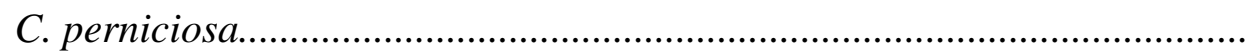

6 Gel de eletroforese mostrando padrão de amplificação de regiões do

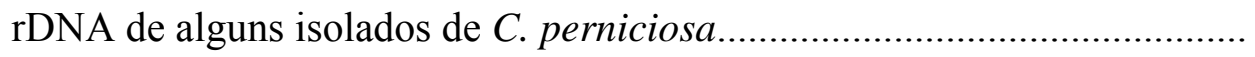

7 Dendrograma construído com a análise das seqüências de rDNA (ITS1 +

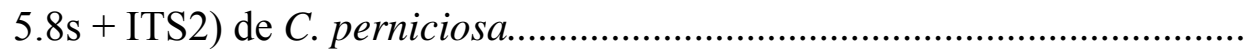

8 Relação Halo/Colônia $(\mathrm{H} / \mathrm{C})$ das linhagens de $C$. perniciosa com relação à

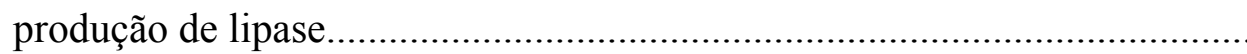

9 Relação Halo/Colônia $(\mathrm{H} / \mathrm{C})$ das linhagens de C. perniciosa com relação à produção pectinase.

10 Relação Halo/Colônia $(\mathrm{H} / \mathrm{C})$ das linhagens de $C$. perniciosa com relação à produção endoglicanase 
11 Relação Halo/Colônia $(\mathrm{H} / \mathrm{C})$ das linhagens de C. perniciosa com relação à produção amilase

12 Isolado FA 35 de C. perniciosa crescida em meio mínimo suplementado com tween como fonte de carbono

13 Isolado 3 de C. perniciosa crescida em meio mínimo suplementado com carboximetil celulose como fonte de carbono.

14 Isolado FA 152 de C. perniciosa crescida em meio mínimo suplementado com amido como fonte de carbono.

15 Plantas de T. cacao. A - controle e B - inoculadas com esporos de C. perniciosa

16 Inibição do isolado endofítico 54 de crinipellis perniciosa pelos fungicidas: óxido cuproso, benomil, mancozeb e tebuconazole.

17 Porcentagem de inibição de isolados de C. perniciosa submetidas a 1 ppm do fungicida tebuconazole

18 Porcentagem de inibição de isolados de C. perniciosa submetidas a 10 ppm do fungicida tebuconazole

19 Porcentagem de inibição de isolados de C. perniciosa submetidas a 100 ppm do fungicida benomil

20 Porcentagem de inibição de isolados de C. perniciosa submetidas a 400 ppm do fungicida benomil.

21 Porcentagem de inibição de isolados de C. perniciosa submetidas a 100

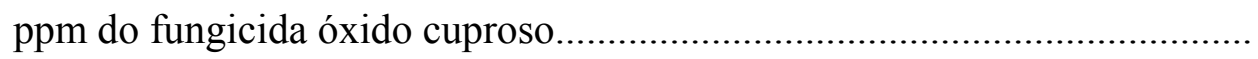

22 Porcentagem de inibição de isolados de C. perniciosa submetidas a 400 ppm do fungicida óxido cuproso.

23 Porcentagem de inibição de isolados de C. perniciosa submetidas a 100 ppm do fungicida mancozeb..................................................................

24 Porcentagem de inibição de isolados de C. perniciosa submetidas a 400 ppm do fungicida mancozeb 


\section{LISTA DE TABELAS}

Página

1 Relação dos isolados de C. perniciosa utilizados no presente trabalho......... 21

2 Seqüência e conteúdo de GC dos oligonucleotídeo iniciadores utilizados para análise de C. perniciosa por marcadores RAPD... 


\title{
CARACTERIZAÇÃO GENÉTICA E FISIOLÓGICA DE Crinipellis perniciosa
}

\author{
Autora: TAÍS GUIMARÃES LANA \\ Orientadora: Profa. Dra. REGINA TERESA ROSIM MONTEIRO
}

\section{RESUMO}

O fungo basidiomiceto Crinipellis perniciosa é o agente causal da vassoura-debruxa do cacaueiro (Theobroma cacao), podendo causar sérios perdas na produção. Este fungo é capaz de colonizar, além do cacau, várias outras plantas hospedeiras, onde pode se adaptar às novas condições, contribuindo, dessa forma, para o aumento da variabilidade genética desse microrganismo. Assim sendo, o objetivo desse trabalho foi isolar e identificar C. perniciosa de tecidos sadios de cacaueiro e comparar a sua variabilidade genética e fisiológica com isolados patogênicos por meio de análises moleculares e fisiológicas. Após a desinfecção e retirada da casca dos ramos, colônias morfologicamente similares a C. perniciosa foram obtidas de tecidos sadios de cacaueiro, os quais foram considerados como endófitos. A identificação preliminar desses isolados foi baseada nas observações morfológicas, tais como coloração da colônia e presença de grampos de conexão. Posteriormente, os isolados de C. perniciosa foram caracterizados geneticamente por RAPD, e sequenciamento de regiões do rDNA $(18 \mathrm{~S}+5.8 \mathrm{~S}+28 \mathrm{~S})$, resistência a fungicidas, produção de exoenzimas e patogenicidade ao cacaueiro. A análise por marcadores RAPD separou os 37 isolados em 8 grupos (G1 a G8), sendo o grupo G1 dividido em 2 subgrupos (G1-1 e G1-2). Por esta análise foi possível observar que linhagens com $100 \%$ de similaridade foram isoladas de locais diferentes, enquanto que isolados obtidos de uma mesma planta podem ser geneticamente diferentes. A análise da seqüência do rDNA dos isolados de $C$. 
perniciosa mostrou a formação de 6 grupos distintos (R1 a R6). Isolados obtidos de uma mesma planta não se agruparam, reforçando a hipótese de que isolados geneticamente diferentes podem ocupar a mesma planta hospedeira. Quanto resistência a fungicidas (tebuconazole, mancozeb, benomil e óxido cuproso), foi observado que tebuconazole foi o mais eficiente na inibição do crescimento miceliar, enquanto benomil apresentar menor taxa de inibição. Isolados endofíticos e patogênicos apresentaram comportamento similar em relação aos fungicidas. Resultado semelhante foi observado quanto a produção de exoenzimas (amilase, lipase, pectinase, exo e endoglicanase). Foi observada a produção de todas as enzimas avaliadas, sendo possível detectar variações entre os isolados. Entretanto, esta variação não foi correlacionada ao hábito endofítico ou patogênico. A patogenicidade de 8 isolados de C. perniciosa foi avaliada em mudas de cacau Catongo. A porcentagem de plantas infectadas com sintomas variou de 55\% a $100 \%$. Isolados endofíticos apresentaram baixa virulência sobre o cacaueiro, tendo o isolado endofítico 31 induziu sintomas em 60\% das plantas inoculadas, resultado este provavelmente devido à alta pressão de inóculo. Este trabalho mostra pela primeira vez C. perniciosa como endófito em tecidos não meristemático do cacaueiro. 


\title{
GENETIC AND FISIOLOGICAL CHARACTERIZATION DE Crinipellis perniciosa
}

\author{
Author: TAÍS GUIMARÃES LANA
}

Adviser: Profa. Dra. REGINA TERESA ROSIM MONTEIRO

\section{SUMMARY}

The basidiomycete fungus Crinipellis perniciosa (Stahel) Singer is the causal agent of Witches' Broom Disease of Cacao (Theobroma cacao L.) which is the main factor limiting cocoa production in the Americas. Pod losses of up to $90 \%$ are experienced in affected areas as evidenced by the 50\% drop in production in Bahia province, Brazil following the arrival of the C. perniciosa in the area in 1989. The disease has proven particularly difficult to control and many farmers in affected areas have given up cacao cultivation. Any useful control strategy for Witches' Broom disease must be effective against in range strains of the pathogen. It is already known that pathogenic variation exists among isolates of Crinipellis perniciosa obtained from different areas and host plants. However, any study was developed about the variability between endophytic and pathogenic population. In order to evaluate the genetic variability of 35 isolates of endophytic and pathogenic populations of Crinipellis perniciosa, the RAPD technique, ITS sequencing and fungicide susceptibility were performed. Genetic variability between 35 isolates of $C$. perniciosa was analysed by the random amplified polymorphic DNA (RAPD) technique, which indicated that isolates from other host plants were more diverse than isolates obtained from cacao plants. Among cacao isolates was observed at least two groups, one formed mainly by endophytic isolates and other by pathogenic ones. Analysis by ITS sequence grouped 
isolates independently of endophytic or pathogenic status. Fungicide susceptibility showed that cupric oxide inhibits statistically more endophytic isolates than pathogenic ones, showing that could have physiological differences between these populations. The present study highlighted the possible genetic and physiological differences between endophytic and pathogenic population of C. perniciosa. 


\section{INTRODUÇÃO}

O fungo basidiomiceto Crinipellis perniciosa, agente causal da vassoura-debruxa, é um conhecido e destrutivo patógeno das lavouras cacaueiras, causando grandes prejuízos à produção de cacau. Este fungo é um patógeno hemibiotrófico, que ataca tecidos meristemáticos quando na fase biotrófica e mais tarde cresce saprofiticamente em tecidos mortos, formando o basidiocarpo. Os basidiósporos liberados pelos basidiocarpos germinam e penetram nos tecidos da planta hospedeira induzindo sintomas em gemas vegetativas, almofadas florais, flores e frutos. Nas brotações vegetativas, as infecções induzem a hiperplasia do ramo, com emissão de lançamentos curtos e brotações laterais, com folhas apresentando, na sua maioria, crescimento reduzido.

Até 1989, data em que a vassoura-de-bruxa chegou à Bahia, este Estado correspondia a cerca de $84,5 \%$ da produção nacional e $15 \%$ da mundial, porém, com a ocorrência da doença na região cacaueira baiana, a produção de cacau caiu drasticamente transformando o Brasil de exportador em importador de cacau. Dessa forma, tendo em vista o grande impacto econômico e social representado por esta doença nas regiões produtoras de cacau, inúmeros programas de controle foram desenvolvidos, resultando, porém, no controle parcial da doença.

Estudos de variabilidade genética e fisiológica de C. perniciosa não são ainda conclusivos, pois apesar de existirem diferentes formas patogênicas, não se pode afirmar a existência de raças, visto que ainda não se estabeleceram hospedeiros diferenciais. Estudos genéticos deste patógeno poderiam fornecer valiosas informações de como este fungo interage coma planta hospedeira, permitindo a identificação de isolados 
hipovirulentos ou avirulentos, os quais poderiam contribuir para o desenvolvimento de estratégias de controle da doença.

Dessa forma, o presente trabalho teve por objetivos:

- Isolar C. perniciosa de tecidos sadios de cacau (Thebroma cacao);

- Analisar a variabilidade genética de isolados endofíticos e patogênicos de $C$. perniciosa por meio de marcadores RAPD (Random Amplified Polimorfism DNA);

- Analisar a variabilidade genética de isolados endofíticos e patogênicos de $C$. perniciosa por meio da análise de regiões do rDNA;

- Analisar a variabilidade genética de isolados de C. perniciosa de diferentes regiões por meio de marcadores RAPD e regiões do rDNA;

- Avaliar a relação entre a produção das exoenzimas pectinase, exo e endoglicanase, amilase e lipase e a patogenicidade de C. perniciosa;

- Avaliar a patogenicidade de C. perniciosa sobre Theobroma cacao;

- Avaliar, in vitro, a resistência/sensibilidade dos fungicidas benomil, folicur, mancozeb e óxido cuproso sobre os isolados endofíticos e patogênicos de C. perniciosa. 


\section{REVISÃO DE LITERATURA}

\subsection{A vassoura-de-bruxa}

\subsubsection{Aspectos gerais}

O fungo Crinipellis perniciosa é o agente causal da vassoura-de-bruxa (VB) causando grandes perdas na produção de cacau na América Latina e em várias ilhas do Caribe. Na Brasil o patógeno está presente em grandes áreas produtoras como no estado da Bahia causando perdas de até 90\% da produção (Purdy \& Schimidt, 1996). Por esse motivo, a área cultivada com o cacaueiro vem decrescendo de forma bastante significativa nos estados do Amazonas, Pará, Acre, Rondônia e, principalmente, no sul da Bahia, com uma redução em torno de 75\% na produção (Luz et al., 1997). Atualmente essa doença é um ponto de estrangulamento para a implantação de novos cultivos e para competitividade da cacauicultura nacional no mercado internacional (Silva, 1997).

Em 1957 foi criado pelo Governo Federal a "Comissão Executiva do Plano da Lavoura Cacaueira" - CEPLAC - com o objetivo de auxiliar os produtores de cacau no manejo das culturas. Porém, desde que a doença começou a dizimar as culturas de cacau na Bahia, um dos principais objetivos da CEPLAC tornou-se o estudo e desenvolvimento de técnicas para controlar a doença. O controle correto da vassoura-debruxa depende da fitossanitização (Bastos, 2000; Rudgard, 1987; Wheeler, 1987) que é caracterizada pela remoção de grupos de vassouras infectadas, nas quais os basidiocarpos são formados antes da estação chuvosa (Andebrhan et al., 1995), aplicação de fungicidas químicos e seleção de hospedeiros resistentes. Para a lavoura 
cacaueira no sul da Bahia a melhor opção tem sido a obtenção de cultivares resistentes à VB, a partir de germoplasmas selvagens, visto que a adoção de práticas de sanitização e aplicação de fungicidas cúpricos recomendados não foram suficientes para barrar a disseminação do patógeno. Além disso, o uso de cultivares resistentes é o método de controle preferido por ser o mais barato e de mais fácil manipulação (Andebrhan et al., 1995).

A vassoura-de-bruxa provoca, como sintoma característico, a formação dos brotos hipertrofiados, desenvolvimento excessivo nas regiões terminais da planta, aparecimento de inúmeras ramificações com entre nó curtos e folhas geralmente grandes, curvadas ou retorcidas, aparentando vassouras. No início, o desenvolvimento das vassouras é rápido, porém depois de 5-12 semanas começam a secar (Wheeler, 1987), podendo cair ou permanecer na planta. Nas almofadas florais os sintomas também podem ser caracterizados pela formação de vassouras. A gema reprodutiva é revertida para vegetativa que desenvolve brotações. Os frutos provenientes de flores infectadas apresentam forma modificada (frutos com formato de morango) que morrem prematuramente. Quando infectados ainda jovens $(1 \mathrm{~cm}$ de comprimento) ocorre a paralisação de seu crescimento e produzem deformações que lhe dão a forma característica de cenoura, secando e apodrecendo em seguida. Os frutos provenientes de flores normais são susceptíveis entre 8 a 12 semanas após a polinização e sob alto nível de infecção apresentam manchas amarelas ou escuras e duras no seu interior, em ambos os casos, apodrecidos ou endurecidos e petrificados. Nos frutos mais desenvolvidos (8 $\mathrm{cm}$ de comprimento) pode aparecer mancha negra, dura e irregular ficando as amêndoas unidas entre si, portanto, inaproveitáveis para consumo (Tovar, 1991). A disseminação do fungo ocorre, geralmente, pela dispersão dos basidiósporos pelo vento, chuva ou homem uma vez que estas estruturas são a única forma infectiva da doença (Rocha \& Wheeler, 1985). 


\subsubsection{O Fungo Crinipellis perniciosa}

O fungo Crinipellis perniciosa (Stahel) Singer é um destrutivo patógeno, causador da vassoura-de-bruxa em cacau (Theobroma cacao). Pertence à divisão Eumycota, subdivisão Basidiomycotina, ordem Agaricales e família Tricholomataceae. Em 1915, Stahel denominou o patógeno de Marasmius perniciosus e, em 1942, Singer, revisando o gênero Marasmius, o renomeou de C. perniciosa (Stahel) Singer (Griffth et al., 1994). Este fungo representa atualmente, um dos principais fatores limitantes na produção de cacau na América do Sul e nas Ilhas do Caribe, sendo assumido como o mais importante patógeno do cacaueiro que coevoluiu, com T. cacao, ambos endêmicos da Bacia Amazônica (Griffith et al., 1994).

A doença foi descrita pela primeira vez por Alexandre Rodrigues Ferreira, entre os anos de 1785 e 1787, porém só se tornou conhecida no começo deste século, quando os sintomas ocorridos no Suriname em 1895, foram descritos por Went em 1904 (Griffth et al., 1994). Além de causar a vassoura-de-bruxa no cacau, o fungo $C$. perniciosa também afeta outras espécies na família Sterculiaceae, como T. grandiflorum (cupuaçu), T. specious (cacauí), T. subincanum (cupuí) e T. obovatum (cacau cabeça de urubu); bem como membros da família Solanaceae, como Solanum lasiantherum e $S$. rugosum (juçara) (Bastos \& Evans, 1985), e membros da família Bixaceae, como Bixa orellana (urucunzeiro) (Bastos \& Anderbrhan, 1986). Recentemente, Rezende et al. (2000), reportaram Heteropterys acutifolia, pertencente à família Malpighiaceae, como um novo hospedeiro de C. perniciosa em Minas Gerais, um Estado não produtor de cacau. Basidiósporos, produzidos naturalmente neste hospedeiro, foram inoculados em mudas de cacau e induziram o desenvolvimento de sintomas da doença, sugerindo ser este um hospedeiro alternativo.

A capacidade de colonizar uma ampla variedade de hospedeiros alternativos pode contribuir para o aumento da variabilidade de C. perniciosa o qual parece apresentar 4 biótipos (Bastos et al., 1988): o biótipo-S, causador da vassoura-de-bruxa em solanáceas; o biótipo-B, causador de vassoura-de-bruxa em Bixa orellana; o biótipoL que coloniza liana, cujos basidiocarpos já foram encontrados em Arrabidaea 
verrucosa (cipó), embora sem qualquer evidência de sintomas da doença (Evans, 1978) e finalmente, o biótipo-C, que causa vassoura-de-bruxa no cacau. O fato de que $C$. perniciosa do cacau é capaz de causar os sintomas da vassoura-de-bruxa em B. orellana (Bastos \& Evans, 1985), juntamente com evidências culturais e moleculares, sugerem que o biótipo B é idêntico ao biótipo-C, já o biótipo-S e biótipo-C foram claramente diferenciados por perfis de isoenzimas e padrões de DNA mitocondrial (Griffith et al., 1994).

O biótipo-C de C. perniciosa possui um ciclo de vida hemibiotrófico, onde o fungo invade os tecidos meristemáticos da planta hospedeira como um biotrófico, mas posteriormente cresce saprofiticamente sobre os tecidos mortos. A infecção inicia-se quando tubos germinativos dos basidiósporos penetram em tecidos merismáticos da planta, como brotos apicais, flores e frutos (Muse et al., 1996 e Orchard et al., 1994). Silva \& Matsuoka (1999) observaram que o tubo germinativo penetra na planta hospedeira por meio dos estômatos, sem a formação de apressórios. Após a penetração do tubo germinativo entre as células do meristema jovem, o fungo inicia sua fase de crescimento biotrófico, denominado de fase primária (Muse et al., 1996 e Orchard et al., 1994). Nesta fase o fungo cresce intercelularmente, suas hifas medem de 5 a $20 \mu \mathrm{m}$, são irregularmente espessas, monocarióticas, sem grampos de conexão (Calle et al., 1982; Muse et al., 1996; Orchard et al., 1994 e Silva \& Matsuoka, 1999) e sem a formação de haustórios (Silva \& Matsuoka, 1999). Durante a invasão do fungo nos tecidos vegetais, ocorrem mudanças morfológicas na planta hospedeira, e, embora os mecanismos não estejam completamente elucidados, esta fase primária do fitopatógeno parece estimular tais respostas, as quais estão localizadas no ponto de infecção, onde ocorre considerável espessamento dos tecidos e desenvolvimentos das vassouras-de-bruxas (Orchard et al., 1994).

O fungo permanece na fase primária por um período de 4 a 6 semanas (Griffith \& Hedger, 1993) no interior das vassoura, quando então ocorre a necrose dos tecidos do hospedeiro. Esta mudança é associada a dicariotização do fungo e leva a uma outra fase, denominada fase secundária ou saprofítica (Muse et al., 1996). Existem duas hipóteses para a morte da vassoura: a primeira seria que as células morreriam em conseqüência da 
infecção primária, induzindo a dicariotização do fungo e, assim, à fase saprofítica (Orchard et al., 1994), ou como sugerido por Evans (1980), a dicariotização ocorreria primeiro, resultando na fase saprofítica, e, posteriormente, na morte da vassoura. Nesta fase em que o fungo se torna dicariótico, as hifas são menos espessas, com diâmetro de 1,5-3,0 $\mu \mathrm{m}$, apresentando grampos de conexão (Calle et al., 1982) e crescendo intracelularmente (Calle et al., 1982; Muse et al., 1996 e Silva \& Matsuoka, 1999). O fungo continua seu crescimento saprofítico dentro das vassouras mortas por um período de 6 a 24 meses quando então surgem os basidiocarpos sobre as vassouras e o ciclo recomeça (Griffith \& Hedger, 1993).

A observação, de que culturas monospóricas de basidiósporos produzem grampos de conexão, após a formação do micélio secundário, sugerem que $C$. perniciosa, biótipo-C, é uma espécie homotálica (Delgado \& Cook, 1975). Esta característica foi confirmada por meio da produção de basidiocarpos a partir de culturas monospóricas de basidiósporos (Purdy et al., 1983). Sendo o fungo homotálico, os mecanismos pelos quais surgem variantes permanecem desconhecidos. A variabilidade, quanto a patogenicidade de C. perniciosa sugere que se algumas vassouras-de-bruxa surgem de infecção por múltiplos basidiósporos e anastomoses entre hifas de diferentes basidiósporos, isto forneceria a oportunidade de formação de heterocários e, conseqüentemente, aumento da variabilidade genética na próxima geração (Wheeler \& Mepsted, 1988).

\subsubsection{Controle da doença}

Os métodos de controle da vassoura-de-bruxa incluem o controle químico, podas fitossanitárias e resistência genética. A remoção de todos os tecidos infectados tem sido a principal medida de controle, adotada com o objetivo de reduzir a fonte de inóculo e os danos causados por C. perniciosa. Todavia a eficiência e o custo dessa prática depende de vários fatores, principalmente do nível de infecção da planta (Bastos, 1996a). A poda fitossanitária só é efetiva quando realizada regularmente de forma extensiva. Embora seja eficaz em reduzir as fontes de inóculo, as infecções observadas 
em áreas onde foi realizado esse tipo de controle são provenientes das fontes não removidas ou daquelas localizadas em outras áreas (Andebrhan, 1985). Dessa forma, se a poda não for generalizada, o controle efetivo da doença se torna difícil, sendo nestas circunstâncias, necessária a aplicação de fungicida para minimizar as perdas (Andebrhan \& Bastos, 1980).

O controle químico da vassoura-de-bruxa com fungicidas de contato não é suficiente, pois eles não protegem os tecidos em crescimento ativo, necessitando inúmeras pulverizações (Cronshaw, 1979). Embora fungicidas sistêmicos poderiam restringir o número de aplicações necessárias, a maioria avaliada tem demonstrado eficiência somente em testes in vitro não apresentando esta repetibilidade no campo. $\mathrm{O}$ tebuconazole tem demonstrado eficiência no controle de C. perniciosa in vitro e no campo, porém o seu uso apresenta limitações devido ao alto custo do produto comercial (Tovar et al., 1991).

Almeida et al. (1998) testaram o efeito da poda fitossanitária associada à aplicação de óxido cuproso na concentração de 3,6 a 9g de ia/planta/aplicação. Foi observado que o cobre controlou as infecções eficazmente em frutos, mas não em gemas vegetais ou almofadas florais. Foi verificado ainda que a aplicação deste produto não foi viável economicamente em todas áreas tratadas. A aplicação do óxido cuproso, fungicida de contato, juntamente com o fungicida sistêmico triadimenol (Bayfidan) mostrou um bom controle da doença durante o período de aplicação (Pereira et al., 1996). Também, Bastos \& Medeiros (1979), avaliaram in vitro a ação de 41 fungicidas nas concentrações de 10, 50 e 100 ppm sobre o crescimento de C. perniciosa. Entretanto os 12 fungicidas sistêmicos, somente Bayleton foi eficaz a $10 \mathrm{ppm}$. Os fungicidas cúpricos foram eficientes nas concentrações de 50 e 100 ppm.

Vários compostos químicos vêm sendo testados com o objetivo de prevenir ou erradicar a vassoura-de-bruxa, porém os resultados não têm sido satisfatórios (Mcquilken et al., 1988 e Soberanis et al., 2000), pois o rápido crescimento da superfície dos frutos durante os dois ou três meses de desenvolvimento, faz com que o fungicida tenha que ser aplicado freqüentemente e isto é especialmente difícil em árvores muito altas (Soberanis et al., 2000). 
Alternativamente, o controle biológico vem sendo testado como uma alternativa para o controle de fitopatógenos. Trichoderma spp. têm se destacado como promissor, não só no controle de fitopatógenos habitantes do solo (Papavizas, 1985) como também no controle daqueles que colonizam as partes aéreas de plantas (Elad et al., 1993). O controle biológico envolvendo antagonistas capazes de suprimir a formação ou destruir os basidiomas de C. perniciosa em vassouras secas de cacaueiros, constitui uma linha de pesquisa promissora. Neste contexto, Bastos (1996a), mostrou a eficiência de $T$. viride no controle de C. perniciosa, reduzindo a incidência de frutos infectados, quando comparado com os tratamentos por poda fitossanitária. Bastos (1996b), observou que o micélio do patógeno perdeu a viabilidade após o tratamento de culturas e de vassouras secas de cacau, com suspensão de conídios de T. viride, o qual parasita as hifas do fitopatógeno.

Recentemente foi desenvolvido pela CEPLAC/CEPEC um biofungicida, denominado Tricovab, a partir do fungo micoparasita Trichoderma stromaticum, antagonista a C. perniciosa (Bastos, 2000). A eficiência do biofungicida é de $90 \%$ e atua eliminando o fungo por inanição, visto que T. stromaticum compete com C. perniciosa por nutriente e espaço.

Um outro método de controle é a indução na planta hospedeira de resistência sistêmica adquirida (SAR), método que consiste em ativar o sistema de defesa da planta antes que ocorra a interação patógeno-hospedeiro. A SAR se desenvolve sistêmica ou de forma localizada em resposta a um patógeno que causa uma lesão necrotrófica, reação de hipersensibilidade (HR), ou por aplicação exógena de ácido salicílico (AS) ou compostos sintéticos como o benzotiadiazole (BHT) e o ácido 2,6-dicloroisonicotínico (INA). Neste caso, a resistência geralmente é efetiva contra um amplo espectro de patógenos e está associada à produção de proteínas relacionadas à patogenicidade (Hammerschmidt \& Smith-Becker, 1999, citado por Perez (2002).

Os produtos BION (acibenzolar-S-methyl) e o BHT têm mostrado resultados promissores na indução da resistência sistêmica em cacaueiros (Andrade et al., 2001). Resende et al. (2000), avaliaram a capacidade do benzotiadiazole em induzir SAR contra C. perniciosa, neste caso, foi verificada uma redução de 33,5 a 84,5\% na 
incidência da doença, quando pulverizado a 3, 15 ou 30 dias antes da inoculação de plântulas de cacau do tipo Catongo. O efeito do BHT na proteção de mudas foi comparado ao efeito dos fungicidas óxido cuproso e tebuconazole. O BHT reduziu a incidência da doença em $60,2 \%$ indicando uma melhor performance que o tebuconazole e tendência a superar o óxido cuproso.

Quanto ao uso de resistência genética como fonte de controle, vários esforços foram realizados. No passado, o grande número de progênies e indivíduos envolvidos no melhoramento e a ênfase à 'imunidade', não permitiram análises criteriosas da resistência ao patógeno e vários genótipos com características de tolerância foram perdidos. Atualmente, as dificuldades no controle da variabilidade genética do patógeno e o pouco entendimento das interações com o hospedeiro, são as principais limitações para identificação de variedades para o melhoramento visando a resistência (Andebrhan et al., 1998). A resistência à doença é o principal componente de um sistema para o controle da vassoura-de-bruxa. O Brasil tem a maior coleção de germoplasma de cacau estabelecido na Estação de Recursos Genéticos do Cacaueiro, em Marituba (PA), e a identificação de genótipos resistentes tem sido dificultado por vários fatores. Um modo para identificação de genótipos de cacau resistentes a $C$. perniciosa pode ser por meio da germinação de esporos na seiva extraída de diferentes genótipos de cacau. Bastos \& Albuquerque (2000) verificaram que a seiva de clones resistentes inibiu a germinação dos esporos enquanto a seiva de plantas susceptíveis não teve efeito inibitório.

Apesar de nas últimas duas décadas esforços terem sido feitos no sentido de controlar a doença ou reduzí-la a níveis aceitáveis, as medidas de controle utilizadas até o momento não têm alcançado resultados satisfatórios, principalmente devido à alta variabilidade do patógeno e às condições ambientais, o que inviabiliza e dificulta a obtenção de cultivares resistentes. Neste contexto, alguns estudos foram realizados no sentido de entender os mecanismos fisiológicos da complexa interação patógeno-planta, porém os estudos genéticos deste patógeno são limitados, principalmente devido à falta de detalhes de sua organização e de seu material genético.

Atualmente, jardins clonais, com plantas resistentes a C. perniciosa, têm sido implantados em várias áreas de produção de cacau, sendo dessa forma um início da 
reestruturação da cacauicultura na Bahia. Entretanto, tendo em vista que esta resistência pode ser quebrada pelo patógeno, estudos para um melhor entendimento deste patossistema devem ser mantidos. Neste contexto, o melhor conhecimento da variablilidade genética de C. perniciosa poderia permitir o melhor entendimento da interação entre este patógeno e as diferentes espécies hospedeiras, bem como o desenvolvimento de estratégias de controle deste fungo.

\subsection{Variabilidade genética detectada por RAPD (Random Amplied Polymorphic DNA)}

Várias técnicas têm sido empregadas para análise de variabilidade em microrganismos. As metodologias clássicas utilizam a caracterização de fenótipos a partir de características morfológicas ou bioquímicas, principalmente por auxotrofia. Nas últimas décadas, várias técnicas baseadas em análise de proteínas e DNA, tem sido desenvolvidas.

A técnica de RAPD (Random Amplied Polymorphic DNA) é baseada na amplificação de fragmentos não específicos de DNA, onde a estratégia é utilizar 1 único oligonucleotídeos de 10-15 bases de sequência arbitrária como iniciador para amplificar o DNA genômico por PCR (Williams et al., 1990). A amplificação ocorre quando este primer reconhece um sítio de homologia em uma das fitas e também o mesmo sítio, porém com orientação invertida, na outra fita da molécula de DNA dentro do intervalo limite da PCR $(4 \mathrm{~Kb})$. Os oligonucleotídeos dispostos nas extremidades da seqüência a ser amplificada fornecem a extremidade 3' livre para a atuação da DNA polimerase (Williams et al., 1990).

Os produtos da amplificação são separados em gel de agarose, onde cada banda de DNA amplificado é o resultado da interação entre o oligonucleotídeo e o DNA molde. O polimorfismo é reconhecido pela presença de um fragmento amplificado em um dos genótipos em relação à ausência deste mesmo fragmento no outro genótipo, os quais são devido a diversos fatores como deleção, duplicação, ou mutação no sítio de anelamento do primer (Williams et al., 1990). Essa técnica tem a vantagem de ser 
altamente sensível a diferenças de nucleotídeos entre o oligonucleotídeo e o DNA molde. É uma técnica rápida, não envolve hibridização ou radioatividade (Michelmore et al., 1991), além de requerer pequena quantidade de DNA e não necessariamente de alta qualidade (Manulis et al., 1993).

O agrupamento de isolados de C. perniciosa de diferentes regiões se basea na morfologia, características culturais, compatibilidade vegetativa, reações bioquímicas, degradação de lignocelulose e sintomas da doença sobre cacau e outras espécies de Theobroma. Em adição aos métodos acima, a técnica RAPD oferece um meio de agrupar organismos independente do ambiente, estágio de desenvolvimento e idade do organismo. Segundo Andebrhan \& Furtek (1994), a comparação entre isolados provenientes de Theobroma cacao (SCA 6 e SVB), T. grandiflorum, T. obovatum, T. subicanum, Herrania sp., Bixa orellana e Solanum rugosum indicaram que a o local de origem é um fator mais importante que a espécie hospedeira para a determinação da relação genética entre isolados. Neste aspecto, foi verificado, que há duas fontes de inóculo diferentes próximas a Belém e que isolados de B. orellana são mais proximamente relacionados que os isolados de T. cacao SVB. Foi ainda observado que o padrão de bandas foi similar entre basidiocarpo da mesma vassoura, porém, diferenças foram detectadas entre culturas monospóricas de um mesmo basidiocarpo.

Niella (2000) estudou a variabilidade genética de 10 isolados monomórficos de C. perniciosa provenientes de 6 estados brasileiros (AM, BA, MG, MT, PA e RO) e de 3 hospedeiros (T. cacao, Heteropterys acutifolia e Solanum lycocarpum), sendo possível a observação de um grupo principal, com 3 isolados da BA e um do PA. Os demais isolados foram distintos do grupo principal, sendo que os de MG (cacau, cipó e lobeira) foram os mais divergentes. Embora os autores tenham utilizado um número reduzido de isolados, os resultados mostraram a existência de variabilidade genética em $C$. perniciosa nos 6 estados, dentro da região cacaueira da BA e nos 3 hospedeiros.

Os isolados do biotipo-C coletados na BA foram diferenciados pela análise de RAPD em duas populações, sendo que um grupo foi mais similar geneticamente aos isolados da AM e PA e o outro grupo mais próximo geneticamente aos isolados coletados em RO. A distribuição geográfica dos grupos na Bahia sugere dois focos 
independentes de introdução da doença nessa região (Andebrhan et al., 1999). Trabalhos como estes podem mostrar se existe correlação entre a variabilidade genética de $C$. perniciosa e os níveis/especificidade de patogenicidade observados.

\subsection{Variabilidade genética por sequenciamento do rDNA (DNA ribossômico)}

O DNA ribossomal (rDNA) está presente em todos os organismos e é composto de várias regiões distintas (genes e espaçadores). O rDNA é útil para estudos filogenéticos em vários níveis taxonômicos, inclusive na identificação de espécies (Silva, 1997). Entre espécies, as regiões dos espaçadores internos transcritos (ITS1 e ITS2) auxiliam estudos taxonômicos em vários grupos, como fungos (Carbone \& Kohn, 1997). A síntese de proteínas depende da participação do rRNA no processo de tradução da informação genética. A codificação do rRNA é feita em regiões específicas do genoma pelo chamado rDNA, o qual está contido nas regiões organizadoras do nucléolo e tem sido objeto de um grande número de estudos, com diversas aplicações na genética, evolução e melhoramento. O rDNA é caracteristicamente repetitivo, uma propriedade que permite um grande número de aplicações. $\mathrm{O}$ fato de ser repetitivo implica que uma certa estrutura ou sequência de nucleotídeos se repita lado a lado (em "tandem") inúmeras vezes. Sendo assim, por ser repetitivo e por estar situado em regiões específicas do genoma, a proporção do rDNA é, em geral, alta em relação ao conteúdo total de DNA da espécie (Fungaro, 2000).

O rDNA, ao contrário de outras seqüências repetitivas que aparentemente não tem função conhecida no genoma, codifica o rRNA, associado ao processo de tradução de proteínas. Em geral, as regiões $28 \mathrm{~S}, 18 \mathrm{~S}$ e $5.8 \mathrm{~S}$ das unidades de repetição não apresentam variação de seqüência, enquanto que as regiões internas variam (Fungaro, 2000).

A região 18S, por exemplo, é a mais conservada e por isso é utilizada apenas para comparação de organismos filogeneticamente mais distantes. A porção $28 \mathrm{~S}$ é mais variável e, portanto, é apropriada para a comparação de diferentes gêneros ou, em alguns casos, de diferentes espécies. As regiões ITS evoluem rapidamente e, então, são 
apropriadas para discriminar espécies relacionadas ou até mesmo variedades de uma mesma espécie. O fato das regiões ITS serem flanqueadas por regiões conservadas (genes $18 \mathrm{~S}, 5.8 \mathrm{~S}$ e $28 \mathrm{~S}$ ), serem relativamente curtas (500 a 800pb) e aparecerem um grande número de cópias no genoma permite que sejam amplificadas e sequenciadas com facilidade. Como conseqüência disso, é grande o número de seqüências ITS de diferentes fungos que estão atualmente disponíveis nos bancos de dados de seqüências de nucleotídeos. A utilização de programas computacionais, que permitem a comparação destas seqüências de organismos alvos e não alvos, permite definir regiões apropriadas para síntese de primers utilizados para detectar uma determinada espécie de fungo (Fungaro, 2000).

A região ITS tem sido utilizada para verificar polimorfismo de tamanho, alterações nos sítios de restrição de enzimas e diferenciação na constituição dos pares de bases das seqüências ocasionadas por alterações ao longo da evolução das espécies (Leal Jr, 2002). Sendo assim, os dados de seqüenciamento de diversos genes com interação dos diferentes métodos moleculares, permitirão a reconstrução segura da filogenia e consequentemente um melhor entendimento dos fatores essenciais os quais tiveram a biodiversidade deste grupo, além de nortear estudos taxonômicos (Vicente, 2000) e permitir o desenvolvimento de primers para a detecção de patógenos.

\subsection{Enzimas extracelulares}

A descrição da presença de enzimas capazes de degradar a parede celular de um fitopatógeno parece ser uma constante nos trabalhos envolvendo a utilização de outros microrganismos como agentes de biocontrole. Inúmeros estudos foram conduzidos com o intuito de melhor caracterizar as enzimas envolvidas nesse processo. Como exemplo, ensaios em meio sólido mostraram considerável atividade das enzimas celulases, amilase e protease em Trichoderma viride, antagonista de C. perniciosa (Bastos, 1996b). Segundo o autor, essas enzimas têm papel importante tanto no início da infecção quanto no calapso das hifas do hospedeiro. 
O patógeno é considerado um invasor passivo e incapaz de desenvolver força física para romper as barreiras estruturais do hospedeiro. Assim, se o patógeno depende de enzimas ou outros metabólitos em sua patogênese, uma produção adequada destes é necessária (Wulff, 2002). A interação patógeno-hospedeiro é determinada geneticamente por meio dos mecanismos de ataque do patógeno e de defesa da planta. Porém, algumas alterações podem ocorrer nesta interação devido a fatores ambientais (Bocchese et al., 2003). As enzimas produzidas por fungos são importantes no processo de infecção do hospedeiro e quebra da matéria orgânica. A produção de enzimas por estes fungos é geralmente determinada pelo crescimento do micélio sobre um meio e observando-se a formação de halos de atividade enzimática. As exoenzimas são estudadas à décadas devido a sua importância em processos industriais bem como em interações de patogenia. Dentre as principais hidrolases secretadas, são descritos os grupos formados pelas amilases, celulases, lipases, pectinases e proteases (Archer \& Wood, 1993).

Lipídios são compostos formados por ácidos graxos, sendo que diferentes tipos são encontrados nas células vegetais: óleos e gorduras, principalmente nas sementes, ceras e cutículas, fosfolipídios e glicolipídios nas membranas. Várias bactérias e fungos podem degradar esses compostos através da ação das enzimas lipolíticas (lipases, fosfolipases, etc) liberando ácidos graxos que podem ser utilizados diretamente por esses patógenos (Pascholati, 1995). As lipases têm sido extensivamente estudadas devido à sua ação e potencial aplicação em detergentes, óleos e indústrias alimentícias (Onish et al., 1994). Os fungos são fontes preferenciais de lipases porque estes excretam extracelularmente, facilitando a extração em meios de fermentação. A produção desta enzima tem sido estudada em vários fungos, Fusarium solani FS1 (Maia et al., 1999), Verticillium lecanii (Lopez-Llorca \& Carbonell, 1999), e várias espécies de Trichoderma (Barbosa et al., 2001).

O amido é um polímero de glicose e constitui o principal polissacarídeo de reserva nas células vegetais. A maioria dos patógenos produz amilase, que degradam esse polímero em moléculas de glicose diretamente utilizáveis nas atividades metabólicas desses microrganismos (Pascholati, 1995). Já a celulose é um polímero 
linear não ramificado contendo unidades de glicose ligadas por ligações $\beta$ (1-4) glicosídicas, as quais são hidrolisadas pelas enzimas celulolíticas. Algumas bactérias e fungos produzem só um tipo de celulase (endocelulases), a qual por si mesma, não é capaz de hidrolisar suficientemente a celulose. Os organismos celulolíticos verdadeiros são saprófitas que obtém a sua energia degradando materiais celulósicos. Eles são capazes de produzir um complexo celulolítico, isto é, várias enzimas com diferentes modos de ação. Esse complexo celulolítico é capaz de hidrolisar eficientemente a celulose cristalina a açucares solúveis (Rounas, 1988). O complexo celulase é formado por pelo menos três enzimas comumentente chamadas exocelulases, endocelulases e celobiase (Lee \& Fan, 1980). As endocelulases hidrolisam as cadeias de celulose ao acaso, atacando os polímeros de celulose internamente (Ryu \& Mandels, 1980) e tem atividade limitada sobre a celulose cristalina. Entretanto, a presença dessa enzima aumenta a atividade da exoglucanase na hidrólise da celulose cristalina, devido aos ataques ao acaso da endocelulase sobre a celulose o qual cria novos sítios terminais reativos para a exocelulase, esse efeito complementar da endocelulase com a exocelulase é chamado de efeito sinergístico da celulase. A celobiase hidrolisa a celobiose em glicose (Araújo \& Souza, 1986).

Trabalhos com Pseudomonas solanacearum e hastes de tomateiro fornecem evidências da degradação de celulose durante a patogênese, bem como correlação positiva entre virulência e atividade celulolítica. Isolados bacterianos pouco virulentos ou avirulentos exibem menor atividade celulolítica quando comparado aos virulentos. No caso de fungos a maioria dos resultados sobre celulases e hemicelulases envolvem fungos degradadores de madeira. Patógenos causadores de murcha, como Fusarium oxysporum produzem celulases em culturas e in vitro (Pascholati, 1995), mostrando também o envolvimento destas enzimas na patogenicidade destes fungos.

A parede celular de plantas apresenta uma grande quantidade de substâncias pécticas, as quais podem dificultar a entrada de patógenos. Estas substâncias, após degradação pelas pectinases originam primeiramente ácido galacturônico, ramnose, e uma menor quantidade de galactose, arabinose, metanol, acetato e poucas quantidades de outros açúcares (xilose, fucose e apiose), os quais são assimilados e metabolizados 
pelos microrganismos invasor. As enzimas pectinolíticas são as mais estudadas no tocante ao seu papel na patogenicidade (Collmer, 1987). O fitopatógeno geralmente possui uma ou mais pectinases pré formadas, em baixo nível, quando em contato com os polímeros de ácido galacturônico na lamela média ou parede primária, libera monômeros e/ou oligômeros a partir desses polímeros. Esses fragmentos pécticos podem funcionar como sinais para a síntese de pectinases (Pascholati, 1995).

Segundo Hankin \& Anagnostakis (1975), a análise da produção enzimática de fungos em meio sólido é um método simples e rápido para a identificação de variações genéticas em uma população, visto que detecta a presença ou ausência de enzimas específicas, bem como possibilita estudos ecológicos e de diferenciação quimiotaxonômica.

\subsection{Microrganismos endofíticos}

O termo endófito foi inicialmente utilizado por Bary em 1866, e foi aplicado aos microrganismos que vivem internamente nos tecidos vegetais, sendo, a existência destes microrganismos detectada em todas as espécies vegetais avaliadas até o momento (Azevedo et al., 2002). Atualmente são chamados de endófitos os microrganismos que em pelo menos uma fase de seu ciclo de vida colonizam o interior de tecidos vegetais aéreos sem causar dano aparente à planta hospedeira (Petrini, 1991), ou podendo ser isolados de tecidos vegetais desinfectados superficialmente ou do interior destes (Hallmann et al., 1997). Acredita-se que estes microrganismos co-evoluíram com os seus hospedeiros, apresentando uma estreita interação mutualística, onde recebem nutrientes e proteção e conferem ao hospedeiro maior resistência em ambientes com intenso estresse causado por fatores bióticos ou abióticos (Azevedo et al., 2002). Geralmente, essa resistência está associada à produção, por parte dos endófitos, de compostos tóxicos aos herbívoros ou aos patógenos, ou ainda ativando o sistema de defesa da planta. Do ponto de vista evolutivo, para os endófitos presentes em tecidos vegetais, a herbivoria pode impedir a sobrevivência e a disseminação destas espécies, sendo, portanto, interessante uma redução da herbivoria (Azevedo et al., 2002; 
Saikkonen et al., 1998). Segundo Clay (1989), endófitos de gramíneas, produzem compostos biologicamente ativos tanto in vitro como in vivo.

Araújo et al. (2001) sugerem que Pantoea agglomerans e Bacillus spp. isolados endofiticamente de folhas de citros podem interagir com o fungo Guignardia citricarpa, podendo ser inibido (Bacillus spp.) ou estimulado ( $P$. agglomerans) por este fungo, mostrando uma íntima relação entre diferentes populações microbianas associadas aos tecidos do hospedeiro.

O estudo de fungos endofíticos é importante para se conhecer a base biológica de interação endófito-hospedeiro. Estes fungos são potencialmente vantajosos para a produção de metabólitos secundários de interesse farmacológico (Stierle et al., 1993), como vetores genéticos para a introdução de genes de interesse, como, por exemplo, genes de resistência a pragas em plantas hospedeiras (Murray et al., 1992), para o controle biológico de doenças (Calhoun et al., 1992) entre outras características.

Trabalhos demonstram a possibilidade da exploração dos fungos endofíticos como produtores de metabólitos para fins diversos. Neste contexto, Bills \& Pollishook (1991), citado por Silva (1997), fizeram algumas considerações sobre o potencial de alguns microrganismos endofíticos afirmando que os mesmos, especialmente aqueles menos freqüentemente encontrados e restritos a certos hospedeiros, poderiam ter as mais diversas aplicações biotecnológicas. Um exemplo, é a produção de taxol, um agente anti-tumor de seio e ovário. O taxol é obtido, em quantidades muito pequenas, de uma árvore de crescimento lento chamada Taxus brevifolia. Entretanto, foi observado que o fungo endofítico Taxomyces andreane isolado desta planta também produz esse metabólito em meio semi-sintético (Stierle et al., 1993). Embora o taxol, produzido pelo fungo, siga uma via metabólica diferente do produzido pela planta, testes de atividade biológica mostraram que ambos exibem atividades semelhantes quanto à citotoxidade de carcinomas, mostrando que a produção do taxol pelo fungo pode ser uma alternativa para obtenção deste fármaco (Strobel et al., 1996).

$\mathrm{Na}$ associação de endófitos e plantas forrageiras já foi observada que esses hospedeiros infectados ficaram livres da ação de insetos e mamíferos herbívoros quando colonizados por fungos do gênero Epichloe (White \& Cole, 1985). Porém, Schulthess \& 
Cardwell. (2002) verificaram que a presença do endófito Fusarium verticillioides, pode favorecer o ataque da planta hospedeira por lepdópteros e coleópteros. Segundo Bartelt \& Wicklow (1999) o fungo produz substâncias voláteis que são atrativas a besouros.

Estudos de análise citológica, feitos por Benhamou \& Garand (2001), com a linhagem não patogênica de Fusarium oxysporum (Fo47) verificaram que este endófito induz uma série de mecanismos de defesa em células de tecidos da raíz de ervilha. As células invadidas pelo endófito sofreram uma série de alterações, entre elas deposição de um material opaco na parede celular e vasos do xilema, dificultando a entrada de patógenos nos tecidos do hospedeiro, sendo por isso esta linhagem endofítica considerada um potencial agente para o biocontrole de doenças da raiz.

Em estudos recentes, foi observado que citros pode ser colonizado por duas populações do fungo Guignardia citricarpa. Uma população é constituída por isolados patogênicos, os quais causam a mancha preta dos citros (MPC), enquanto que a outra população apresenta um comportamento endofítico, não causando nenhum tipo de doença para frutos e folhas de citros (Glienke-Blanco et al., 2002; Glienke, 1995), sendo denominado posteriormente de G. mangiferae (Bayeen et al., 2003), mostrando que fungos aparentemente patogênicos podem apresentar uma relação mutualística com a planta hospedeira. Esta linhagem endofítica poderia ser utilizada para o controle desta doença, visto que o endófito ocupa o mesmo nicho que o patógeno, permitindo dessa forma a redução da MPC por competição entre linhagens endofíticas e patogênicas. 


\section{MATERIAL E MÉTODOS}

O trabalho foi desenvolvido no Laboratório de Genética de Microrganismo "Professor João Lúcio de Azevedo" do Departamento de Genética da Escola Superior de Agricultura "Luiz de Queiroz" - USP.

\subsection{Isolados de C. perniciosa}

Foram utilizados isolados de C. perniciosa obtidos de diferentes hospedeiros como cacau (Theobroma cacao), Liana, Solanum lycocarpum e Solanum cernuum proveniente de diversas regiões do Brasil (Tabela 1) e gentilmente cedidos pelo Dr. Alan W. V. Pomella (Almirante Cacau S/A, Itajuípe, BA). Isolados endofíticos e patogênicos foram também obtidos durante a execução deste trabalho. A linhagem FA42 foi utilizada como padrão de patogenicidade.

\subsection{Meios de cultura e soluções}

\subsubsection{Meio Batata Dextrose Ágar (BDA)}

$\begin{array}{ll}\text { Batata } & 200,0 \mathrm{~g} \\ \text { Ágar } & 15,0 \mathrm{~g} \\ \text { Água } & 1000 \mathrm{~mL}\end{array}$

A batata foi cozida por 30 minutos e filtrada em gaze. $\mathrm{O}$ pH foi ajustado para $6,8 \mathrm{com}$ $\mathrm{NaOH} 1 \mathrm{~N}$. 
Tabela 1. Relação dos isolados de C. perniciosa utilizados no presente trabalho

\begin{tabular}{|c|c|c|c|c|}
\hline Linhagens & Hospedeiro & Local de Coleta & $\begin{array}{c}\text { Parte da } \\
\text { planta } \\
\text { utilizada } \\
\end{array}$ & $\begin{array}{l}\text { Local de } \\
\text { Isolamento }\end{array}$ \\
\hline $1,2,3,4,5,6,79$ & Cacau & Uruçuca (BA) & $\begin{array}{l}\text { Vassoura } \\
\text { verde }\end{array}$ & Neste trabalho \\
\hline $7,8,9,10$ & Cacau & Lomanto Júnior (BA) & $\begin{array}{l}\text { Vassoura } \\
\text { verde }\end{array}$ & Neste trabalho \\
\hline 11 & Cacau & Rondônia & - & Neste trabalho \\
\hline 12 & Solanum sp. & - & - & Neste trabalho \\
\hline 31,54 & Cacau & Uruçuca (BA) & Ramo sadio & Neste trabalho \\
\hline 13 & $\begin{array}{l}\text { Solanum } \\
\text { lycocarpum }\end{array}$ & - & - & Neste trabalho \\
\hline FA 23 & Cacau & Lomanto Júnior (BA) & Fruto jovem & $\begin{array}{l}\text { Almirante } \\
\text { Cacau }\end{array}$ \\
\hline $\begin{array}{l}\text { FA 42, FA 276, } \\
\text { FA } 282\end{array}$ & Cacau & Lomanto Júnior (BA) & $\begin{array}{l}\text { Vassoura } \\
\text { verde }\end{array}$ & $\begin{array}{l}\text { Almirante } \\
\text { Cacau }\end{array}$ \\
\hline FA 277 & Cacau & Lomanto Júnior (BA) & $\begin{array}{l}\text { Vassoura } \\
\text { mole }\end{array}$ & $\begin{array}{l}\text { Almirante } \\
\text { Cacau }\end{array}$ \\
\hline FA 278 & Cacau & Lomanto Júnior (BA) & $\begin{array}{l}\text { Vassoura } \\
\text { dura }\end{array}$ & $\begin{array}{l}\text { Almirante } \\
\text { Cacau }\end{array}$ \\
\hline FA 283 & Cacau & Lomanto Júnior (BA) & Fruto jovem & $\begin{array}{l}\text { Almirante } \\
\text { Cacau }\end{array}$ \\
\hline FA 35 & Cacau & Belém (PA) & - & $\begin{array}{l}\text { Almirante } \\
\text { Cacau }\end{array}$ \\
\hline FA104 & $\begin{array}{l}\text { Solanuun } \\
\text { cernuum }\end{array}$ & Viçosa (MG) & - & $\begin{array}{l}\text { Almirante } \\
\text { Cacau }\end{array}$ \\
\hline FA 136 & Liana & - & - & $\begin{array}{l}\text { H. Evans- } \\
\text { CABI(UK) }\end{array}$ \\
\hline FA 152 & Cacau & $\begin{array}{l}\text { Ouro Preto D'Oeste } \\
\text { (RO) }\end{array}$ & - & $\begin{array}{l}\text { L. Nakayama } \\
\text { (CEPLAC) }\end{array}$ \\
\hline FA 154 & Cacau & Ariquemes (RO) & - & $\begin{array}{l}\text { Almirante } \\
\text { Cacau }\end{array}$ \\
\hline FA 279 & Cacau & Uruçuca (BA) & - & $\begin{array}{l}\text { Almirante } \\
\text { Cacau }\end{array}$ \\
\hline FA 281 & Cacau & Aiquara (BA) & $\begin{array}{l}\text { Vassoura } \\
\text { verde }\end{array}$ & $\begin{array}{l}\text { Almirante } \\
\text { Cacau }\end{array}$ \\
\hline FA 284 & Cacau & Barra do Rocha (BA) & $\begin{array}{l}\text { Vassoura } \\
\text { verde }\end{array}$ & $\begin{array}{l}\text { Almirante } \\
\text { Cacau }\end{array}$ \\
\hline FA 286 & Cacau & Inema (BA) & $\begin{array}{l}\text { Vassoura } \\
\text { verde }\end{array}$ & $\begin{array}{l}\text { Almirante } \\
\text { Cacau }\end{array}$ \\
\hline FA 287 & Cacau & Inema (BA) & Fruto jovem & $\begin{array}{l}\text { Almirante } \\
\text { Cacau }\end{array}$ \\
\hline FA 292 & Cacau & Itapé (BA) & Fruto jovem & $\begin{array}{l}\text { Almirante } \\
\text { Cacau }\end{array}$ \\
\hline 322 & Liana & - & - & Gareth (UK) \\
\hline
\end{tabular}




\subsubsection{Meio BDA enriquecido}

Ao meio BDA (item 3.2.1) foi acrescentado 1,5g de caseína hidrolisada, 2,0g de extrato de levedura e $2,0 \mathrm{~g}$ de peptona.

3.2.3 Meio Mínimo (Pontecorvo et al., 1953)

$\begin{array}{ll}\mathrm{NaNO}_{3} & 6 \mathrm{~g} \\ \mathrm{KCl} & 0,5 \mathrm{~g} \\ \mathrm{KH}_{2} \mathrm{PO}_{4} & 1,5 \mathrm{~g} \\ \mathrm{MgSO}_{4} \cdot 7 \mathrm{H}_{2} \mathrm{O} & 0,5 \mathrm{~g} \\ \mathrm{ZnSO}_{4} & 0,01 \mathrm{~g} \\ \mathrm{FeSO}_{4} & 0,01 \mathrm{~g} \\ \text { Ágar } & 15,0 \mathrm{~g} \\ \text { Água } & 1000 \mathrm{~mL}\end{array}$

$\mathrm{O} \mathrm{pH}$ foi acertado para $6,8 \mathrm{com} \mathrm{NaOH} 1 \mathrm{~N}$.

\subsubsection{Meio Mínimo modificado para produção de pectinases}

$\begin{array}{ll}\mathrm{K}_{2} \mathrm{HPO}_{4} & 7 \mathrm{~g} \\ \mathrm{KH}_{2} \mathrm{PO}_{4} & 2 \mathrm{~g} \\ \left(\mathrm{NH}_{4}\right)_{2} \mathrm{SO}_{4} & 1 \mathrm{~g} \\ \mathrm{MgSO}_{4} \cdot 7 \mathrm{H}_{2} \mathrm{O} & 0,1 \mathrm{~g} \\ \text { Ágar } & 15,0 \mathrm{~g} \\ \text { Água } & 1000 \mathrm{~mL}\end{array}$

$\mathrm{O} \mathrm{pH}$ foi acertado para $6,8 \mathrm{com} \mathrm{NaOH} 1 \mathrm{~N}$. 


\subsubsection{Meio Ágar-Água}
Ágar
$20 \mathrm{~g}$
Água
$1000 \mathrm{~mL}$

\subsubsection{Substrato para produção de basidiocarpos}

Vassoura seca moída

$\mathrm{Ca}_{2} \mathrm{SO}_{4}$

Farinha de aveia

Água
$517,0 \mathrm{~g}$

$2 \mathrm{~g}$

$138 \mathrm{~g}$

$700 \mathrm{~mL}$

Autoclavar por 2 vezes a $121^{\circ} \mathrm{C}$ e 1 atm.

\subsubsection{Tampão de corrida TBE 10X}

$\begin{array}{lc}\text { Trizma base } \mathrm{pH} 8,0 & 54 \mathrm{~g} \\ \mathrm{H}_{3} \mathrm{BO}_{3} & 2,7 \mathrm{~g} \\ \text { EDTA } & 4,65 \mathrm{~g} \\ \mathrm{H}_{2} \mathrm{O} & 500 \mathrm{~mL}\end{array}$

A solução foi autoclavada e mantida à temperatura ambiente. No momento do uso foram feitas diluições apropriadas.

\subsubsection{Gel de agarose}

Agarose

TBE 1X
$0,8 \mathrm{~g}(0,8 \%)$ ou $1,4 \mathrm{~g}(1,4 \%)$

$100 \mathrm{~mL}$ 


\subsubsection{Solução de brometo de etídio (Sambrook et al., 1989)}

O brometo de etídio $(1 \%-\mathrm{p} / \mathrm{v})$ foi dissolvido em água destilada, agitado por várias horas e estocado à temperatura ambiente. No momento do uso, $3 \mu \mathrm{L}$ desta solução foram adicionados a $100 \mathrm{~mL}$ de tampão TBE (1x).

\subsubsection{Solução de iodo}

Iodo

Iodeto de potássio

Água $\log$

$6 g$

$20 \mathrm{~mL}$

O volume foi completado para $100 \mathrm{~mL}$ com etanol $90 \%$.

\subsubsection{Solução de brometo hexadeciltrimetilamonia (1\%)}

Brometo hexadeciltrimetilamonia

Água $\lg$

$100 \mathrm{~mL}$

\subsubsection{Solução de vermelho congo $(0,1 \%)$}

Vermelho congo

Água $\lg$

$1000 \mathrm{~mL}$

\subsubsection{Solução para coleta de esporos}

Glicerol

Ácido MÊS (2-[N-Morpholino]ethanesulfônico)

Água
$80 \mathrm{~mL}$

$0,98 \mathrm{~g}$

$500 \mathrm{~mL}$ 


\subsection{Isolamento de $C$. perniciosa de $T$. cacao}

O fungo C. perniciosa foi isolado de ramos sadios e doentes (vassoura verde) de cacaueiros mantidos em fazendas de Uruçuca (BA) e Lomanto Júnior (BA).

\subsubsection{Desinfecção superficial}

A desinfecção superficial foi feita tratando fragmentos de ramos de cacau (12 $\mathrm{cm}$ ) em álcool $70 \%$ por $1 \mathrm{~min}$, hipoclorito de sódio (2-4\% de $\mathrm{Cl}^{-}$ativo) por $3 \mathrm{~min}$, álcool $70 \%$ por 1 min e finalmente lavado por 2 vezes em água destilada esterilizada. Após a desinfecção superficial, os ramos do cacaueiro foram cortados em fragmentos pequenos, descascados e colocados (7 fragmento por placas) sobre meio BDA (item 3.2.1) com tetraciclina $50 \mu \mathrm{g} / \mathrm{ml}$, para evitar crescimento de bactérias. As placas foram incubadas a $28^{0} \mathrm{C}$ por 2 a 15 dias.

\subsubsection{Seleção de isolados de C. perniciosa}

Após o período de incubação, colônias de morfologia semelhante a $C$. perniciosa foram transferidas para placas de Petri contendo meio BDA enriquecido (item 3.2.2) por 10 dias a $28^{0} \mathrm{C}$. Hifas da borda dessas colônias foram transferidas para placas individuais e observadas em microscópio. Colônias que apresentaram grampos de conexão foram selecionadas para análise posterior por sequenciamento de regiões do rDNA.

\subsection{Caracterização e análise da variabilidade genética de $C$. perniciosa por RAPD e seqüenciameto de regiões do rDNA}




\subsubsection{Extração de DNA total}

Após 10 dias de crescimento em meio BDA enriquecido (item 3.2.2) fragmentos do micélio secundário de C. perniciosa foram transferidos para frascos de $250 \mathrm{~mL}$, contendo $100 \mathrm{~mL}$ de meio BDA enriquecido líquido. Os frascos foram incubados sem agitação por $10-15$ dias a $28^{\circ} \mathrm{C}$, quando então o micélio foi recolhido por filtração em papel de filtro e lavado com água destilada esterilizada. A extração de DNA total foi realizada conforme descrito por Raeder \& Broda (1985).

\subsubsection{Quantificação do DNA}

A quantificação do DNA foi estimada por meio de eletroforese em gel de agarose $0,8 \%$ (item 3.2.8), juntamente com DNA de fago $\lambda$ com concentração conhecida. Após a eletroforese, o gel foi corado com brometo de etídio (item 3.2.9), observado sobre transiluminador de luz U.V. e fotodocumentado.

\subsubsection{Otimização das reações de RAPD}

A reação de RAPD foi otimizada testando diferentes concentrações de $\mathrm{Mg}^{++}$ $(2,0 ; 2,5 ; 3,0 ; 3,5$ e 4,0mM), 2 concentrações de taq DNA Polimerase (3 e 5U/reação) e quantidades de DNA (10 e $20 \mathrm{ng}$ ).

\subsubsection{Análise da variabilidade por RAPD}

As reações de amplificação foram realizadas em um volume total de $25 \mu \mathrm{L}$, contendo $10 \mathrm{ng}$ de DNA total, 40 pmoles de cada oligonucleotídeo iniciador (Tabela 2), 3,5 mM de $\mathrm{MgCl}_{2}, 100 \mu \mathrm{M}$ de cada dNTPs (dATP, dTTP, dGTP e dCTP) e 5 unidades de Taq DNA polimerase em Tris- $\mathrm{HCl}$ 10mM (pH 8,3); KCl 50mM. As amplificações foram feitas em termociclador (Gene Amp System 9600, Aplied Biosystems, Norwalk, CT, EUA), programado para realizar uma desnaturação inicial a $94^{\circ} \mathrm{C}$ por 5 min, 
seguido de 40 ciclos, sendo que cada ciclo consiste de uma etapa de desnaturação (60 seg a $\left.92^{\circ} \mathrm{C}\right)$, uma etapa de anelamento $\left(60 \mathrm{seg}\right.$ a $\left.35^{\circ} \mathrm{C}\right)$ e uma etapa de alongamento $(2$ min a $72^{\circ} \mathrm{C}$ ), e finalmente uma extensão final a $72^{\circ} \mathrm{C}$ por $5 \mathrm{~min} . \mathrm{O}$ resultado da reação foi avaliado por meio de eletroforese em gel de agarose 1,4 \% (item 3.2.8), coloração feita com brometo de etídio (item 3.2.9), observação sobre luz U.V. e fotodocumentado. O controle negativo foi preparado omitindo o DNA na reação. Todas as reações foram repetidas em experimentos independentes.

Os dados obtidos nos géis de eletroforese foram transformados em dados binários ( 1 para presença e 0 para ausência de bandas). Foram consideradas somente bandas fortes. Os dados foram colocados no programa NTSYS - (Numerical Taxonomy and Multivariante Analysis System, versão 2.02), o qual construiu uma matriz de similaridade, utilizando o coeficiente de Simple Machting (SM). A partir dessa matriz foi construído o dendrograma pelo método UPGMA (Unweighted Pair Group Method Using Arithmetic Average), estabelecendo as relações genéticas entre os diferentes isolados. O consenso do dendrograma foi obtido com o número de 1000 replicas (valores de bootstrap) usando o programa Winboot (Yap \& Nelson, 1996). O dendrograma agrupou os isolados mostrando o nível de similaridade genética entre eles.

Tabela 2. Seqüência e conteúdo de GC dos oligonucleotídeos iniciadores utilizados para análise de C. perniciosa por marcadores RAPD

\begin{tabular}{lcc}
\hline Oligonucleotídeos & Seqüência 5'- $3^{\prime}$ & Conteúdo GC(\%) \\
\hline OPAX 10 & CCAGGCTGAC & 60 \\
OPAX 3 & CCAAGAGGCT & 60 \\
OPAX 20 & ACACTCGGCA & 60 \\
OPP 16 & CCAAGCTGCC & 70 \\
OPA 7 & GAAACGGGTG & 60 \\
OPA 20 & GTTGCGATCC & 60 \\
OPC 08 & TGGACCGGTG & 70 \\
OPX 17 & GACACGGACC & 70 \\
OPA 16 & AGCCAGCGAA & 60 \\
\hline
\end{tabular}




\subsubsection{Sequenciamento do rDNA de C.perniciosa.}

O rDNA (regiões ITS1+5,8S+ITS2) foi amplificado usando os oligonucletídeos iniciadores ITS 1 (5' CGT AAC AAG GTT TCC GTA GG 3') e ITS 4 (5' TCC TCC GCT TAT TGA TAT GC 3'). As reações de PCR foram realizadas em um volume final de $25 \mu \mathrm{L}$, contendo: tampão de enzima (Tris- $\mathrm{HCl} 20 \mathrm{mM} \mathrm{pH=8,4; \textrm {KCl }}$ 50mM); 3,7mM de $\mathrm{MgCl}_{2} ; 0,2 \mathrm{mM}$ de cada dATP, dTTP, dCTP e dGTP; 0,4 $\mu \mathrm{M}$ de cada iniciador; 1,0 U de Taq DNA polimerase e 25ng de DNA. As amplificações foram realizadas no termociclador (Gene Amp System 9600, Aplied Biosystems, Norwalk, CT, EUA) programado para realizar uma desnaturação inicial de $94^{\circ} \mathrm{C}$ por $5 \mathrm{~min}, 25$ ciclos de $94{ }^{\circ} \mathrm{C}$ por $30 \mathrm{seg} ; 55^{\circ} \mathrm{C}$ por $30 \mathrm{seg} ; 72^{\circ} \mathrm{C}$ por $30 \mathrm{seg}$ e finalmente uma extensão final a $72{ }^{\circ} \mathrm{C}$ por $7 \mathrm{~min}$. O produto da amplificação foi avaliado por meio de eletroforese em gel de agarose 1,4\% (item 3.2.8), coloração com brometo de etídio (item 3.2.9) e fotodocumentado sobre luz U.V.

Os fragmentos de DNA amplificados foram purificados com o Kit GFX (Amershan Pharmacia) e seqüenciados no laboratório do Dr. Ricardo Harekava (Instituto Biológico, São Paulo). Seqüências de C. perniciosa foram obtidas do GenBank usando o programa BLAST (http://www.ncbi.nlm.nih.gov/BLAST). O alinhamento das seqüências foi feito usando o programa Clustal $\mathrm{X}$, e as análises filogenéticas foram feitas de acordo com o método Neighbor-Joining para a construção do dendrograma (Felsenstein, 1985).

\subsection{Produção de enzimas extracelulares}

Os isolados de C. perniciosa foram avaliados quanto à sua capacidade de produzir exoenzimas em meio sólido. Para isso, discos de $8 \mathrm{~mm}$ de diâmetro do micélio do fungo, retirados da borda de colônias com aproximadamente 5 dias, foram transferidos individualmente para o centro de placas contendo meio mínimo (item 3.2.3) mais o substrato para a enzima a ser avaliada, e incubados por 11 dias a $28^{0} \mathrm{C}$. Todos os experimentos foram realizados em triplicata. 
A atividade lipolítica foi avaliada em meio mínimo suplementado com Tween 20 a $1 \%$. Após o crescimento fúngico as placas foram incubadas por 24 horas a $4^{0} \mathrm{C}$. A ação da lipase foi caracterizada pela formação de um precipitado branco ao redor das colônias.

A produção de amilase foi observada crescendo o fungo em meio mínimo suplementado com $1 \%$ de amido solúvel. Após crescimento do fungo, $10 \mathrm{~mL}$ de solução de iodo (item 3.2.10) foram adicionados sobre o meio de cultura. A atividade da amilase foi observada pela formação de halo claro ao redor das colônias em contraste com o meio azulado do restante da placa.

A atividade pectinolítica foi determinada em meio mínimo modificado (item 3.2.4) acrescido de $1 \%$ de pectina cítrica. Após 11 dias de crescimento, a atividade pectinolítica foi caracterizada pela observação de um halo de degradação após adição de solução de brometo hexadeciltrimetilamonia 1\% (item 3.2.11).

Para análise de endoglicanases, ao meio mínimo foi adicionado $1 \%$ de $\mathrm{CMC}$ (Carboximetilcelulose) como fonte de carbono. Após o crescimento fúngico, $5 \mathrm{~mL}$ de Vermelho Congo - 1\% (item 3.2.12), incubado a temperatura ambiente por 15 minutos e lavado com uma solução de $\mathrm{NaCl}(4 \mathrm{~N})$. A produção de endoglicanases foi detectada pela observação de um halo claro em torno da colônia.

As endoglicanases foram também avaliadas em conjunto com exoglicanases. Para isso, o meio mínimo foi suplementado com $1 \%$ de sigmacel como única fonte de carbono. A produção destas enzimas foi caracterizada pelo crescimento do isolado em análise, visto que microrganismos que não produzem este complexo enzimático não crescem nestas condições.

A produção de enzimas foi quantificada pela análise da relação $\mathrm{H} / \mathrm{C}$ obtido pela divisão do diâmetro do halo $(\mathrm{H})$ pelo diâmetro da colônia $(\mathrm{C})$. As análises estatísticas foram feitas com o auxílio do programa SAS versão 8.0 (SAS Institute Inc., 1999, Cary, NC, USA). Os dados foram transformados obtendo-se a raiz quadrada do valor obtido somado a 0,5 . A análise estatística foi feita utilizando-se o Teste de Dunnett (1\%), comparando todas as linhagens com a linhagem FA 42, a qual é reconhecidamente patogênica ao cacaueiro. 


\subsection{Teste de patogenicidade}

A patogenicidade de 8 isolados de $C$. perniciosa $(5,6,8,9,10,31,79$ e FA 284) foi avaliada em plântulas de cacau Catongo, o qual é susceptível a vassoura-debruxa. O isolado FA 42 foi usado como controle positivo por apresentar em testes anteriores uma alta virulência.

Discos de micélio crescido em BDA foram transferidos para placas contendo substrato para produção de basidiocarpos (item 3.2.6) e incubados a $28^{\circ} \mathrm{C}$ até o micélio cobrir completamente o substrato. O substrato com o micélio de C. perniciosa foi dependurado em câmara úmida a $28^{\circ} \mathrm{C}$ e molhado em $800 \mathrm{~mL}$ de água por 1 minuto 3 vezes por semana. Este substrato foi mantido em fotoperíodo de 12 horas no claro por 12 horas no escuro. Para estimular a produção de basidiocarpos, após 15 dias de crescimento nas condições acima, foi dado um estresse hídrico por 4 dias e novamente voltou-se à rega normal para que ocorresse a formação dos basidiocarpos.

Os basidiocarpos foram coletados e mergulhados por 10 segundos em uma solução de estreptomicina $0,1 \%$, lavados em água esterilizada e colocados invertidos sob uma tampa para que os esporos fossem ejetados sobre uma solução à base de glicerol (item 3.2.13) contida em um Béquer. O Béquer usado para coleta ficou sob

agitação lenta por aproximadamente 14 horas. Após esse tempo a viabilidade dos basidiósporos foi avaliada por meio da sua semeadura sobre meio ágar-água (item 3.2.5) e incubando por 3 horas a $28^{\circ} \mathrm{C}$ para cálculo da taxa de germinação. A partir dessa suspensão foram feitas diluições para a concentração de $5 \times 10^{5}$ esporos viáveis $/ \mathrm{mL}$ para aplicação nas plantas.

Para o teste de patogenicidade, as plântulas a serem avaliadas foram mantidas em câmaras úmida por 24 horas para abertura dos estômatos antes da aplicação de $70 \mu \mathrm{L}$ da suspensão de basidiósporos. Esta suspensão foi aplicada nas gemas apicais, laterais e folhas jovens de cacau Catongo de aproximadamente 45 dias e, após a aplicação, as plântulas foram novamente mantidas em câmaras úmidas por 48 horas.

Foi utilizado o delineamento de blocos ao acaso, com 3 blocos de 5 plantas cada. As análises estatísticas foram feitas com o auxílio do programa SAS versão 8.0 
(SAS Institute Inc., Cary, NC, USA, 1999) usando o teste de Dunnett comparando todos isolados com o isolado FA 42.

\subsection{Avaliação in vitro da resistência/susceptibilidade de $C$. perniciosa a diferentes fungicidas}

Foram utilizados os fungicidas: Tebuconazole (Folicur) nas concentrações de 1

e 10 ppm) e Óxido cuproso (Cobre Sandoz), Benomil (Benlate) e Mancozeb (Manzate) nas concentrações de 100 e 400 ppm. Cada fungicida (ingrediente ativo) foi testado em diferentes concentrações, sendo incorporados ao meio BDA. As avaliações foram realizadas em triplicata ( 3 placas para cada tratamento). Para o controle, o fungo de interesse foi cultivado em meio BDA sem fungicida.

Para a análise, discos de $8 \mathrm{~mm}$ de diâmetro do meio BDA contendo micélio de C. perniciosa foram colocados sobre o meio de cultura contendo os fungicidas de interesse, e mantido a $25^{\circ} \mathrm{C}$. As avaliações foram realizadas 10 dias após as inoculações, por meio da medição do diâmetro das colônias e cálculo da porcentagem de inibição em relação ao controle.

As análises estatísticas foram feitas com o auxílio do programa SAS versão 8.0 (1999) by SAS Institute Inc., Cary, NC, USA. A análise estatística foi feita utilizando-se o Teste de Dunnett (1\%), considerando individualmente cada fungicida, comparando todas as linhagens com a linhagem FA 42. Essa linhagem foi escolhida pois testes anteriores de patogenicidade mostraram sua alta capacidade de induzir sintomas em mudas de cacau. 


\section{RESULTADOS E DISCUSSÃO}

\subsection{Isolamento de Crinipellis perniciosa endofítico de cacau}

Após a desinfecção superficial dos ramos de cacau, foi possível isolar colônias fúngicas com morfologia semelhante à C. perniciosa, tanto de ramos sadios como de ramos com sintomas da vassoura-de-bruxa. Embora na literatura não se tenha registro de isolamento de C. perniciosa de tecidos sadios, neste trabalho foram obtidos 2 isolados (31 e 54) de ramos sadios de cacaueiro proveniente de plantações na cidade de Uruçuca (BA) (Tabela 1). Tendo em vista que a casca contendo gemas laterais foi removida, este dado sugere que estes isolados apresentam a capacidade de colonizar de forma assintomática os tecidos internos (parênquima ou vasos) da planta hospedeira.

Utilizando a metodologia descrita anteriormente, foram também obtidos de ramos com sintomas da vassoura-de-bruxa 11 isolados com características morfológicas de $C$. perniciosa. Sete isolados $(1,2,3,4,5,6$ e 79) foram de plantas provenientes de fazendas no município de Uruçuca (BA) e quatro $(7,8,9$ e 10) de Lomanto Júnior (BA)(Tabela 1). Todas as linhagens obtidas no presente trabalho apresentaram grampos de conexão (Figura 1) e coloração branca (Figura 2), de forma característica a $C$. perniciosa. O sequenciamento do rDNA confirmou que realmente todas as linhagens são realmente C. perniciosa.

No campo todas as partes da planta estão expostas aos basidiósporos de $C$. perniciosa, mas os sintomas da vassoura-de-bruxa são observados somente nos tecidos meristemáticos, isto é, nos meristemas terminais e brotos laterais. Este fato se deve possivelmente à presença de barreiras físicas impostas pelas cutículas de folhas maduras (Abo-Hamed et al., 1983) e grande número de compostos secundários nos tecidos 
maduros (Jalal \& Collin, 1977) os quais têm papel na defesa da planta (Muse et al., 1996). Tendo em vista que C. perniciosa foi isolado de tecidos maduros e sadios, podemos sugerir que ou este fungo penetrou nos tecidos vegetais quanto estes ainda são jovem ou estes isolados apresentam capacidade de romper as barreiras de defesa e se estabelecer em tecidos maduros do cacaueiro. Outro ponto importante é o fato destes isolados não terem induzido sintomas típicos da vassoura-de-bruxa, sugerindo se tratar de isolados endofíticos. Entretanto, outros testes devem ser realizados para confirmar esta hipótese.

Outra hipótese é de que estes isolados endofíticos seriam C. perniciosa patogênicos, mas que permaneceram em estado de latência nos ramos avaliados. McOnie (1964) observou que isolados patogênicos de Guinardia citricarpa, agente causal da mancha preta dos citros, podem resultar em infecções assintomáticas e sintomáticas. McOnie (1964), observou ainda que isolados fitopatogênicos parecem infectar somente citros enquanto os isolados não patogênicos infectam um ampla faixa de hospedeiros. O mesmo não acontece com C. perniciosa, pois linhagens patogênicas ao cacau podem também induzir sintomas em outros hospedeiros como Theobroma speciosum e Herrania spp. (Bastos et al., 1988).

A infecção latente de patógenos em plantas tem sido observada e é considerada como um dos mais altos níveis de parasitismo, uma vez que o hospedeiro e o parasita coexistem com mínimo dano ao hospedeiro. Segundo Agrios (1988), infecção latente é o estágio em que um hospedeiro é infectado com um patógeno mas não apresenta sintomas. A infecção latente persiste até os sinais ou sintomas aparecem por condições nutricionais, ambientais ou pelo estágio de maturidade do hospedeiro ou do patógeno (Sinclair \& Cerkauskas, 1996).

Segundo Sinclair (1991), a infecção latente pode ser reconhecida como um tipo de tolerância ou resistência a certos patógenos, onde o parasita encontra o ambiente interno impróprio para crescimento e multiplicacão, e resulta de um processo de coevolução entre plantas e patógenos. Este tipo de infecção é importante na epidemiologia e controle de doenças de plantas e também na obtenção de resistência ou tolerância a um patógeno. 
Glienke-Blanco et al. (2002) obtiveram 12 isolados de G. citricarpa de folhas sadias de citros e após comparação com isolados patogênicos porém não foram observadas diferenças morfológicas. No presente trabalho nenhuma diferença morfológica foi observada entre os isolados endofíticos e patogênicos de C. perniciosa.

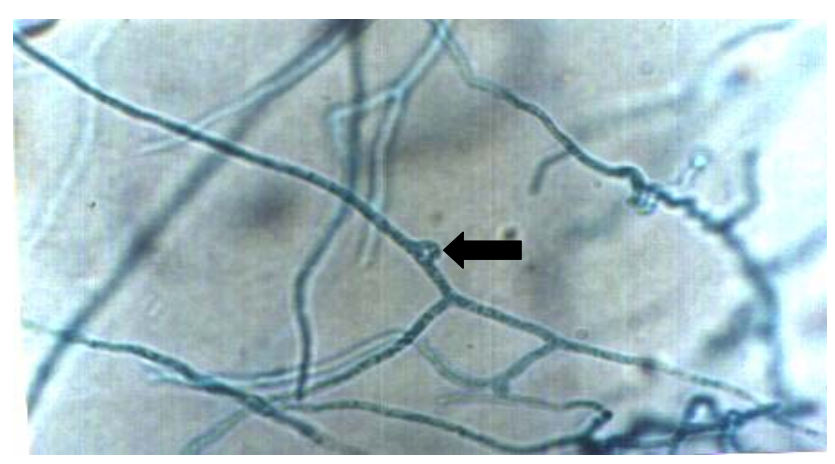

Figura 1 - Aspecto morfológico de hifas do isolado 31 de C. perniciosa. A seta indica a presença de grampo de conexão

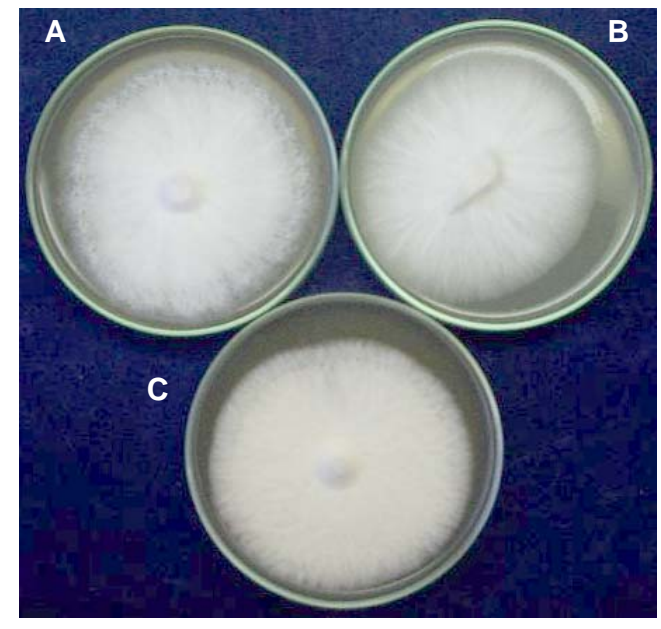

Figura 2 - Aspectos morfológicos de diferentes linhagens de C. perniciosa. A - Isolado 13 (Solanum lycocarpum); B - Isolado 79 (Theobroma cacao); C - Isolado 6 (Theobroma cacao) 
Neste aspecto, o entendimento da interação dos isolados patogênicos de $C$. perniciosa com a planta hospedeira e a confirmação de isolados endofítico poderão permitir um melhor conhecimento da variabilidade do patógeno assim como a utilização destes endófitos para o controle da vassoura-de-bruxa, visto que poderiam ser inoculados no cacaueiro, ativando o sistema de defesa da planta ou competindo com isolados patogênicos por nutrientes.

\subsection{Análise de variabilidade genética de $C$. perniciosa por meio de marcadores RAPD}

\subsubsection{Padronização da técnica de RAPD e seleção de oligonucleotídeos}

A classe de marcadores conhecida como RAPD permite identificar o grau de similaridade entre os genótipos de organismos de interesse. A técnica se baseia na amplificação de fragmentos não específicos de DNA, distribuídos de forma aleatória no genoma do organismo alvo. Esta metodologia utiliza oligonucleotídeos iniciadores (primers) de 10 bases para amplificar, via PCR, fragmentos do DNA genômico.

Para obtenção de melhores resultados, as condições de amplificação devem ser otimizadas, incluindo a seleção de primers, concentração de íons $\mathrm{Mg}^{++}$e concentração de DNA na reação. No presente trabalho, foram avaliados inicialmente 2 isolados de $C$. perniciosa, um endofítico (31) e outro patogênico (79). Foram avaliados os perfis de RAPD destes isolados utilizando 24 primers, dos quais foram selecionados 9 primers (Tabela 2) que mostraram um melhor perfil de bandas.

Com base na otimização da reação de RAPD, foi observado que a melhor condição, foi quando se utilizou $3,5 \mathrm{mM}$ de íons $\mathrm{Mg}^{++}$e $5 \mathrm{U}$ de enzima por reação (Figura 3). Segundo Williams et al. (1993), a concentração de DNA na reação é um fator muito importante na análise por RAPD, visto que em altas concentrações de DNA é observado um borrão (background), dificultando a leitura das banda, enquanto que em concentrações baixas ocorre a perda de bandas importantes, que seriam visíveis em concentrações adequadas. Niella (2000) analisando a variabilidade entre isolados de $C$. 
perniciosa, também utilizando a técnica de RAPD, só obteve bons resultados com uma quantidade maior de DNA por reação (30ng). Dessa forma, no presente trabalho foram também avaliadas 2 concentrações de DNAs (10 e 20ng). Entretanto, não foi observada diferença no padrão de bandas nestas concentrações de DNA, sendo dessa forma optado pela utilização de 10ng de DNA por reação.

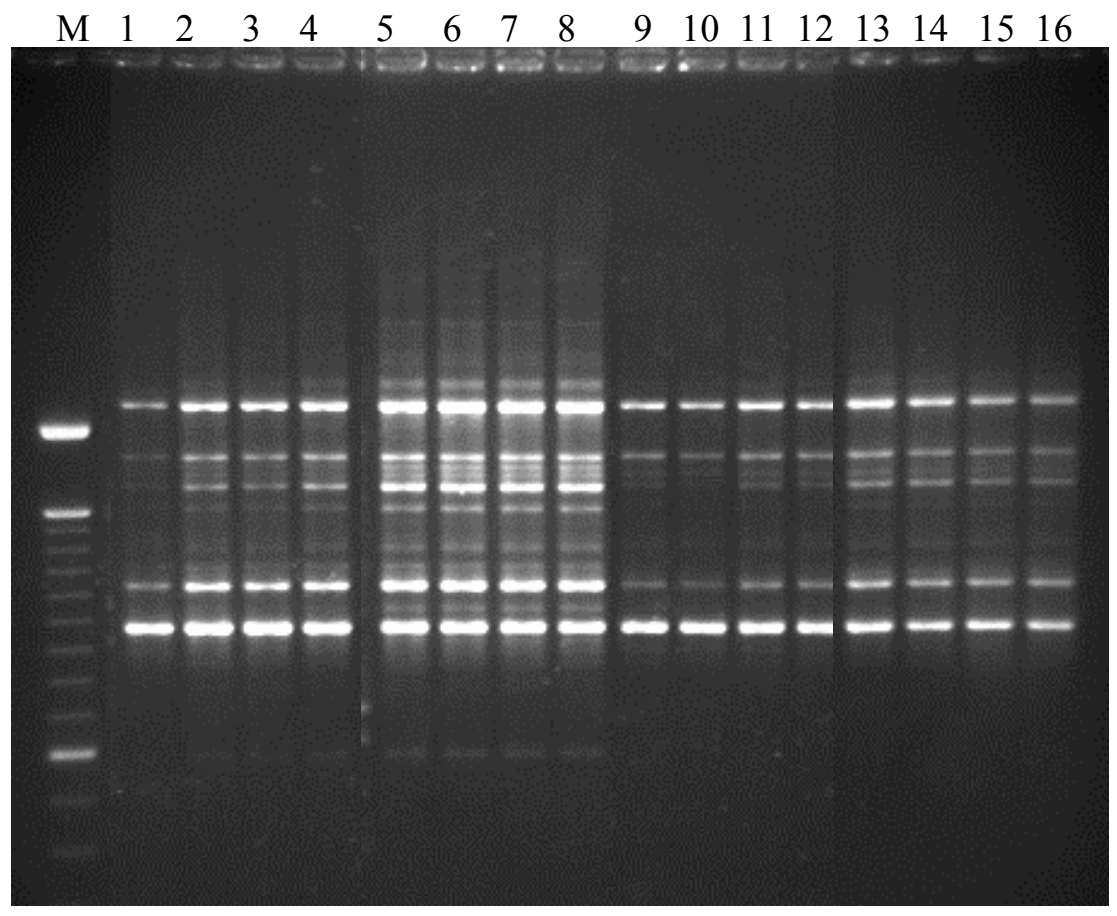

Figura 3 - Amplificação de DNA de C. perniciosa com o primer OPX17, para verificar a condição ótima de reação, em função da concentração de íons $\mathrm{Mg}^{++}$e Taq polimerase. Linhas 1 a 4: 3,5mM Mg${ }^{++}$e $3 \mathrm{U}$ Taq polimerase; Linhas 5-8: 3,5 e $5 \mathrm{U}$ Taq polimerase; Linhas 9-12: 2,5mM Mg e 3U Taq polimerase; Linhas 13-16: 2,5mM e 5U. M marcador ladder $1 \mathrm{~Kb}$ 


\subsubsection{Variabilidade genética de $C$. perniciosa por marcadores de RAPD}

Utilizando as condições otimizadas no item 4.2.1 foi possível avaliar a diversidade genética de 35 isolados de C. perniciosa. No presente estudo foram utilizados 9 primers, os quais geraram um total de 64 bandas com ótimo nível de repetibilidade. Destas bandas, 57 (98,9\%) mostraram-se polimórficas, ou seja estiveram ausentes em pelo menos um isolado avaliado. A Figura 4, mostra o perfil de bandas obtidos com o primer OPX 17 para os 35 isolados.

A análise combinada das 64 bandas permitiu a construção de um dendrograma (Figura 5) que mostrou as relações genéticas entre os isolados avaliados. Utilizando uma linha arbitrária a 96\% de similaridade, foi observada a formação de 8 grupos distintos (G1, G2, G3, G4, G5, G6, G7 e G8) sendo que dentro do grupo G1 ocorreu uma divergência dos isolados FA 35 e FA 152 que foram colocados em 2 subgrupos distintos, G1-1 e G1-2, respectivamente.

Os isolados 1, 2, 3, 4, 5 e 6 obtidos de uma mesma planta do município de Uruçuca (BA) apresentaram 100\% de similaridade entre eles e com os isolados FA 23, FA 154, FA 277, FA 279, FA 283 e FA 287, e foram agrupados no grupo G1. Tendo em vista que todos os isolados foram obtidos na Bahia, com exceção do isolado FA 154 coletado em Rondônia. Também Bastos (1990) através de testes bioquímicos e de estudo de compatibilidade vegetativa comparou um isolado procedente de Uruçuca com isolados da região Amazônica e observou semelhanças entre aquele e os provenientes de Rondônia. Podemos sugerir que Rondônia pode ter sido uma fonte inicial de inoculo de C. perniciosa para a região da Bahia. Estes resultados mostram também que isolados de C. perniciosa geneticamente semelhantes colonizam plantas de cacau cultivadas em áreas geograficamente diferentes, sugerindo que possa existir uma disseminação clonal deste patógeno. Colauto et al., (2002) caracterizando 5 isolados de Agaricus blazei, também por análises de RAPD, verificou que apesar de terem sido obtidos em locais diferentes não apresentaram divergências, sendo caracterizados como isolados de uma mesma origem. 
Os isolados FA 152, proveniente de Rondônia, e FA 35 proveniente do Pará (Tabela 1), embora tenha apresentado uma diversidade maior, também foram incluídos no grupo G1, mas foram agrupados nos subgrupos G1-1 e G1-2, respectivamente. Os isolados FA 154 e FA 152, provenientes de Rondônia embora sejam geneticamente diferentes, apresentam uma alta similaridade genética. Entretanto, o isolado 11, obtido também de Rondônia, foi colocado no grupo G3, mostrando ser geneticamente diferente dos demais isolados e sugerindo que possam existir pelo menos 2 populações divergentes em Rondônia. De fato, resultado semelhante foi observado por Andebrhan et al. (1998) que identificaram, por estudos de compatibilidade somática, dois grupos distintos de C. perniciosa em Rondônia, um de Ariquemes e Cocoal e outro de Ouro Preto D’Oeste e Jaru.

Embora alguns autores (Andebrhan et al., 1999; Gomes et al., 2000 e Yamada et al., 1998) afirmam que isolados coletados na mesma região tendem a ser geneticamente semelhantes, esta verificação não foi confirmada quando se observou diferentes isolados provenientes da localidade de Lomanto Júnior (BA). Por exemplo, as linhagens FA 23, FA 283, FA277, FA 282 e FA278 pertencem ao grupo G1 enquanto as linhagens 7, 8, 9, 10, FA 42 e FA 276 pertencem ao grupo G2.

Podemos inferir ainda, que linhagens isoladas como endofíticas podem ser geneticamente semelhantes a linhagens isoladas como patogênicas, pois observando o dendrograma (Figura 5), os isolados de ramos sadios (31 e 54) se agruparam no grupo G2 juntamente com isolados patogênicos. O isolado endofítico 31 apresentou $100 \%$ de similaridade com os isolados patogênicos FA 281 e 10 que foram obtidos de ramos com sintomas da vassoura-de-bruxa, assim como os isolado endofítico 54 e os patogênicos 7 , 8, 9, 79, FA 42, FA 276, FA 284, mostrando que, nas condições avaliadas, não ocorreram diferenças entre os isolados obtidos como endófitos ou como patógeno.

Manulis et al. (1993), utilizaram com sucesso 30 oligonucleotídeos arbitrários para distinguir linhagens patogênicas e não patogênicas de isolados de Fusarium oxysporum obtidos de limão cravo. Já Glienke-Blanco et al. (2002), embora tenham observado divergência entre isolados endofíticos e patogênicos de G. citricarpa, os 
quais formaram grupos distintos, alguns isolados endofíticos agruparam como patogênicos, mostrando que pode haver sobreposição entre os grupos.

O dendrograma (figura 5) mostrou também que, embora tenham sido utilizados poucos isolados de outros hospedeiros, estes são geneticamente diferentes dos isolados obtidos de cacaueiro. Como já mostrado em trabalhos anteriores como em Heteropterys acutifolia (Resende et al., 2000; Viana Jr., 2001), Mascagnia cf. sepium (Bastos et al., 1998), isolados de C. perniciosa podem induzir sintomas da vassoura-de-bruxa no cacaueiro, sendo, portanto de grande importância epidemiológica, visto que poderiam ser fonte de variabilidade genética para isolados patogênicos.

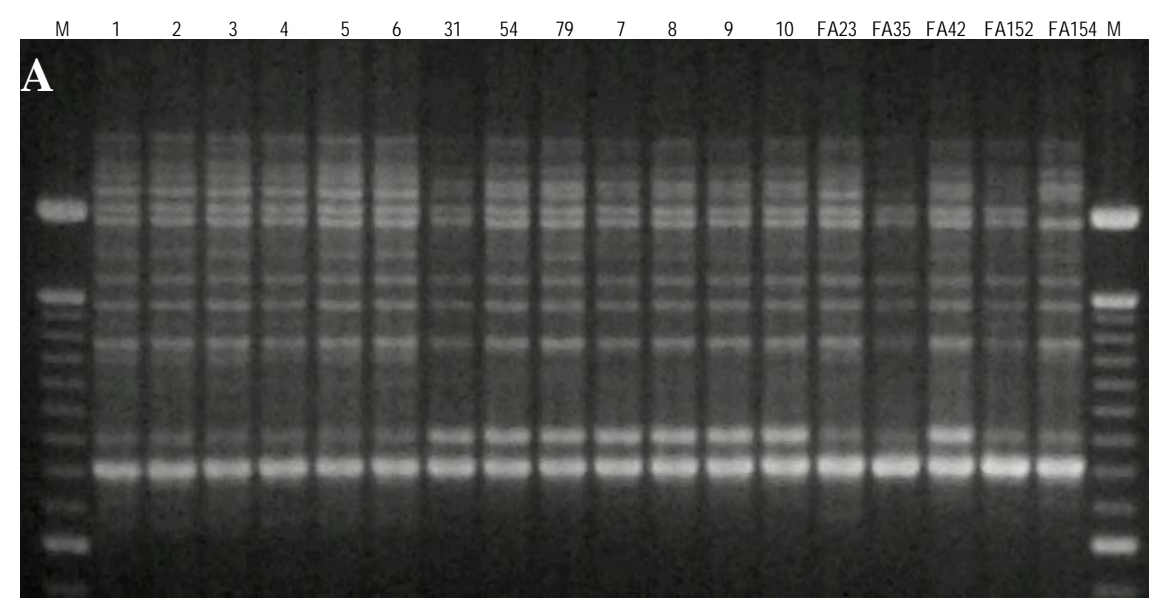

M FA276 FA277 FA278 FA279 FA281 FA282 FA283 FA284 FA286 FA287 FA292 322 FA136 $11 \quad 12 \quad 13 \quad$ FA104 $M$

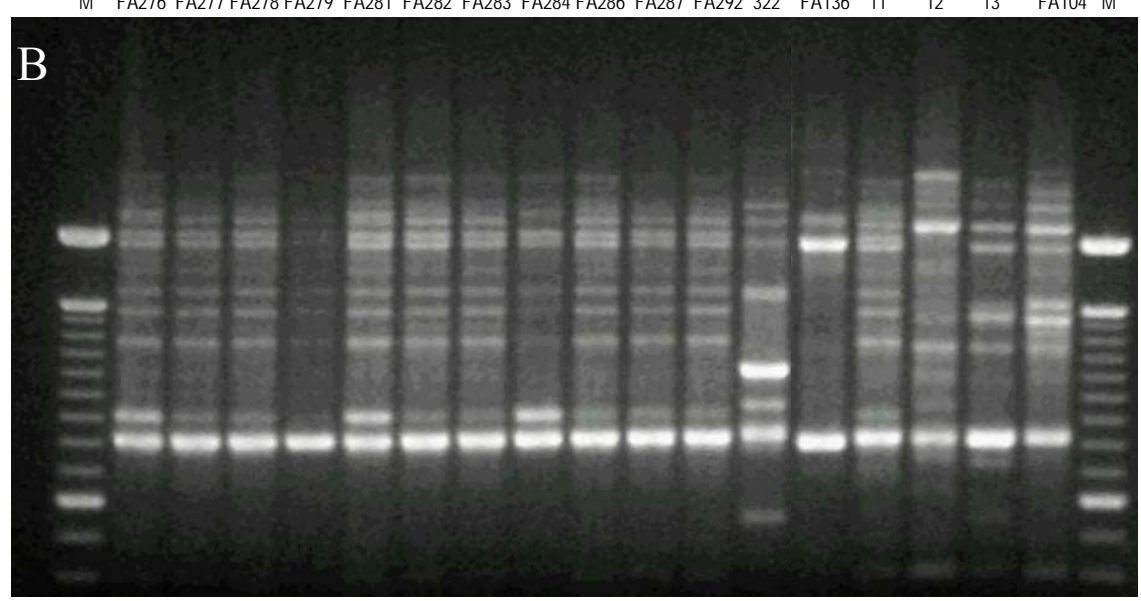

Figura 4 - Gel de eletroforese mostrando padrões de RAPD obtidos de 35 isolados de $C$. perniciosa. A e B mostram os padrões de RAPD usando o primer OPX 17 (5’ - GACACGGACC - 3’). M- marcador Ladder $1 \mathrm{~Kb}$ 
Dessa forma, no presente trabalho, por meio da análise dos dados por RAPD, não foi possível distinguir geneticamente isolados endofíticos e patogênicos. De fato, se a diferença entre endófitos e patógenos estiver associada a poucos genes, uma análise genética utilizando marcadores moleculares aleatórios, dificilmente permitirá a distinção entre isolados patogênicos e endofíticos pertencentes a uma mesma espécie.

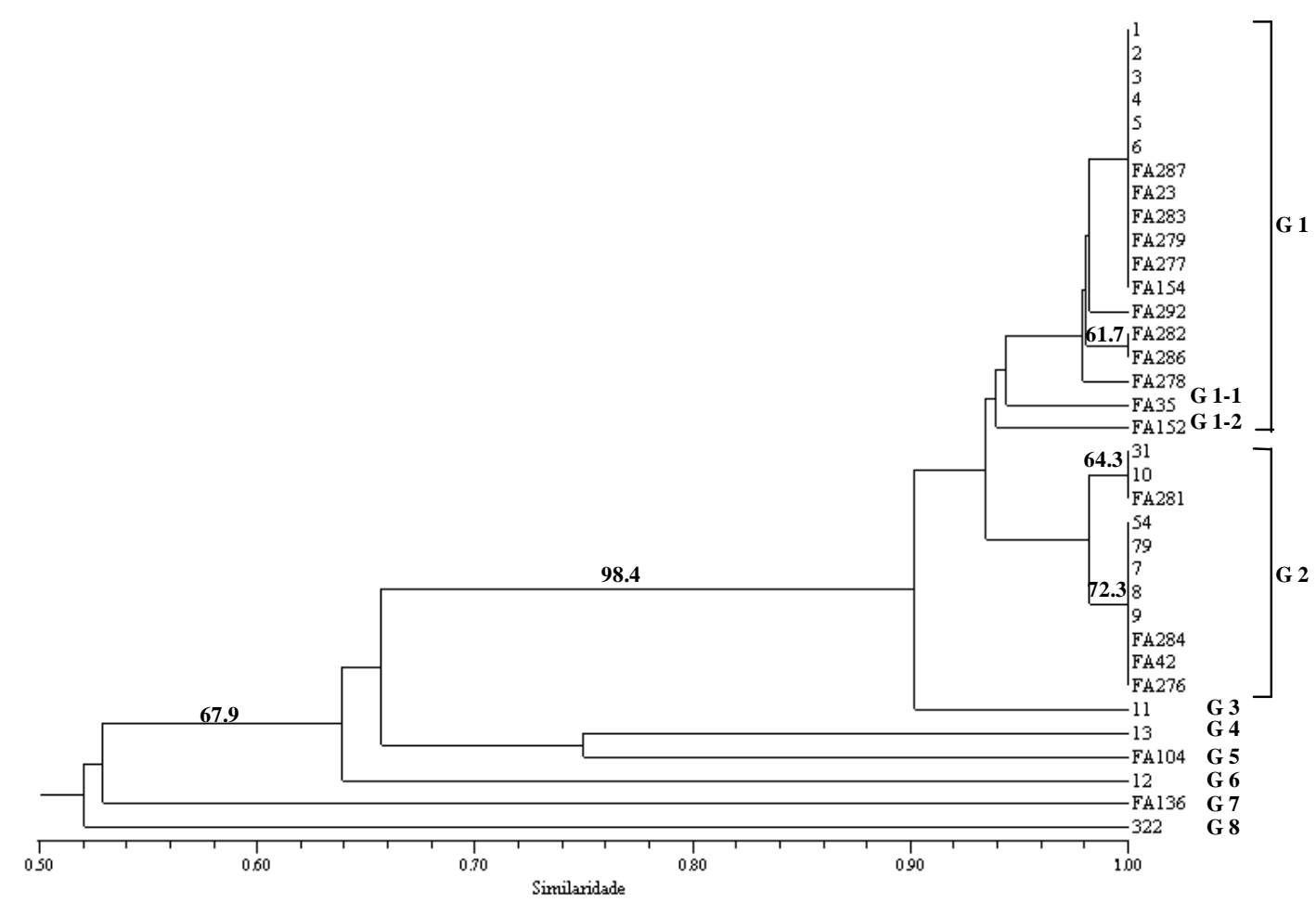

Figura 5 - Dendrograma construído pelo método de UPGMA mostrando as relações genéticas baseadas em padrões de RAPD de C. perniciosa. Os isolados estão descritos na Tabela 1

\subsection{Análise do rDNA de C. perniciosa.}

Os produtos de PCR obtidos da amplificação das regiões ITS1, 5.8S e ITS2 do rDNA de C. perniciosa apresentaram em torno de 750 pb, não mostrando polimorfismo quanto ao tamanho do fragmento amplificado (Figura 6). Estes fragmentos amplificados foram posteriormente sequenciados (Anexo A) e alinhados (item 3.4.5) e comparados 
com outras seqüências depositadas no GenBank. Todas as seqüências avaliadas apresentaram alta homologia com C. perniciosa, mostrando que os isolados utilizados no presente trabalho são de fato da espécie de interesse. Arruda et al. (2003b) também não observaram polimorfismo entre 120 isolados de C. perniciosa de diferentes localidades e hospedeiros utilizando os mesmos primers ITS 1 e ITS 4. Além disso, os autores não verificaram polimorfismo após digestão destes fragmentos com as enzimas HinfI, HinpI e MspI. Resultado semelhante foi observado por Leal Jr. (2002) entre linhagens isoladas de cacau e de vários outros hospedeiros, com a exceção de apenas uma linhagem coletada de Herrania que apresentou um fragmento com peso molecular diferente dos demais. Estes resultados mostram a importância de se avaliar toda a seqüência do rDNA de C. perniciosa, visto que a variabilidade genética nesta região parece ser reduzida nesta espécie.

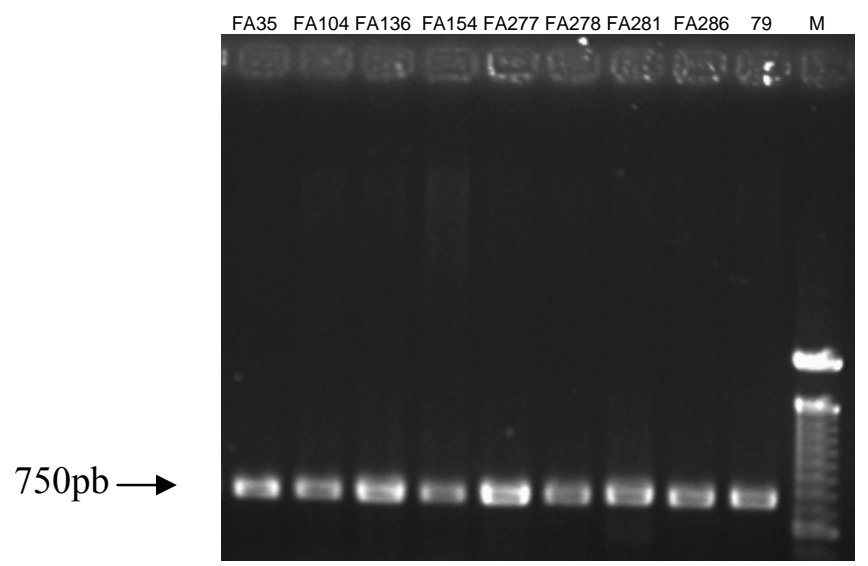

Figura 6 - Gel de eletroforese mostrando padrão de amplificação de regiões do rDNA de alguns isolados de C. perniciosa. M - marcador Ladder 100 pb 
As seqüências obtidas permitiram a construção de um dendrograma (Figura 7), o qual mostrou a relação genética entre os isolados avaliados. Foram observados 6 grupos (R1, R2, R3, R4, R5 e R6), sendo que a maioria dos isolados foram distribuídos nos grupos R3, R5 e R6. Com base nestas seqüências foi possível observar que diferentemente das análises de RAPD ocorreu diferenciação entre isolados coletados na mesma planta, pois os isolados 1, 2, 3, 4, 5 e 6 não formaram um mesmo grupo. Ocorreu uma distribuição destes isolados nos grupos de R3 a R6, sendo que o isolado 3 formou um grupo unitário (R4), mostrando que isolados obtidos de uma mesma planta embora sejam muito semelhantes por marcadores de RAPD, apresentaram variação quanto à seqüência do rDNA. Yamada et al. (1998) e Gomes et al. (2000) observaram que isolados obtidos de uma mesma região apresentam uma maior similaridade genética. Por outro lado, Anderbrhan \& Furtek (1994) observaram uma pequena similaridade genética entre isolados de C. perniciosa obtidos de uma mesma região.

A variabilidade genética observada entre isolados da mesma região, ou seja, próximos geograficamente, indica a relevância da seleção de isolados para a utilização em programas de melhoramento visando a resistência. Isolados obtidos de locais distantes e pertencentes a grupos diferentes nas análises de RAPD, como o isolado 8 (isolado em Lomanto Júnior/BA) e o 11 (isolado em Rondônia) pertencem ao mesmo grupo (R3) reforçando a idéia de que C. perniciosa foi introduzido na Bahia por meio de isolados provenientes de Rondônia.

Por outro lado, C. perniciosa pode também ter sido introduzido recentemente na Bahia a partir da região amazônica, pois considerando que variedades de T. cacao cultivadas na Bahia vieram desta região, e que estes isolados como observado no presente trabalho poderiam estar colonizando endofiticamente estas plantas, e posteriormente, como citado por Luz et. al. (1997) ao encontrarem no sudeste da Bahia clima favorável puderam desenvolver os sintomas da vassoura-de-bruxa. Análises de ERIC-PCR feitas por Arruda et al. (2003a) revelaram considerável variabilidade dentro de C. perniciosa de T. cacao, distinguindo a maioria dos isolados com base na origem geográfica produzindo padrões únicos. Os autores mostraram ainda que 5 isolados de Ilhéus se agruparam com isolados de Belém (PA) em um grupo e em outro grupo com 
isolados de Belém e Canavieiras (BA). Essa similaridade segundo os autores sugerem introdução de C. perniciosa juntamente com cacau proveniente da região amazônica.

O dendrograma mostrou ainda o agrupamento dos isolados FA 136 e 322 obtidos da planta hospedeira Liana (Grupo R1), enquanto que os isolados provenientes de outros hospedeiros se agruparam aos isolados provenientes de cacau. Os isolados 31 e 54 obtidos de tecidos sadios e supostamente endofíticos apresentaram alta divergência, estando incluídos nos grupos R3 e R6, respectivamente. Além disso, não foi observada nenhuma seqüência que pudesse diferenciar as linhagens possivelmente endofíticas das patogênicas. A partir das seqüências obtidas poderão ser desenvolvidos primers para permitir a detecção deste fungo em tecidos sadios, antes mesmo da manifestação de sintomas da vassoura-de-bruxa permitindo estudos de epidemiologia, distribuição do patógeno em áreas de cultivo de cacau e importante ferramenta para seleção de germoplasmas no melhoramento de variedades de cacau resistentes ao patógeno.

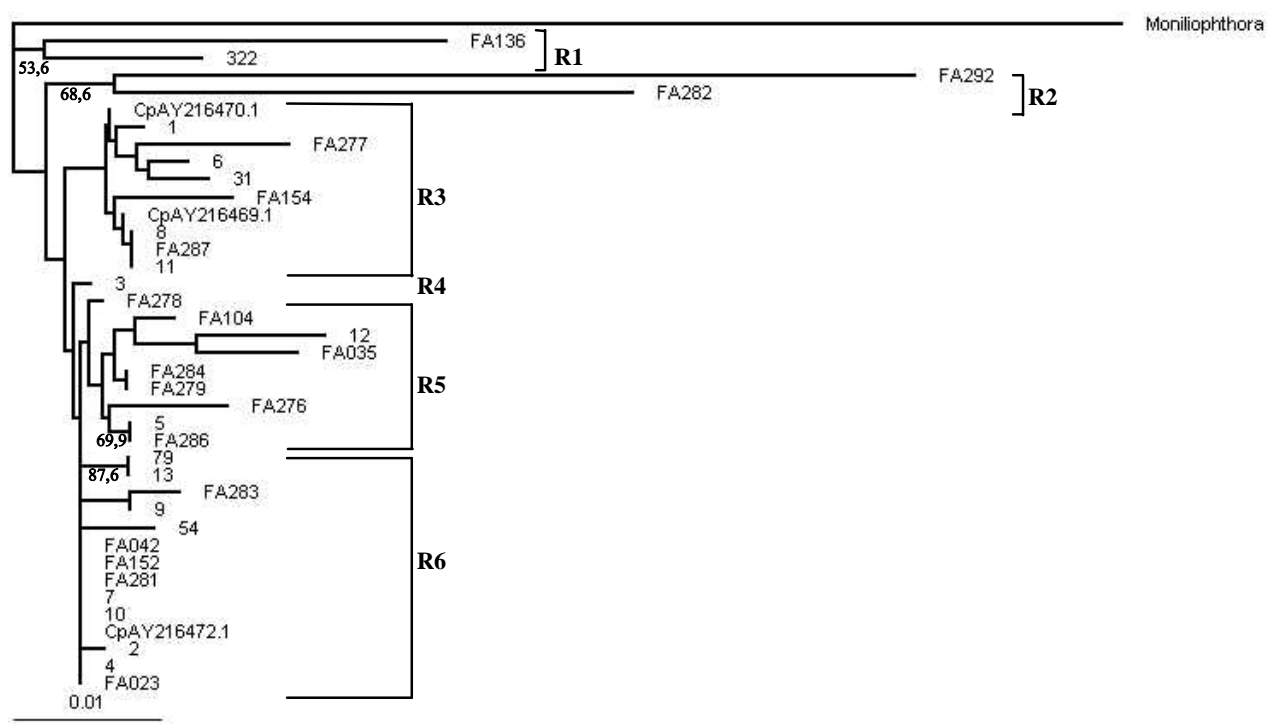

Figura 7 - Dendrograma construído com a análise das seqüências de rDNA (ITS1 + 5.8s + ITS2) de C. perniciosa. Os isolados estão descritos na Tabela 1 


\subsection{Produção de enzimas extracelulares}

Todas as linhagens da Tabela 1 foram analisadas quanto à capacidade de produzir enzimas extracelulares. A produção foi avaliada como descrito no item 3.5. Na figura 12 podem ser observados os halos de degradação produzidos pela ação da lipase. Foi observado que a maior produção enzimática ocorreu com a enzima lipase, mas não foi observada diferença estatística entre os isolado avaliados e a linhagem padrão (FA 42). Porém, as maiores variações nos valores de $\mathrm{H} / \mathrm{C}$ entre os isolados foram verificadas nessa enzima. $\mathrm{O}$ isolado FA 136 apresentou valor de $\mathrm{H} / \mathrm{C}$ igual a 4,13 e o menor valor observado foi com o isolado FA 286 que foi de 1,67 (Figura 8).

Lealem \& Gashe (1994) recomendam um valor do índice de atividade enzimática maior ou igual a 2 para mostrar a habilidade do microrganismo em degradar amido em meio sólido. Considerando este valor, a maioria dos isolados mostrou uma relação $\mathrm{H} / \mathrm{C}$ maior que 2 quanto a produção de lipases, enquanto para as enzimas endoglicanases, e amilase somente 3 isolados $\mathrm{H} / \mathrm{C}$ apresentaram índice maior que 2.

Como exemplo de produção de lipases por outros microrganismos podemos citar Fusarium solani FS1 em meio contendo óleo de oliva 0,5\% (v/v) (Maia et al., 1999) e linhagens endofíticas de Nocardiopsis sp. (Stamford et al., 1998). Sendo estes microrganismos endofíticos ou patogênicos, podemos sugerir que esta enzima pode estar envolvida com a interação planta-microrganismo. Entretanto, no presente trabalho nenhuma diferença foi observada entre os isolados endofíticos e patogênicos quanto a produção de lipase.

Foi observada uma baixa produção de pectinases pelos isolados avaliados, tendo sido observado que somente os isolados 10, FA 104, FA 136, FA 278 e FA 281

apresentaram relação $\mathrm{H} / \mathrm{C}$ maior que 2 , enquanto que 5 dos isolados não produziram quantidades detectáveis desta enzima (Figura 9). Bastos (1988) não observou nenhuma produção de pectinases por isolados de C. perniciosa, sugerindo que esta enzima não está associada à patogenicidade de C. perniciosa.

As enzimas pectinolíticas são as mais estudadas no tocante ao seu papel na patogênese segundo Collmer (1987), citado por Pascholati, (1995), uma das razões para 
esse interesse deve-se ao tratamento de tecidos vegetais com pectinases purificadas, $\mathrm{o}$ que ocasiona na separação das células e morte das mesmas. Esse processo ocorre durante o desenvolvimento de muitas doenças, principalmente nas podridões moles onde os tecidos perdem a rigidez. Segundo Pascholati (1995), a produção de pectinases in vitro, ou mesmo in situ, por bactérias ou fungos não se constitui em prova definitiva da importância das mesmas na patogênese. A indução pode estar mais ligada á obtenção de nutrientes do que especificamente associada à patogenicidade.

Quanto á capacidade de degradar CMC pela produção de endoglicanases (carboximetil celulase), quase todos isolados foram semelhantes ao FA 42, com exceção dos isolados 54, FA 283, FA 286 e 322 que produziram significativamente mais endoglicanases e os isolados 2 e FA 35 que produziram significativamente menos desta enzima (Figura 10). O halo de degradação do CMC pelo isolado pode ser visualizado na figura 13. Embora tenha sido observada variação significativa entre os isolados avaliados quanto a produção de endoglicanases, nenhuma correlação entre endofitismo e a produção desta exoenzima foi observada.

A produção de amilase pode ser observada na figura 11 e 14 . Os isolados 8, 9, 12, 31, 54, 79, FA 152, FA 154 e FA 286 mostraram produção enzimática maior que a da linhagem padrão FA 42, sendo que o isolado 12 proveniente de Solanaceae se destacou na produção desta enzima com valor de H/C igual a 4,6 enquanto as demais mostraram valores entre 2,5 e 0,6. Coincidentemente este mesmo isolado foi o que produziu uma maior quantidade de pectinases, o segundo maior produtor de lipase e também ficou entre os melhores produtores de endoglicanases (Anexo B), sugerindo que se estas enzimas são importantes para a patogenicidade este isolado poderia apresentar uma maior capacidade de infectar a planta hospedeira.

Almeida et al. (1998) observando modificações morfológicas em variedades de cacau Catongo e o híbrido SCA-6 x Catongo verificou que a quantidade de amido existente em plantas de cacau pode estar associada com o seu grau de tolerância à vassoura-de-bruxa. Produtos da hidrólise do amido pode aumentar potencial osmótico das células impedindo o crescimento das hifas ou serem usadas em rotas bioquímicas para defesa da planta. Também Bastos (1988) observou variabilidade na produção das 
enzima lipase amilase, celulases, peroxidase, esterase e polifenoloxidase, quando analisou 7 isolados de C. perniciosa de cacau, obtidos de pimenteira e cupuaçu provenientes do Pará e um isolado de juçara coletado no Amazonas.

Quanto a capacidade de utilizar sigmacel como fonte de carbono, foi observado que todos os isolados cresceram sobre este substrato, mostrando que produziram in vitro endo e exocelulases (Anexo B). Foi observado que os isolados que apresentaram um menor tamanho de colônia $(1,12,13$ e FA 152) também mostraram menor crescimento sobre meio mínimo com glicose, concluindo assim que o crescimento destes isolados é mais lento que os demais e não devido à fonte de carbono utilizada (Dados não mostrados).

Isolados obtidos de um mesmo tecido $(1,2,3,4,5$ e 6$)$, embora tenha apresentado $100 \%$ de similaridade por marcadores de RAPD e serem diferentes quanto a seqüência de rDNA, na presente análise mostraram que são diferentes fisiologicamente, pois diferem quanto a produção de pectinases e endoglicanases e crescimento sobre meio de cultura suplementado com sigmacel (Anexo B). O isolado 31, obtido de tecido sadio, se diferenciou da linhagem patogênica FA 42 apenas quanto á produção da enzima amilase, enquanto o isolado 54 apresentou alta similaridade, nas características avaliadas com o isolado patogênico. Baayen et al. (2002) observaram diferenças genéticas e fisiológicas entre linhagens endofíticas e patogênicas de Guignardia sendo proposto que isolados endofíticos pertencem á espécie G. mangifenae. No presente trabalho nenhuma variação genética (rDNA ou RAPD) ou fisiológica (produção de exoenzimas) permitiu a distinção entre isolados patogênicos e endofíticos. 


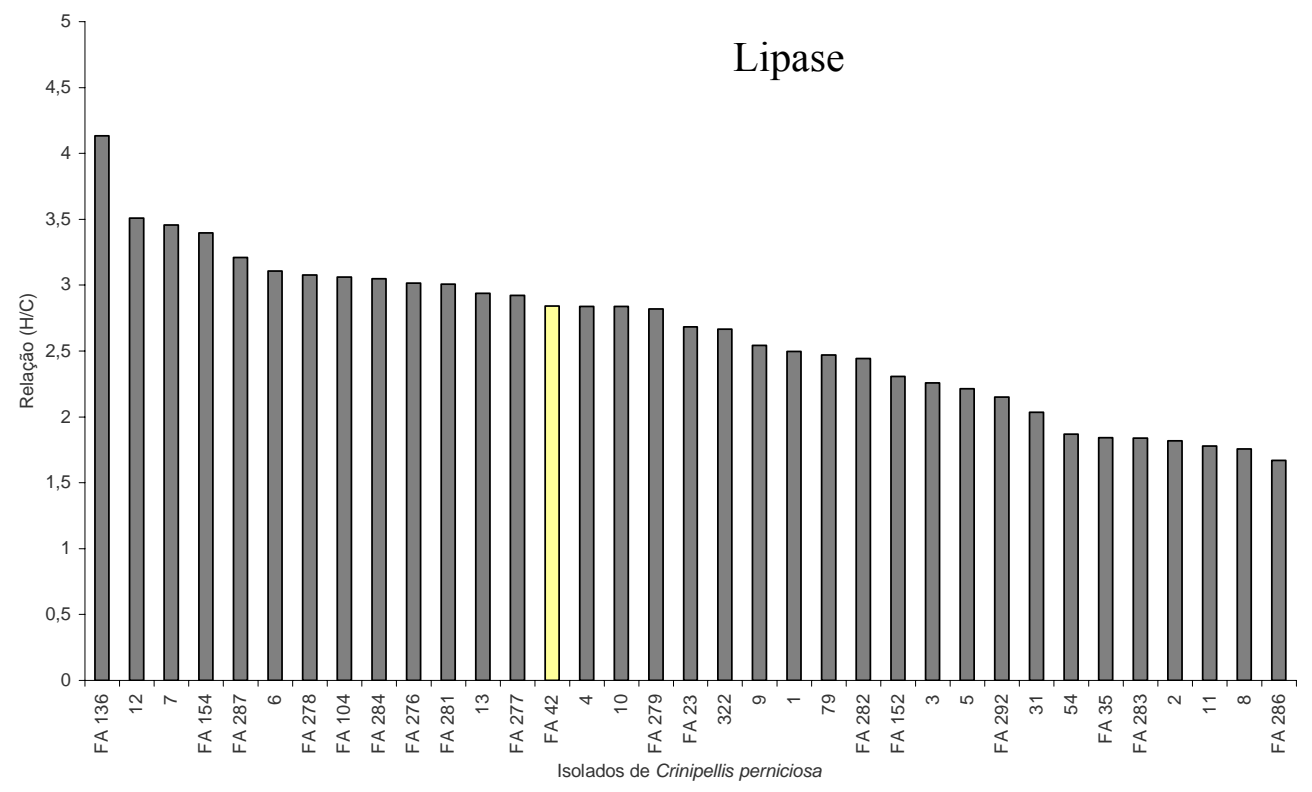

Figura 8 - Relação Halo/Colônia $(\mathrm{H} / \mathrm{C})$ das linhagens de C. perniciosa com relação à produção de lipase. ( $\square$ ) - Isolados estatisticamente iguais ao isolado FA 42

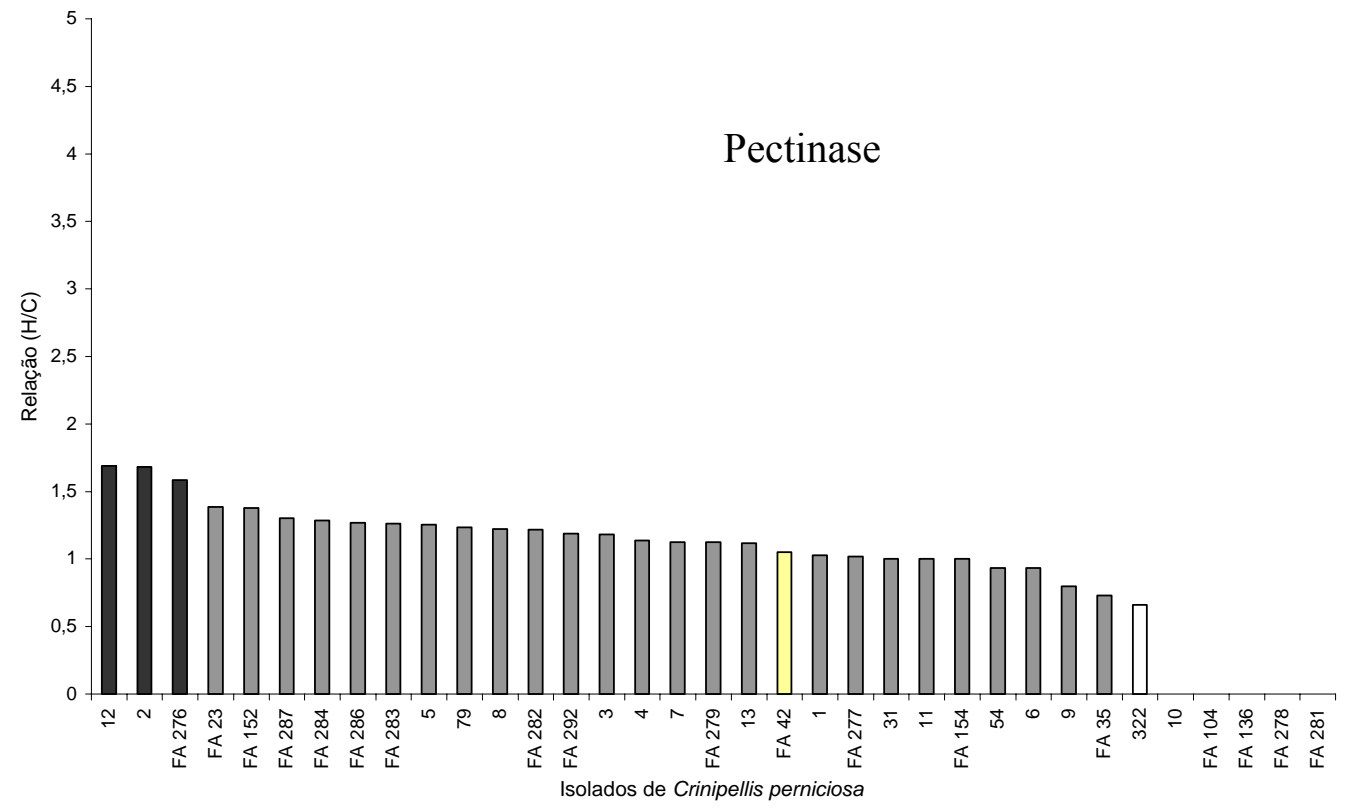

Figura 9 - Relação Halo/Colônia $(\mathrm{H} / \mathrm{C})$ das linhagens de C. perniciosa com relação à produção de pectinases. ( 1 ) H/C igual ao isolado FA 42; ( $)$ H/C maior que o isolado FA 42; ( $\square$ ) H/C menor que o isolado FA 42 


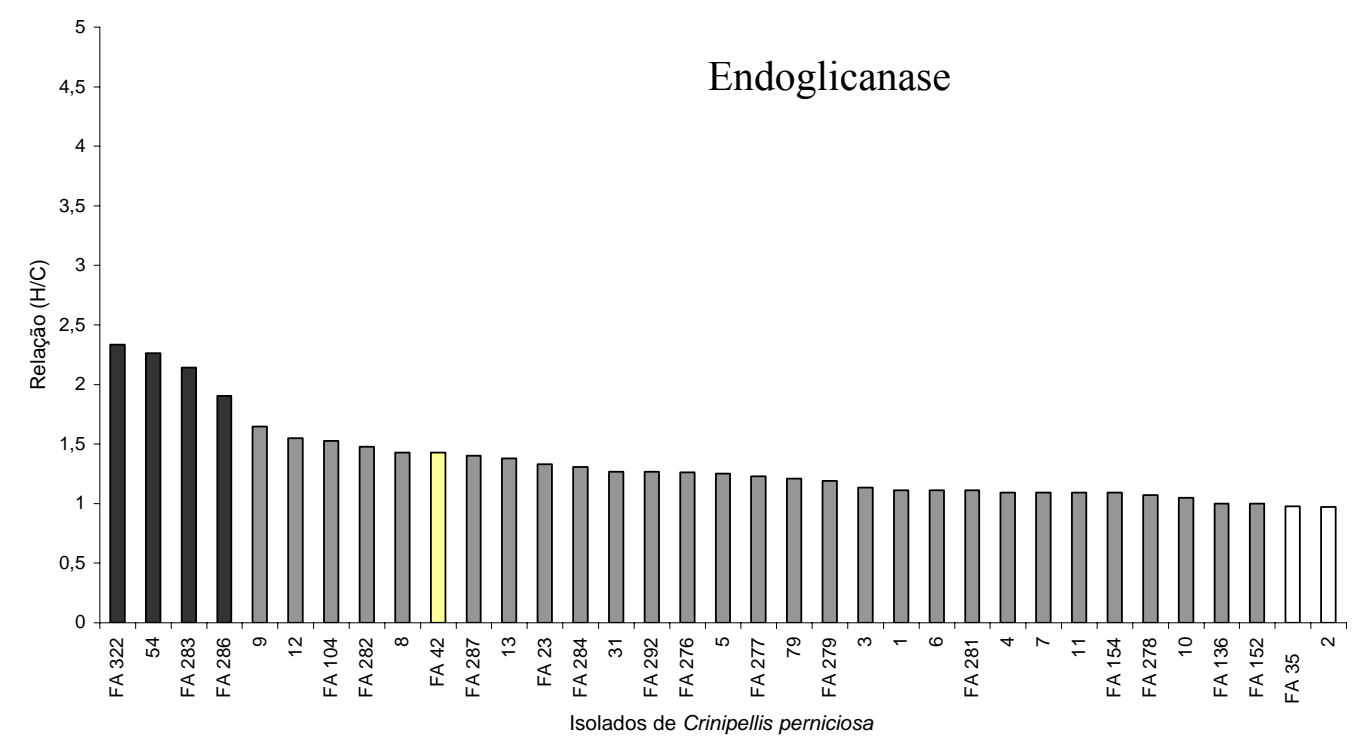

Figura 10 - Relação Halo/Colônia (H/C) das linhagens de C. perniciosa com relação à produção de endoglicanases. ( $\square_{\text {) }} \mathrm{H} / \mathrm{C}$ igual ao isolado FA 42; ( $\square$ ) H/C maior que o isolado FA 42; ( $\square$ ) H/C menor que o isolado FA 42

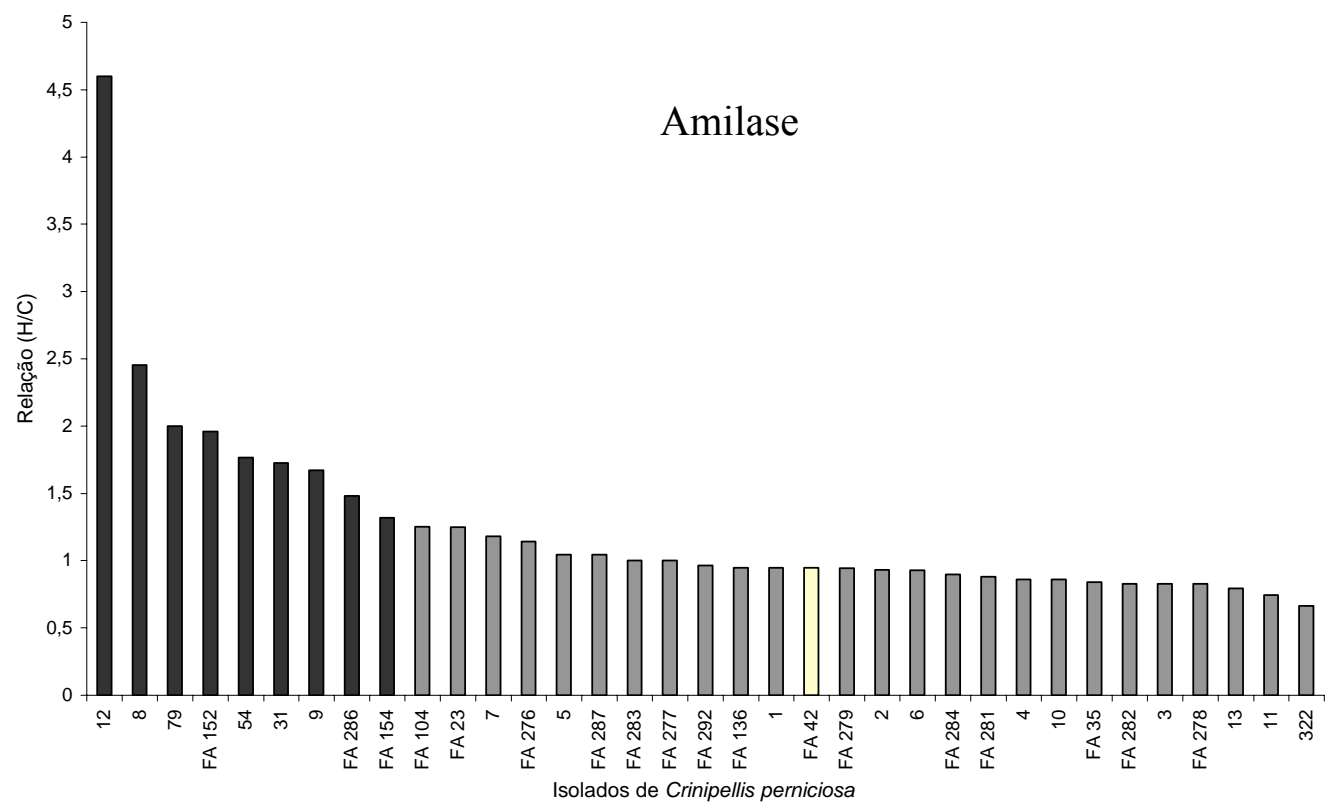

Figura 11 - Relação Halo/Colônia (H/C) das linhagens de C. perniciosa com relação à produção de amilase. ( $\square_{\text {) }}$ H/C igual ao isolado FA 42; ( $\quad$ ) H/C maior que o isolado FA 42; ( $\square$ ) H/C menor que o isolado FA 42 


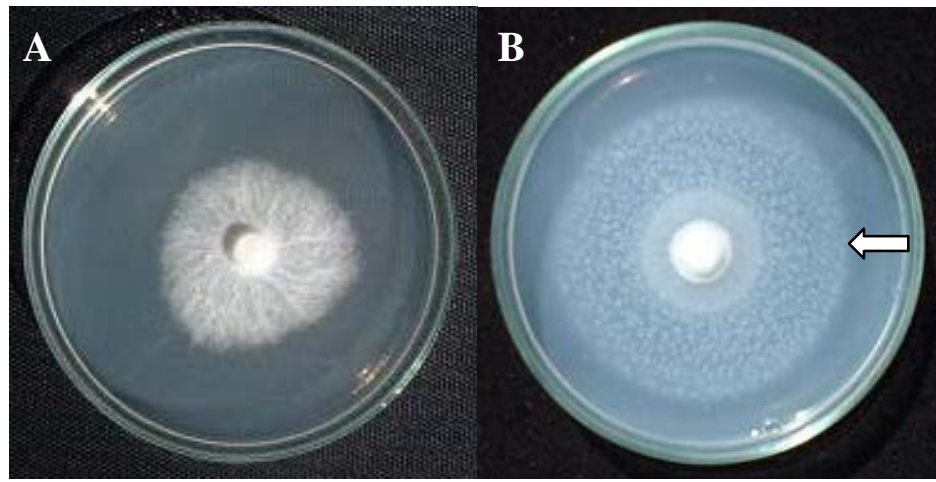

Figura 12 -Isolado FA 35 de C. perniciosa crescido em meio mínimo suplementado com tween como fonte de carbono. A - meio mínimo com glicose; B - halo de degradação do tween por lipases (seta)

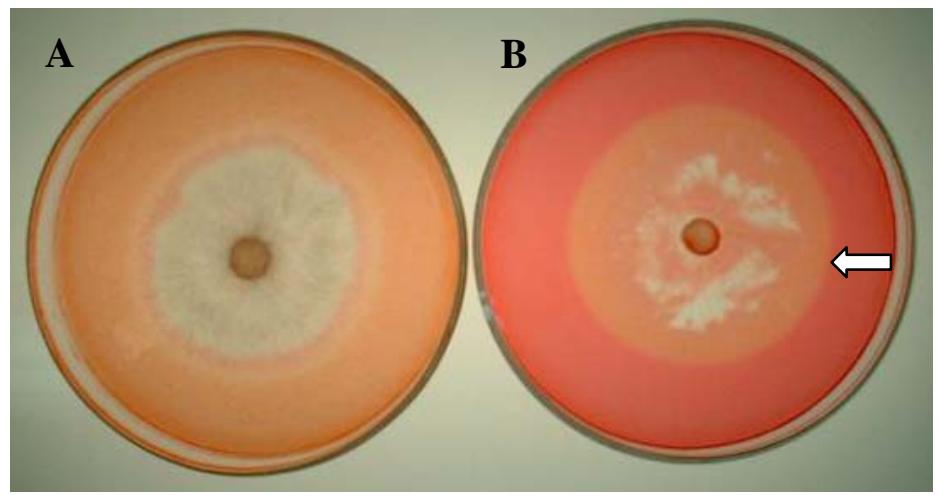

Figura 13 - Isolado 3 de C. perniciosa crescido em meio mínimo suplementado com CMC como fonte de carbono. A - meio mínimo com glicose; B - halo de degradação do CMC por endoglicanases (seta) 


\subsection{Análise de patogenicidade}

Os isolados 5, 6, 8, 9, 10, 31, 79 e FA 284 de C. perniciosa foram avaliados quanto a capacidade de induzir o aparecimento de sintomas da vassoura-de-bruxa em plantas cacau susceptíveis do tipo Catongo. Foi observado que todos os isolados avaliados foram capazes de induzir sintomas típicos da vassoura-de-bruxa em plantas avaliadas, sendo o sintoma mais evidente da infecção da planta pelo C. perniciosa o superbrotamento nas regiões terminais e engrossamento do caule (figura 15).

A análise estatística mostrou que não houve diferença significativa entre os isolados avaliados e a linhagem padrão FA 42, utilizado como controle positivo. Entretanto, observando a porcentagem de plantas infectadas, foi verificado os isolados 8 e 9 foram tão agressivos quanto a linhagem padrão, induzindo a formação de sintomas em $93,3 \%$ e $100 \%$ da plantas, respectivamente. Enquanto outros isolados se mostraram menos agressivos, como os isolados 6,10 e 31 com a incidência da doença igual a 55, 53,3 e $60 \%$, respectivamente. Os isolados 6 e 10, embora tenham sido obtidos de ramos doentes mostraram baixa virulência, podendo ser isolados hipovirulentos ou endofíticos (avirulentos), habitando um tecido doente. Neste caso, a indução de sintomas nas condições avaliadas se deve provavelmente à alta pressão de inóculo utilizada $\cong 7 \times 10^{5}$ basidiósporos/planta). Os demais induziram aproximadamente $80 \%$ de sintomas.

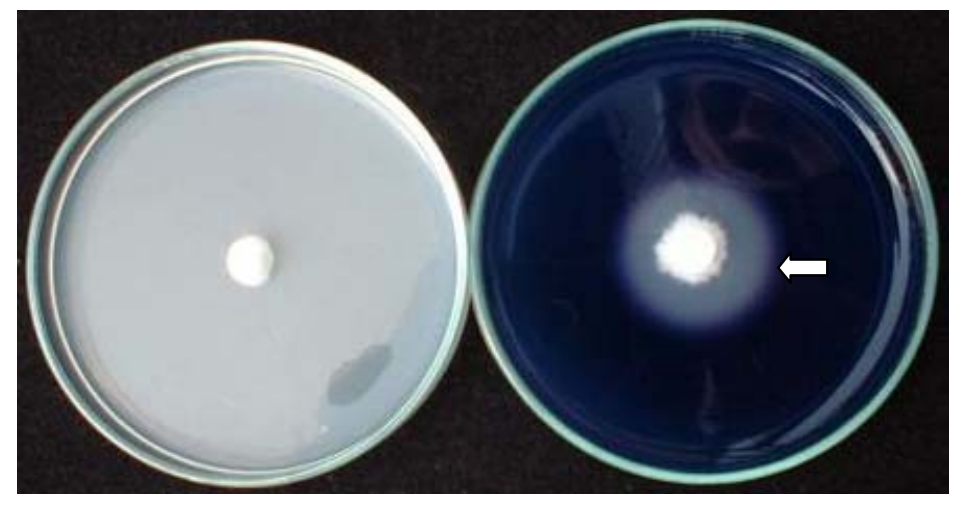

Figura 14 - Isolado FA 152 de C. perniciosa crescido em meio mínimo suplementado com amido como fonte de carbono. A - meio mínimo com glicose; B - halo de degradação do amido por amilases (seta) 
Segundo Peixoto Neto et al. (2002) linhagens avirulentas ou hipovirulentas de microrganismos patogênicos também têm sido utilizadas para a indução de resistência sistêmica (IRS), pois estas podem colonizar a planta sem causar doenças, mas são reconhecidas pela planta que ativa o seu sistema de defesa, impedindo o estabelecimento do patógeno. Pode haver também competição com o patógeno pelo nicho ecológico, diminuindo a possibilidade da linhagem patogênica em colonizar a planta hospedeira. Em tomate, a doença causada por Fusarium oxysporum pode ser controlada utilizando linhagens avirulentas do patógeno, as quais colonizam endofiticamente o hospedeiro e impedem a entrada de linhagens virulentas (Azevedo et al., 2002).

Os isolados patogênicos 5 e 6 foram coletados na mesma planta, sendo muito semelhantes quanto a produção de exoenzimas e análises de RAPD, mas se diferenciaram pela análise de rDNA e patogenicidade, sendo o isolado 5 considerado de agressividade intermediária. $\mathrm{O}$ isolado 6, embora isolado como patogênico, em testes feitos em casa de vegetação, mostrou uma reduzida capacidade de causar doença nas condições avaliadas. Este resultado mostra mais uma vez que isolados de genótipos diferentes podem coexistir na mesma planta.

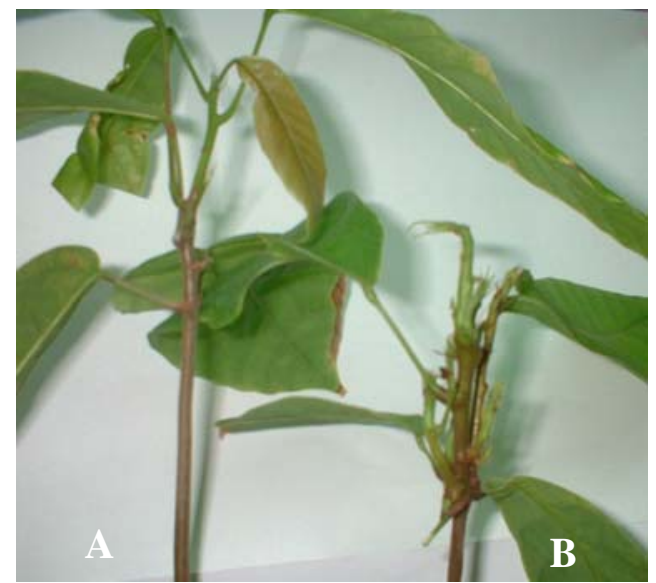

Figura 15. Plantas de T. cacao. A - controle e B - após a inoculação com esporos do isolado 8 de C. perniciosa

Anderbrhan \& Furtek (1994) observaram que condições de campo permitem que vários basidiósporos, que podem ter vindo de diferentes basidiocarpos, contribuem para a infecção natural, conseqüentemente, basidiocarpos iguais da mesma vassoura 
poderiam ser originados de micélio geneticamente diferente. Dessa forma, pode ser afirmado que o micélio dentro das vassouras são geneticamente polimórficos, e este polimorfismo pode ser refletido nos basidiósporos, uma vez que pode ocorrer anastomose de hifas diferentes dentro do hospedeiro oferecendo assim oportunidade para que ocorra heterocariose e recombinação (Weeler \& Mepsted, 1988) ou simplesmente formação, na mesma vassoura, de basidiocarpos de diferentes isolados. $\mathrm{O}$ potencial de diversidade especialmente dentro de uma região produtora de cacau é importante no planejamento de programas de manejo da doença que incluem o uso de resistência do hospedeiro (Niella, 2000).

A análise combinada dos testes de patogenicidade e produção de exoenzimas não mostrou relação entre estes fatores, visto que os isolados 5 e 6 apesar de se comportarem estatisticamente igual, quanto à produção de enzimas, quando comparadas à linhagem FA 42, mostraram diferentes capacidades de induzirem sintomas em cacau Catongo. Por outro lado, os isolados 8 e 9 apresentaram o mesmo nível de patogenicidade, mas diferiram quanto a produção de amilase e endo/exoglicanases reforçando assim a hipótese sugerida. Barbosa et al. (2001) verificaram em Cladosporium herbarum que a produção das enzimas lipase, pectinase, celulase e protease está associada ao processo de infecção do hospedeiro Passiflora edulis Sims. No presente trabalho esta correlação não foi observada.

\subsection{Efeito de fungicidas sobre o crescimento micelial in vitro de $C$. perniciosa}

A hipótese para o estudo das diferenças entre isolados de C. perniciosa utilizando os testes com fungicidas foi que os isolados endófitos poderiam ser mais resistentes aos fungicidas por estarem expostos constantemente a ação destes, baseandose nisto foi utilizada a metodologia descrita no item 3.7, para avaliar o nível de susceptibilidade dos isolados patogênicos e endofíticos de C. perniciosa. A Figura 16 mostra a inibição do crescimento do isolado 54 na presença dos fungicidas avaliados.

Para os fungicidas benomil, óxido cuproso e mancozeb foram testadas as concentrações de $100 \mathrm{ppm}$ e 400ppm de ingrediente ativo enquanto o fungicida 
tebuconazole foi testado nas concentrações de 1ppm e 10ppm. Estes fungicidas foram escolhidos por serem utilizados em campo nos cacaueiros com o objetivo de controlar a vassoura-de-bruxa. Os resultados do efeito inibitório, em porcentagem de inibição, do crescimento micelial de C. perniciosa pelos fungicidas nas respectivas concentrações testadas estão mostrados no Anexo C.

O tebuconazole é um fungicida sistêmico pertencente ao grupo dos triazóis e o seu modo de ação é inibindo a síntese de esteróis (Reis et al., 2001). De acordo com os resultados, este fungicida foi o mais eficaz na inibição ao C. perniciosa, resultando em altas porcentagens de inibição na concentração de $1 \mathrm{ppm}$ para a maioria dos isolados (Figura 17). Este fungicida inibiu de forma indiscriminada isolados endofíticos e patogênicos bem como isolados provenientes de diferentes locais e hospedeiros. Foi observado que poucos isolados apresentaram crescimento (Figura 18) na presença deste fungicida. Esses resultados concordam com Bastos (1989) que também observou que o tebuconazole promoveu $100 \%$ de inibição tanto no crescimento como na germinação de basidiósporos de C. perniciosa na concentração de 1ppm. A alta toxicidade de tebuconazole pode ser atribuída à alta potência desse fungicida que em pequenas concentrações de ingrediente ativo provoca grandes inibições. Laker (1992) avaliando a eficácia de 12 fungicidas sistêmicos na prevenção da esporulação de C. perniciosa em vassouras verdes e secas verificou que o tebuconazole juntamente com o cyproconazole também foi o mais eficiente. Segundo o autor, o uso destes compostos aliados às medidas de controle fitossanitárias podem reduzir significativamente as perdas causadas pela vassoura-de-bruxa. Oliveira (2000) avaliou a inibição do crescimento de $C$. perniciosa in vitro por 36 fungicidas. Entre todos fungicidas o tebuconazole foi o que apresentou maior eficiência na inibição. Em dois testes feitos in vivo, em casa-devegetação o fungicida também apresentou o mesmo comportamento. No primeiro, preveniu o aparecimento de vassoura-de-bruxa até 7 dias após inoculação. Mesmo quando pulverizado aos 14 e 28 dias após inoculação reduziu o número de plantas com sintomas além de retardar ou paralizar o desenvolvimento dos sintomas. No segundo ensaio, mais uma vez se comprovou a eficiência deste fungicida, prevenindo sintomas em mudas na concentração de 250 ppm do ingrediente ativo e na concentração de 500 
ppm, evitou o desenvolvimento de sintomas. Outro efeito também importante foi na redução da produção de basidiocarpos.

Também Mourão et al. (2003) verificaram alta toxicidade em Beauveria bassiana utilizando baixas concentrações, onde $0,42 \mathrm{mg} / \mathrm{mL}$ de ingrediente ativo foi capaz de inibir 99\% do crescimento das linhagens indistintamente. Kimura (1999) analisando a sensibilidade e micelial de Botrytis cinerea a vários fungicidas verificou também uma alta sensibilidade deste ao tebuconazole utilizando também uma concentração de 1ppm. Neste caso, a utilização deste fungicida em campo deve ser avaliada, visto que poderia inibir também fungos benéficos à planta.

O modo de ação dos benzimidazóis como o benomil é baseado na sua ligação à tubulina interferindo na mitose durante a divisão na metáfase. O tubo mitótico é distorcido e os núcleos filhos fracassam em se separar resultando na morte da célula. A resistência ao seu princípio ativo carbendazim, é causada pela mutação em um único gene, resultando em ligeiras alterações na tubulina que leva à redução da afinidade entre ambos (Reis et al., 2001). No presente trabalho, o fungicida benomil permitiu o crescimento micelial praticamente de todos isolados na concentração de $100 \mathrm{ppm}$ e 400ppm não exercendo controle eficiente (Figuras 19 e 20). Outros autores, como Bastos \& Medeiros (1979) verificaram que C. perniciosa foi pouco sensível a esse fungicida. Esse mesmo fato foi observado por Kimura (1999) utilizando também o benomil sobre um isolado de $B$. cinerea. Provavelmente os isolados devem estar se adaptando às condições de pressão de seleção deste fungicida. Ou ainda porque, segundo Marten \& Fletcher (1971) o benomil não é eficiente contra basidiomicetos.

O cobre é prontamente acumulado pelas células do fungo sensível. Este elemento forma complexo com enzimas que possuem grupos sulfidrila, hidroxila, amino ou carboxila, inativando-as e levando a desordem geral do metabolismo e rompendo com a integridade da célula. As enzimas que requerem grupos $\mathrm{S}$ livres para suas atividades parecem ser especialmente suscetíveis a inativação. Por isso que o íon cobre mata os esporos ao combinar-se com os grupos sulfidrila de certas enzimas (Reis et al., 2001). Almeida et al. (1998) mostrou o efeito inibitório de óxido cuproso sobre $C$. perniciosa. Neste caso, este fungicida controlou as infecções nos frutos, mas não 
controlou nas gemas vegetativas e almofadas florais, provavelmente devido ao fato de não ser um fungicida sistêmico, não protegendo assim as áreas em crescimento.

No presente trabalho, o óxido cuproso foi avaliado sobre C. perniciosa nas concentrações de 100ppm e 400ppm (figuras 21 e 22). Foi observado que o óxido cuproso não se mostrou eficiente na inibição quando testado a 100 ppm, pois a maior porcentagem de inibição foi de apenas 43,7 observado no isolado FA 287. Porém na concentração de 400 ppm foi verificada uma maior inibição de vários isolados. Foi verificado ainda que ocorreu uma grande variação na porcentagem de inibição, com isolados sendo 100\% inibidos (FA 152) e outros com baixíssima ou nenhuma inibição, isolados 12 e 322, 4 e 0\% respectivamente (Anexo C). Pode-se sugerir que estes 2 últimos são resistentes ao óxido cuproso. Bastos \& Medeiros (1979) relataram que os fungicidas cúpricos utilizados por eles, dentre eles o óxido cuproso, inibiram completamente o crescimento micelial do fungo nas concentrações de 50 e 100 ppm diferentemente do que foi observado neste trabalho. Segundo Reis et al. (2001) em uma população de fitopatógenos, sensível a um determinado fungicida, células com menor sensibilidade ao produto são selecionadas permitindo o aumento da freqüência de populações resistentes.

Dentre os produtos utilizados no controle químico da doença, o óxido cuproso apresenta resultados positivos em condições de campo, além de ser recomendado para o controle da podridão parda causada por Phythophtora, embora não proporcione boa proteção contra a formação de vassouras vegetativas (Almeida et al., 1998). A dosagem recomendada é de $3 \mathrm{~g}$ de cobre metálico por planta mensalmente ou $6 \mathrm{~g}$ por planta bimestralmente. O principal objetivo de seu uso é a proteção de frutos jovens, porém sua eficiência não é total, pois há rápida expansão da superfície do fruto nos primeiros 3 meses, não permitindo uma boa cobertura do mesmo (Soberanis et al., 2000).

O mancozeb é um fungicida pertencente á classe dos etilenobisditiocarbamatos protetor de órgãos aéreos ou residuais. Os fungidas protetores são aqueles que quando aplicados aos órgãos aéreos das plantas formam uma camada protetora tóxica na superfície da planta. Deste modo, quando o inóculo (esporos), após deposição sobre os tecidos susceptíveis, germinam, o tubo germinativo entra em contato com o fungicida 
absorvendo-o, o que determina posteriormente, por meio de mecanismos bioquímicos a morte do protoplasma. A proteção tem por objetivo evitar a penetração impedindo a infecção que iria ocorrer no futuro (Reis et al., 2001). No presente trabalho, o mancozeb exerceu uma baixa inibição em todos isolados avaliados quando testados a 100ppm (Figura 23). Já a 400ppm, essa inibição foi drasticamente aumentada sendo que vários isolados mostraram inibição acima de 80 \% (Figura 24).

Os estudos in vitro têm a vantagem de expor ao máximo o microrganismo à ação do produto químico, fato que não ocorre em condições de campo, onde vários fatores servem de obstáculo a essa exposição. A alta toxicidade de um produto in vitro pode nem sempre indicar a sua elevada toxicidade no campo.

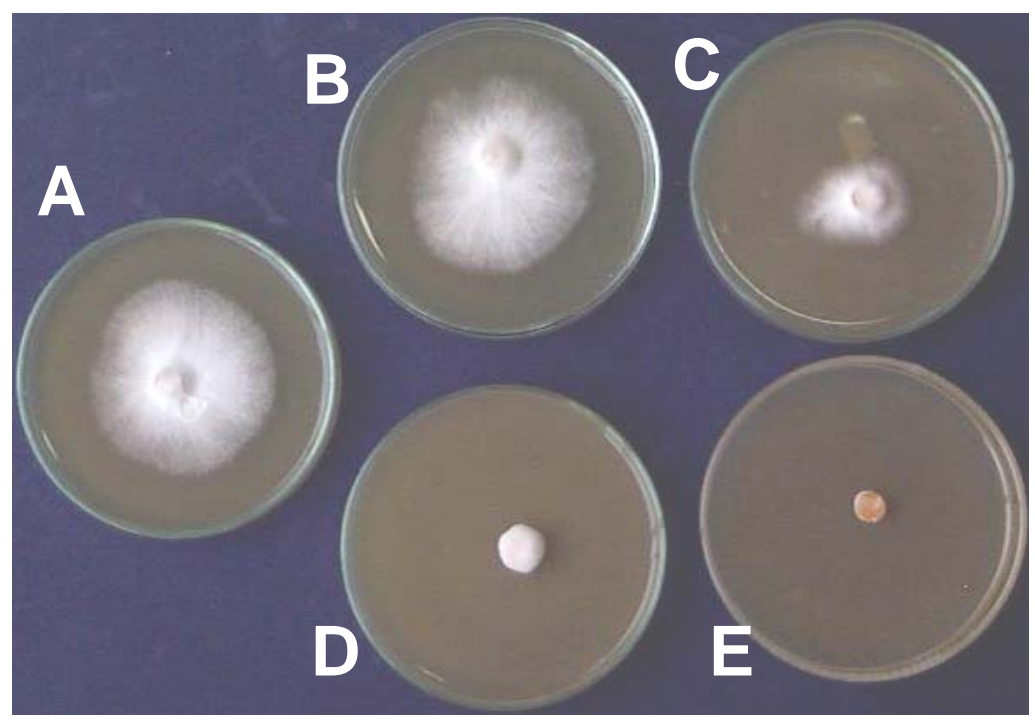

Figura 16. Inibição do isolado endofítico 54 de crinipellis perniciosa pelos fungicidas: óxido cuproso, benomil, mancozeb e tebuconazole. A- controle; B- benomil 400ppm; C- óxido cuproso 400ppm; D- mancozeb 400ppm; E- tebunonazole $10 \mathrm{ppm}$ 
Na presente análise, não foi observada relação entre a sensibilidade/resistência aos fungicidas e a variabilidade genética, fisiológica e patogenicidade dos isolados de $C$. perniciosa. Estes dados mostram que se os isolados descritos como hipovirulentos, forem de fato endófitos, esta adaptação ao hospedeiro não foi refletida nos parâmetros avaliados neste trabalho.

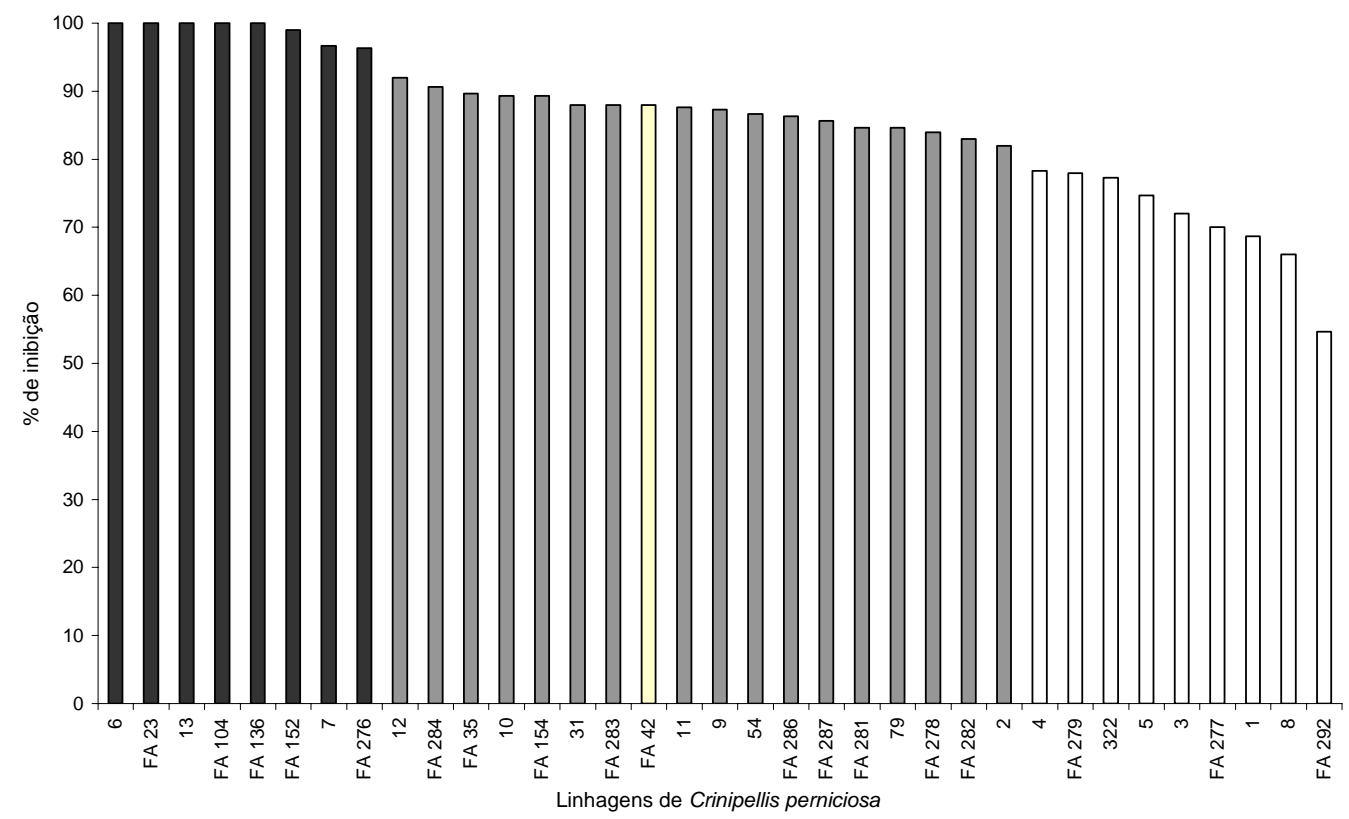

Figura 17 - Porcentagem de inibição de linhagens de C. perniciosa submetidas a $1 \mathrm{ppm}$ do fungicida tebuconazole.( $\square$ ) - H/C igual ao isolado FA 42, ( $\square$ ) - H/C maior que o isolado FA 42 e ( $)$ - H/C menor que o isolado FA 42 


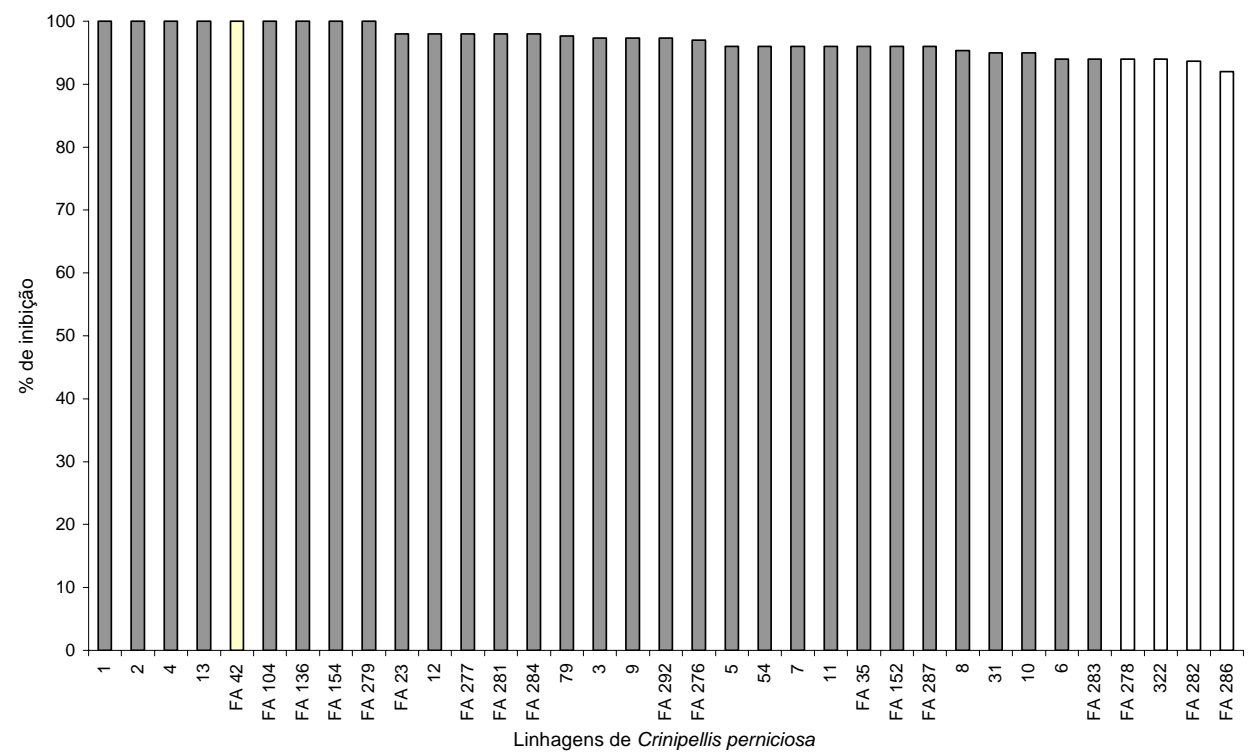

Figura 18 - Porcentagem de inibição de linhagens de C. perniciosa submetidas a 10 ppm do fungicida tebuconazole. ( $\square$ ) - H/C igual ao isolado FA 42 e ( $\square$ ) $\mathrm{H} / \mathrm{C}$ menor que o isolado FA 42

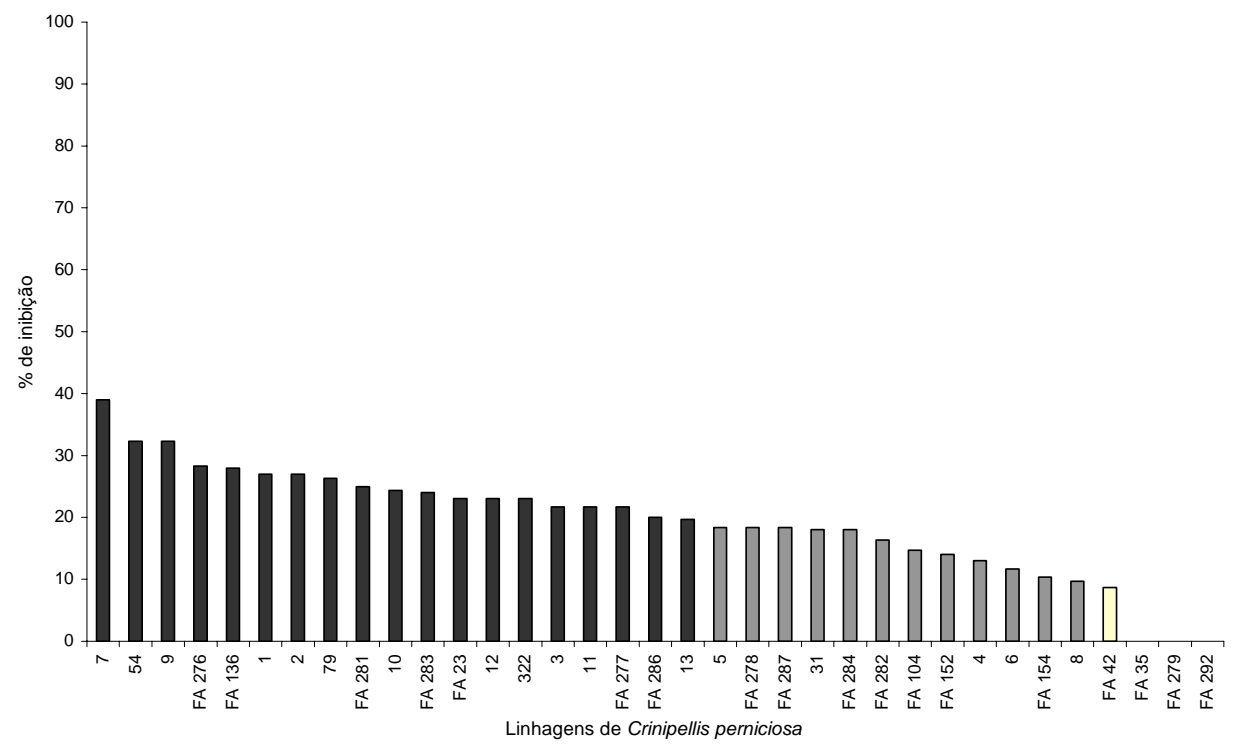

Figura 19 - Porcentagem de inibição de linhagens de C. perniciosa submetidas a 100 ppm do fungicida benomil. ( $\square$ ) - H/C igual ao isolado FA 42, ( $\square$ ) - H/C maior que o isolado FA 42 


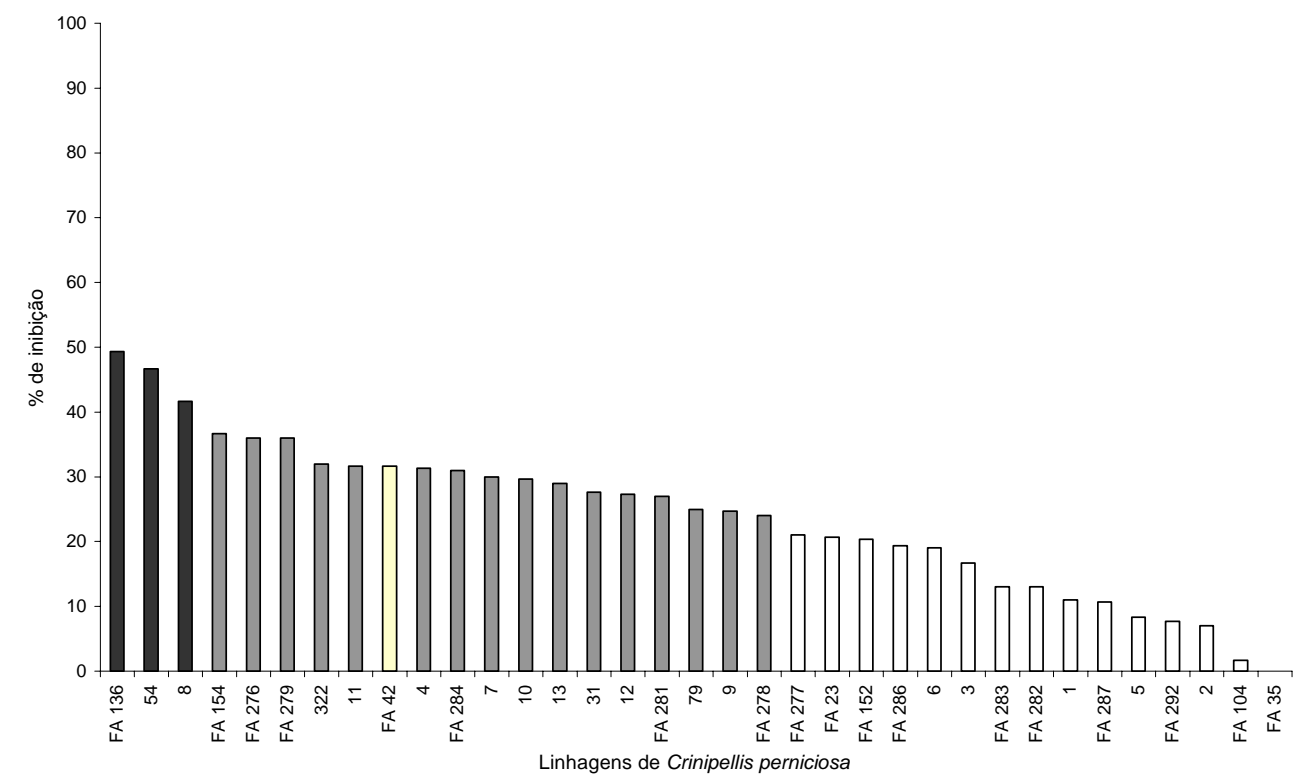

Figura 20 - Porcentagem de inibição de linhagens de C. perniciosa submetidas a 400 ppm do fungicida benomil. ( $)$ - H/C igual ao isoladoFA 42, ( $\square$ ) - H/C maior que o isoladoFA 42 e $(\square)$ - H/C menor que o isolado FA 42

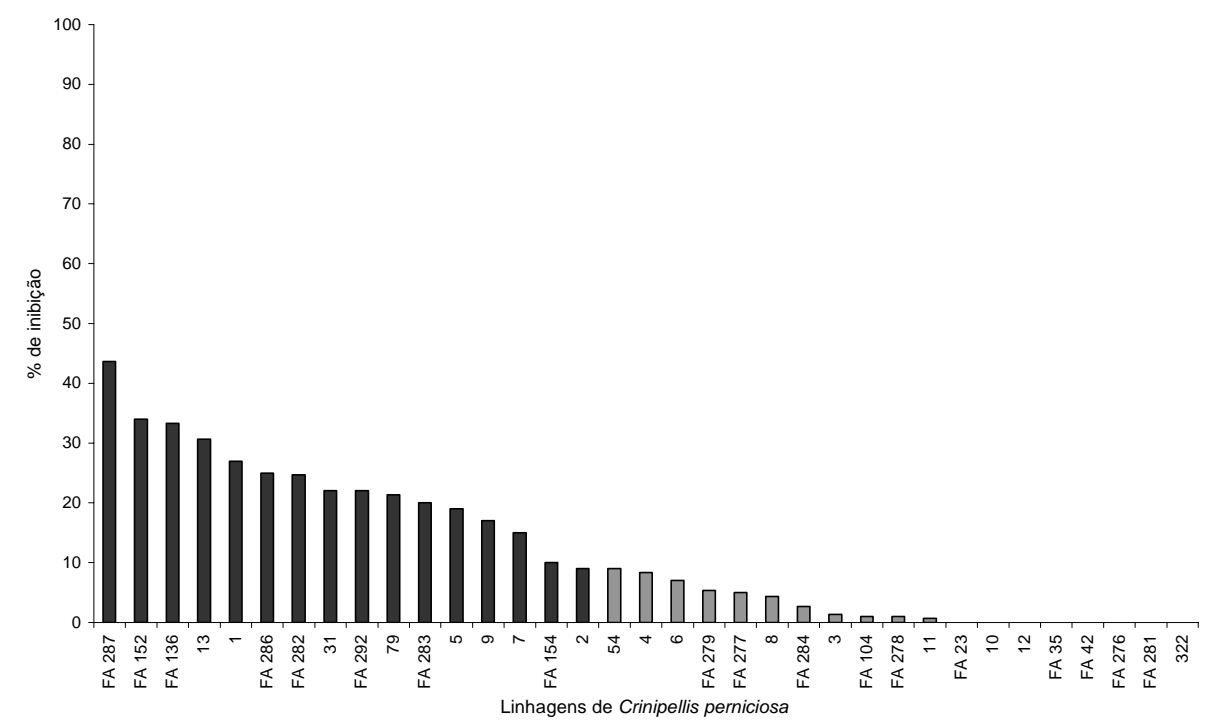

Figura 21 - Porcentagem de inibição de linhagens de C. perniciosa submetidas a 100 ppm do fungicida óxido cuproso. ( $a_{\text {) }}$ - H/C igual ao isolado FA 42, ( $\square$ ) - H/C maior que FA o isolado FA 42 


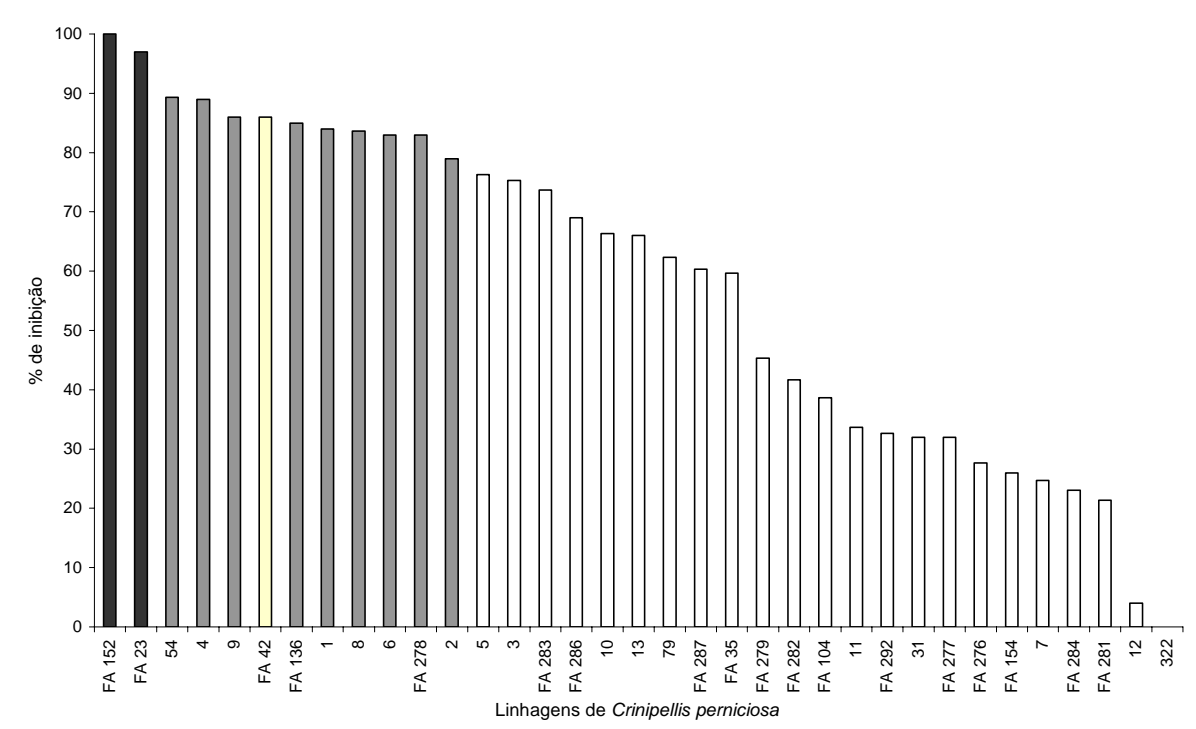

Figura 22 - Porcentagem de inibição de linhagens de C. perniciosa submetidas a 400 ppm do fungicida óxido cuproso. (口 ) - H/C igual ao isolado FA 42, (口) $\mathrm{H} / \mathrm{C}$ maior que o isolado FA 42 e $(\square)$ - H/C menor que o isolado FA 42

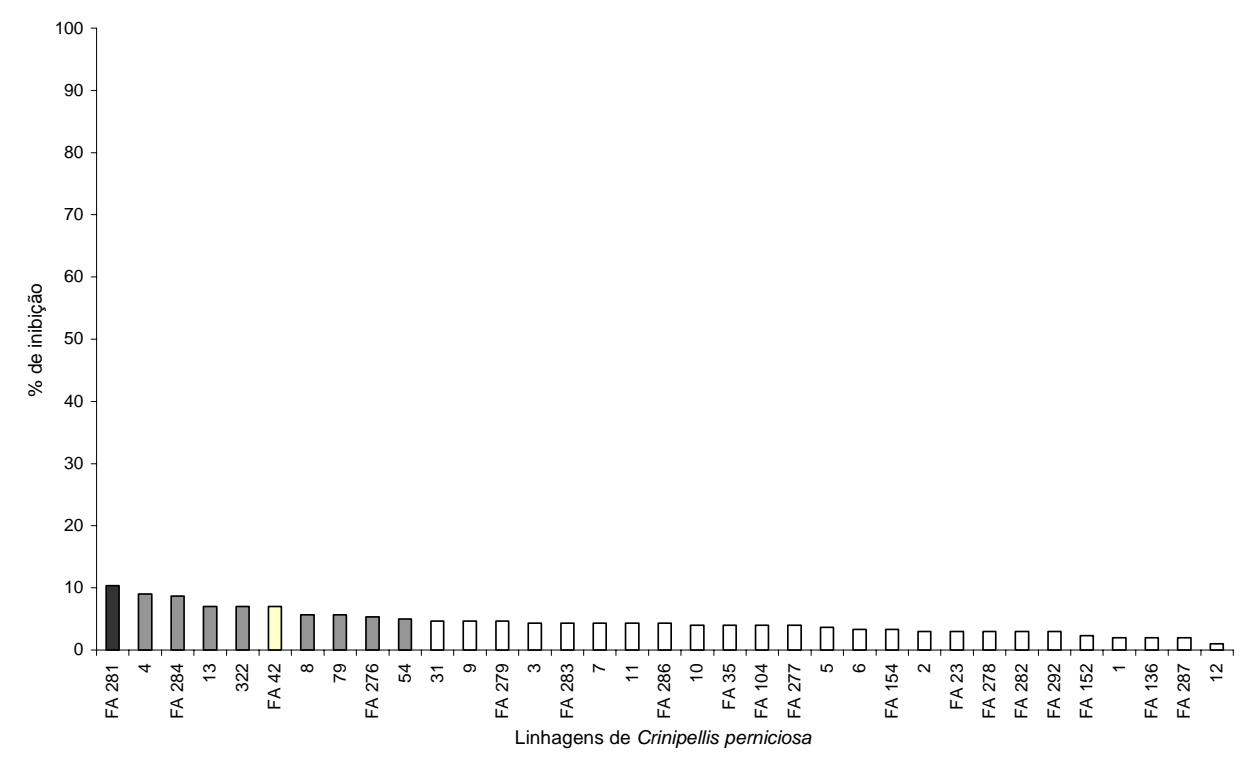

Figura 23 - Porcentagem de inibição de linhagens de C. perniciosa submetidas a 100 ppm do fungicida mancozeb. ( $\square$ ) - H/C igual ao isolado FA 42, ( $)^{\text {) - }}$ $\mathrm{H} / \mathrm{C}$ maior que o isolado FA 42 e $(\square)$ - H/C menor que o isolado FA 42 


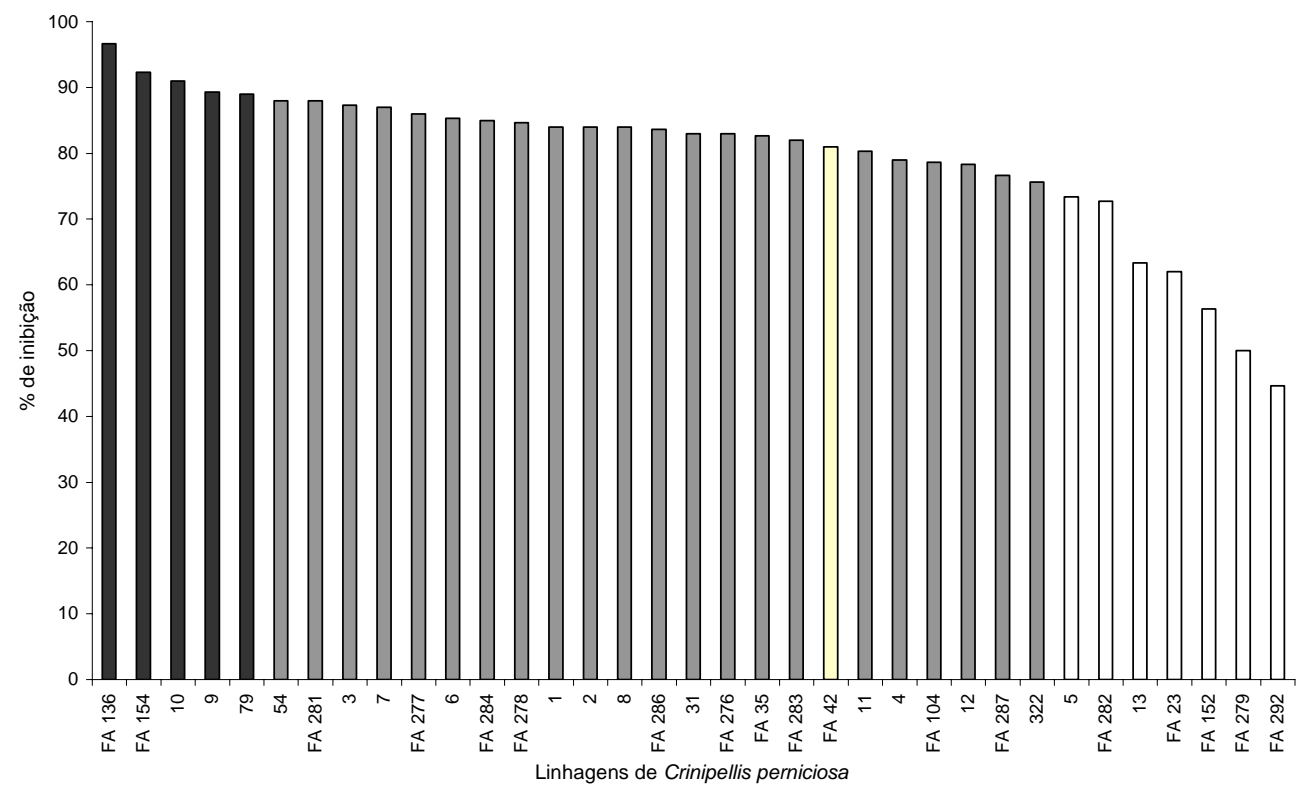

Figura 24 - Porcentagem de inibição de linhagens de C. perniciosa submetidas a 400

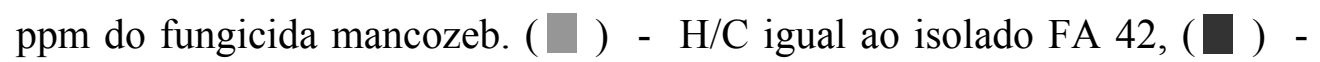
$\mathrm{H} / \mathrm{C}$ maior que o isolado FA 42 e $(\square)$ - H/C menor que o isolado FA 42 


\section{CONCLUSÕES}

Com base nos resultados obtidos podemos concluir que:

- C. perniciosa coloniza ramos de cacau sem causar sintomas de vassoura-de-bruxa, podendo ser denominado de endófito;

- Análise de RAPD não discriminou entre isolados patogênicos e endofíticos;

- Análise de rDNA não discriminou entre isolados patogênicos e endofíticos;

- C. perniciosa existentes na Bahia podem ter sido introduzidos de diferentes regiões;

- Isolados de C. perniciosa geneticamente diferentes podem colonizar o mesmo tecido da planta hospedeira;

- A produção das enzimas pectinase, exo e endoglicanase, amilase e lipase não está diretamente envolvidas com a patogenicidade de C. perniciosa;

- A análise de resistência/sensibilidade aos fungicidas benomil, folicur, mancozeb e óxido cuproso não permitiu discriminar entre isolados endofíticos e patogênicos;

- Isolados hipovirulentos e virulentos não diferem significativamente quanto à análise de DNA e características fisiológicas. 


\section{REFERÊNCIAS BIBLIOGRÁFICAS}

ABO-HAMED, S.; COLLIN, H.A.; HARDWICK, K. Biochemical and physiological aspects of leaf development in cocoa (Theobroma cacao) VII: Growth orientation, surface struture and water loss from developing flush leaves. New Phythologist, v.95, p.9-17, 1983.

AGRIOS, G.N. Plant Pathology, 3 Ed. New York: Academic Press, p.803, 1988.

ALMEIDA, L.C.C.; NIELLA, G.R.; BEZERRA, J.L. Efeito de remoções de partes doentes do cacaueiro associadas a intervalos de aplicação de óxido cuproso no controle da vassoura-de-bruxa na Bahia. Agrotrópica, v.10, n.2, p.95-102, 1998.

ANDERBRHAN, T.; FIGUEIRA, A.; YAMADA, M. M.; CASCARDO, J.; FURTEC, D.B. Molecular fingerprint suggests two primary outbreaks of witches' broom disease (Crinipellis perniciosa) of Theobroma cacao in Bahia, Brazil. European Journal of Plant Pathology, v.105, p.167-175, 1999.

ANDERBRHAN, T; ALMEIDA, L.C.; NAKAYAMA, L.H.I. Resistência de Theobroma cacao L. a Crinipellis perniciosa (Stahel) Singer: A experiência da Amazônia brasileira. Agrotrópica, v.10, n.2, p.49-60, 1998.

ANDERBRHAN, T.; HAMMERSTONE, J.F.; ROMANCZYK, L.J.; FURTEK, D.B. Sensitivity of Crinipellis perniciosa of procyanidins from Thebroma cacao L. Physiological and Molecular Plant Pathology, v.46, p.339-348, 1995.

ANDERBRHAN, T.; FURTEK, D.B. Random amplifield polymorphic DNA (RAPD) analysis of Crinipellis perniciosa isolates from different hosts. Plant Pathology, v.43,p.1020-1027, 1994. 
ANDERBRHAN, T. Studies on the epidemiology and control of witches' broom disease of cacao in the Brazilian Amazon. In: CONFERENCIA IINTERNACIONAL DE PESQUISAS EM CACAU, 9, Atas, Lagos, 1985. Resumos. Cocoa Producer's Alliance, Lomé, 1985, p.395-402.

ANDERBRHAN, T.; BASTOS, C.N. Epidemiologia da vassoura-de-bruxa. Belém: CEPLAC/DEPEA, 1980. p.50-55. (Informe Técnico).

ANDRADE, J.O.;PEREZ, M.L.V.; RESENDE, A.G. Efeito de micronutrientes e do indutor de resistência benzotiadole $(\mathrm{BTH})$ no crescimento micelial de Crinipellis perniciosa. Fitopatologia Brasileira, n.26, p.387, 2001. Suplemento.

ARAUJO, A.; SOUZA, J.D. Characterization of cellulolytic enzyme components from Aspergillus terreus and its mutant. Journal of Fermentation Technology, v.64, n.5, p.463-467, 1986.

ARAÚJO, W.L.; MACCHERONI Jr, W.; AGUILAR-VILDOSO, C.I.; BARROSO, P.A.V.; SARIDAKIS, H.O.; AZEVEDO, J.L. Variability and interactions between endophytic bacteria and fungi isolated from leaf tissues of citrus rootstocks. Canadian Journal of Microbiology, v.47, p.229-236, 2001.

ARCHER, D.B.; WOOD, D.A. Fungal exoenzymes . In: GOW, N.A.R.; GAAD, G.M. (Ed.) The growing fungus. London: Chapman \& Hall, 1995. cap. 7, p. 138-162.

ARRUDA, M.C.C.; MILLER, R.N.G.; FERREIRA, M.A.S.V.; FELIPE, M.S.S. Comperison of Crinipellis perniciosa isolates from Brazil by ERIC repetitive element sequence-based PCR genomic fingerprinting. Plant Pathology, v.52, p.236-244, 2003a.

ARRUDA, M.C.C.; FERREIRA, M.A.S.V.; MILLER, R.N.G.; RESENDE, M.L.V.; FELIPE, M.S.S. Nuclear and mitochondrial rDNA variability in Crinipellis perniciosa from different geographic origens and host. Mycological Research, v.107, n.1, p.25-37, 2003b.

AZEVEDO, J.L.; MACCHERONI Jr, W.; ARAUJO, W.L.; PEREIRA, J.O. Microrganismos endofíticos e seu papel em plantas tropicais. In: SERAFINI, L. A.; BARROS, N.M.; AZEVEDO, J. L (Ed.) Biotecnologia: avanços na agricultura e na agroindústria. Caxias do Sul: EDUCS, 2002. cap. 8, p.233-268. 
AZEVEDO, J.L.; MACCHERONI, Jr.W.; PEREIRA, J.O.; ARAUJO, W.L. Endophytic microorganisms: a review on insect control and recent advances on tropical plants. Eletronic Journal of Biotechnology, v.3, 2000. http: //www.ejb.org/content/vol3/isseu1/full/3/4 (5 nov. 2003).

BAAYEN, R. P.; BONANTS, P. J. M.; VERKLEY, G.; CARROLL, G.C.; VAN DER AA, H. A.; DE WEERDT, M.; VAN BROUWERSHAVEN, I. R.; SCHUTTE, G.C.; MACCHERONI JR., W.; GLIENKE-BLANCO, C.; AZEVEDO J.L. 2002. Nonpathogenic isolates of the citrus black spot fungus, Guignardia citricarpa, identified as a cosmopolitan endophyte of woody plants, G. mangiferae (Phyllosticta capitalensis). Phytopathology, v. 92, p.464-477, 2002.

BARBOSA, M.A.G.;REHN, K.G.; MENEZES, M.; MARIANO, R.L.R. Antagonism of Trichoderma on Cladosporium herbarum and their enzimatic characterization. Brazilian Journal of Microbiology, v.32, p.98-104, 2001.

BARTELT, R.J.; WICKLOW, D.T. Volatiles from Fusarium verticillioides (Sacc.)

Nirenb. and their attractiveness to nitidulid beetles. Journal Agriculture and Food chemicstry, v.47, p.2447-2454, 1999.

BARY, A. Morphologie und physiologie der Pilze, Fleethen, und Myxomyceten. Leipzig: Engelamn, 1866, 316p.

BASTOS, C. N. Retrospectiva e avanços no controle da vassoura-de-bruxa do cacaueiro. Fitopatologia Brasileira, v.25, p.305-306, 2000. suplemento.

BASTOS, C. N.; ALBUQUERQUE, P. S. B. Witches' broom disease assement for resistence in cocoa clones using phloem sap. Fitopatologia Brasileira, v.25, n.3, p.556-558, 2000.

BASTOS, C.N.; FONSECA, S.E.A.; MELO, W.F. Mascagnia cf. sepium, cipó nativo da Amazônia de Crinipellis preniciosa. Fitopatologia Brasileira, v.23, n.4, 1998.

BASTOS, C.N. Potential de Trichoderma viride no controle da vassoura-de-bruxa (Crinipellis perniciosa) do cacaueiro. Fitopatologia Brasileira, v.21, n.4, 1996a.

BASTOS, C.N. Mycoparasitic nature of the antagonism between Trichoderma viride and Crinipellis perniciosa. Fitopatolologia Brasileira, v.21, n.1, 1996 b. 
BASTOS, C.N. Patogenicidade e características do isolado de Crinipellis perniciosa procedente de Uruçuca, Bahia. Fitopatologia Brasileira, v.15, n.4, 1990.

BASTOS, C. N. Avaliação de fungicidas sistêmicos no controle da vassoura-de-bruxa da cacaueiro. Agrotrópica. v.1, n.2, p.128-132, 1989.

BASTOS,C.N. Biologia de crinipellis perniciosa. Belém: CEPLAC/CEPEA, 1988. p.25. (Informe de Pesquisa).

BASTOS, C. N.; ANDERBHRAN, T.; ALMEIDA, L. C. Comparação morfológica de isolados de Crinipellis perniciosa. Fitopatologia Brasileira, v.13, n.3, p. 202-205, 1988.

BASTOS, C. N. Ensaio 'in vitro' de fungicidas no crescimento e germinação de esporos de Crinipellis perniciosa(Stahel) Singer. Belém: CEPLAC/DEPEA, 1987, p.56-58. (Informe de pesquisa).

BASTOS, C. N.; ANDERBHRAN, T. Urucu (Bixa orellana): nova espécie hospedeira da vassoura-de-bruxa (Crinipellis perniciosa) do cacaueiro. Fitopatologia Brasileira, v.11, p.963-965, 1986.

BASTOS, C.H.; EVANS, H.C. A new pathotype of Crinipellis perniciosa (witches' broom disease) on solanaceous hosts. Plant Pathology, v.34, p.306-312, 1985.

BASTOS, C.N.; MEDEIROS, A.G. Seleção in vitro de fungidas a Crinipellis perniciosa (Stahel) Singer, causador da vassoura-de-bruxa do cacaueiro. Revista Theobroma, v.9, p.129-135, 1979.

BENHAMOU, N.; GARAND, C. Cytological analisis of defense-related mechanisms induced in pea root tissues in response to colonization by nonpathogenic Fusarium oxysporum Fo47. Phytopathology, v.91, n.8, 2001.

BILLS, L.A.; POLLISHOOK, J.D. Microfungi from Carpinus carolliniana. Canadian Journal of Botany, v.69, p.1477-1482, 1991.

BOCCHESE, C.A.C.; MARTINELLI, J.A.; MATSUMURA, A.T.S.; FEDERIZZI, L.C.; PRESTES, A.M. Virulência, atividade enzimática e padrões de isoesterases de isolados de Pyrenophora chaetomioides, agente etiológico da mancha de grãos e folhas de aveia. Fitopatologia brasileira, v.28, n.1, p.11-16, 2003. 
CALHOUN, L.A.; FINDLAY, J.A.; MILLER, J.D.; WHITNEY, N.J. Metabolites toxic to spruce budworm from balsam fir needle endophytes. Mycological Research, v.96, n.4, p.281-286,1992.

CALLE, H.; COOK, A.A.; FERNANDO, S. Histology of witches' broom caused in cacao by Crinipellis perniciosa. Phytopathology, v.11, n.72, p.1479-1481, 1982.

CARBONE, I.; KOHN, L. Ribossomal DNA sequence divergence within transcribed spacer 1 of the sclerotiniaceae. Mycological, v.85, p.415-427, 1997.

CLAY, K. Effects of fungal endophytes on the seed and seedling biology of Loliun perene and Festuca arundinacea. Ecologia, v.73, p.358-362, 1989.

COLAUTO, N.C.; DIAS, E.S.; GIMENES, M.A.; EIRA, A.A. Genetic characterization of isolates of the basidiomycetes Agaricus blazei by RAPD. Brazilian Journal of Microbiology, v.33, n.2, p.131-133, 2002.

COLLMER, A. Pectic enzymes and bacterial invasion of plants. In: KOSUGE, T.; NESTER, E.W. (Ed). Plant Microbe Interctions Molecular and Genetic Perspectives. New York: Mac Millan, 1987, vol 2, p.253-284.

CRONSHAW, D.K. Fungicide application together with cultural practices to control cocoa diseases in Ecuador. Tropical Agriculture, v.56, n.2, p.165-171, 1979.

DELGADO, J.C.; COOK, A. A condition of the basidia, basidiosporos and mycelium of Marasmius perniciosus. Cananadian Journal of Botany, v.54, p.66-72, 1975.

ELAD, Y.; ZIMAND, D.G.; ZAQS, Y.; ZURIEL, S.; CHET, I. Use of Trichoderma harzianum in combinations or alternation with fungicides to control cucumber grey mould (Botrytis cinerea) under commercial green-house conditions. Plant Pathology, v.42, p.324-332, 1993.

EVANS, H.C. Witches' broom disease - a case study. Cocoa Groers Bulletin, n.32, p.5-19, 1981.

EVANS, H.C. Pleomorphism in Crinipellis perniciosa, causal agent of witches' broom disease of cocoa. Transactions of the British Mycological Society, v.74, p.515$523,1980$.

EVANS, H.C. Witches' broom disease of cocoa (Crinipellis perniciosa) in Ecuador. Annals of Applied Biology, v.89, n.2, p.185-192, 1978. 
FELSENSTEIN, J. Confidence limits on filogenecy an approach using the bootstrap. Evolution. v.39, 783-791, 1985.

FUNGARO, M.H.P. PCR na micologia. Biotecnologia Ciência \& Desenvolvimento. v.14, p.12-16, 2000.

GLIENKE-BLANCO, C.; AGUILAR-VIDOSO, C.I.;VIEIRA, M.L.C.; BARROSO, P.A.V.; AZEVEDO, J.L. Genetic variability in the endophytic Guinardia citricarpa isolated from citrus plants. Genetic and Molecular Biology, v.25, n.2, p.251-255, 2002.

GLIENKE, C. Variabilidade genética no fungo endófito Guinardia citricarpaKiely detectada por RAPD. Piracicaba, 1995. 115p. Dissertação (Mestrado) - Escola Superior de Agricultura 'Luiz de Queiroz', Universidade de São Paulo.

GOMES, L.M.; MELLO, G. R. P.; FALEIRO, F.G. Diversidade genética de Crinipellis na região sul da Bahia utilizando marcadores moleculares RAPD. Fitopatologia Brasileira, n.25, p. 377, 2000. Suplemento.

GRIFFITH, G.; HEDGER, J.N. A novel method for producing basidiocarps of the cocoa pathogen Crinipellis perniciosa using a bran-vermiculite medium. Netherland Journal of Plant Pathology, v.99, p.227-230, 1993.

GRIFFITH, G.W.; BRAVO-VELASQUEZ, E.; WILSON, F J.; LEWIS, D M.; HEDGER, J.N. Autecology and evolution of the wicthes' broom pathogen (Crinipellis perniciosa) of cocoa. In: BLAKEMAN, J.P.; WILLIAMSON, B. (Ed.) Ecology of Plant Pathogens. Oxon: CAB Internacional, 1994, p.245-267.

HALLMANN, J.; QUADT-HALLAMANN, A. ; MAHAFFEE, W.F.; KLORPPER, J. W. Bacterial endophytes in agricultural crops. Canadian Journal of Microbiology, v.43, p.895- 914, 1997.

HAMMERSCHMITD, R.; SMITH-BECKER, J.A. The role of salicylic acid in disease resistance. In: AGRAWAL, A.A.; TUZUN, S.; BENT, E. (Ed.) Induced plant defenses against pathogens and herbivores-biochemistry, ecology and agriculture. Saint Paul: APS Press, 1999. p.37-53.

HANKIN, L.; ANAGNOSTAKIS, S.L. The use of solide media for detection of enzyme production by fungi. Mycologia, v. 61, p.597-607, 1975. 
JALAL, M.A.F.; COLLIN, H.A. Polyphenols of mature plants, seedlings and tissue cultures of Theobroma cacao. Phytochemistry, v.16, p.1377-1380, 1977.

KIMURA, K.K. Sensibilidade e resistência in vitro de Botrytis cinerea a fungicidas. Lavras, 1999. 132p. Dissertação (Mestrado) - Universidade Federal de Lavras.

LAKER, H.A. Evaluation of antisporulantes for the control of Crinipellis perniciosa, causal agente of witches` broom disease of cocoa. Agrotrópica, v.4, n.11, p.7-15, 1992.

LEAL JÚNIOR, G.A. Diagnóstico de Crinipellis perniciosa em tecidos infectados de Theobroma cacao e caracterização molecular e serológica de isolados coletados de vários hospedeiros. Piracicaba, 2002. 136p. Dissertação (Mestrado). Centro de Energia Nuclear na Agricultura - Universidade de São Paulo.

LEALEM, F.; GASHE, B.A. Amylase production by a gram-positive bacterium isolated from fermentating tef (Eraglostis tef). Journal of Applied Bacteriology, v.5, p.348-352, 1994.

LEE, Y.H.; FAN, L.T. Proprities and mode of action of cellulase. Advance in Biochemistry Engeering, v.18, p.101-129, 1980.

LOPEZ-LLORCA, L.V.; CARBONELL, T. Characterization of Spanish strains of Verticillium lecanii. Revista Iberoamericana de Micologia, v.16, p.136-142, 1999.

LUZ, E.D.M.N.; BEZERRA, J.L.; RESENDE, M.L.V.; OLIVEIRA, M.L. Doenças do cacaueiro. In:. ZAMBOLIM, L.; VALE, F.X.R. Controle de doenças de plantas: grandes culturas. Viçosa: UFV. 1997. cap.13, p.611-649.

MAIA, M.M.D.; MORAIS, M.M.C.; MORAIS Jr, M.A.; MELO, E.H.M.; LIMA FILHO, J.L. Production of extracellular lipase by the phytopathogenic fungus Fusarium solani FS1. Revista de Microbiologia, v.30, p.304-309, 1999.

MANULIS, S.; KOGAN, N.; REUVEN, M.; BEM-YEPHET, Y. Use of the RAPD technique for identification of Fusarium oxysporum and fungal-plant interaction in Cochiobolus heterostrophus. Mycological Research, v.102, p.491-496, 1998. 
MANULIS, S.; KOGAN, N.; REUVEN, M.; BEN-YEPHET,Y. Use of the RAPD technique for identification of Fusarium oxysporum f. sp. dianthi from carnation. Phytopathology, v.84, p.98-101, 1993.

MARTEN, S.; FLETCHEN, J. Benomyl and thiabendazole for control of mushroom disease. Plant Disease Report, v.55, n.2, p.120-121, 1971.

McGEAR, F.M.; WHEELER, B.E.J. Growth rates of and, mycelial interactions between, isolates of Crinipellis perniciosa from cocoa. Plant Pathology, v.37, p.489-498, 1988.

McONIE, K.C. The latent occurrence in Citrus and other host of a Guinardia easily confused with G. citricarpa, the citrus black spot pathogen. Phytopathology, v.54, p.40-43, 1964.

McQUILKEN, M.P.; SUPRIADI; RUDGARD, S. A. Sensitivity of Crinipellis perniciosa to two traizole fungicides in vitro and their effect on development of the fungus in cocoa. Plant Pathology, v.37, p.499-506, 1988.

MICHELMORE, R.W.; PARAN, I.; KESSELI, R.V. Identification of markers linked to disease-resistence genes by bulked segregant analysis: A rapid method to detect markers in specific genomic regions by using segregating populations. Proceeding of the National Academy of Science, v.88, p.828-982, 1991.

MOURÃO, S.A.; VILLELA, E.F.; ZANUNCIO, J.C.; ZAMBOLIM, L.; TUELHE, E.S. Seletividade de defensivos agrícolas ao fungo entomopatogênico Beauveria bassiana. Neotropical Entomology, v.32, n.1,p.103-106, 2003.

MURRAY, F.R.; LATTCH, G.C.M.; SCOTT, D.B. Surrogate transformation of perennial ryegrass, Lolium perene, using genetically modifield Acremonium endophyte. Molecular and Genetics, v.233, p.1-9, 1992.

MUSE, R.; COLLIN, H.A.; ISSAC, S.; HARDWICK, K. Effects of the fungus Crinipellis perniciosa, causal agent of witches' broom disease, on and tissue cultures of cocoa (Theobroma cacao L.). Plant Pathology, v.45, p.145- 154, 1996.

NIELLA, G.R. Frutificação in vitro, caracterização molecular e patogênica de Crinipellis perniciosa (STAHEL) Singer em Theobroma cacao L. Lavras, 2000. 75p. Tese (Doutorado). Universidade Federal de Lavras. 
OLIVEIRA, M.L. Seleção de fungicidas in vitro e in vivo para o controle da vassourade-bruxa do cacaueiro na região sul da Bahia. Agrotrópica, v.12, n.2, p.111-118, 2000.

ONISH, K.;YOSHIDA, Y.; SEKIGUCHI, J. Lipase production of Aspergillus oryzae Journal of Fermentation and Bioengineering, v.47, p.490-495, 1994.

ORCHARD, J.; COLLIN, H.A. HARDWICK, K.; ISAAC, S. Changes in morphology and measurement of cytokinin levels during the development of witches' broom on cocoa. Plant Pathology, v.43, p.65-72, 1994.

PAPAVIZAS, G.C. Trichoderma and Gliocladium: biology, ecology and potential for biocontrol. Annual Review of Phytopathology, v.23, p.23-54, 1985.

PASCHOLATI, S.F. Fitopatógenos: arsenal enzimático. In: BERGAMIN FILHO, A. KIMATI, H.; AMORIM, L. (Ed.). Manual de Fitopatologia: princípios e conceitos. São Paulo: Agronômica Ceres, 1995. v.1, cap.19, p.343-364.

PEIXOTO NETO, P.A.S.; AZEVEDO, J.L.; ARAÚJO, L.W. Microrganismos endofíticos. Biotecnologia Ciência \& Desenvolvimento, n.29, p.62-76, 2002.

PEREIRA, J.L. Renewed advance of witche's broom disease of cocoa: 100 years later. In: INTERNATIONAL COCOA RESERARCH CONFERENCE, 12., Salvador, 1996. Resumos. Salvador: Cocoa Producers’ Alliance, 1999. p.51.

PEREIRA, J.L.; RAM , A.; FIGUEIREDO, J.M.; ALMEIDA, L.C.C. Primeira ocorrência de vassoura-de-bruxa na principal região produtora de cacau do Brasil. Revista Agrotrópica, v.1, n.1, p.79-81, 1989.

PEREZ, J.O. Caracterização de isolados de Crinipellis perniciosa, indução de resistência à vassoura-de-bruxa no cacaueiro e análise de peroxidases na interação planta-patógeno. Lavras, 2002. 81p. Tese (doutorado), Universidade Federal de Lavras.

PETRINI, O. Fungal endophytic of tree leaves. In: ANDREWS, J.H.; HIRANO, S.S. Microbial Ecology of Leaves. New York: Springer Verlag,. 1991. cap.9, p.179197. 
PETRINI, O.; STONE, J.K.; CARROL, F.E. Endophytic fungi in evergreen shrubs in wertern Oregon: a preliminary study. Canadian Journal of Botany, v.60, p.789796, 1982.

PONTECORVO, G.; ROPER, J.A.; FORBES, E. Genetic recombination without sexual reproduction in Aspergillus niger. Journal of General Microbiology, v.8, p.198$210,1953$.

PURDY, L.H.; SCHMITDT, R.A. Status of cacao witches' broom: biology, epidemiology and management. Annual Review of Phytopathology, v.34, p.573594, 1996.

PURDY, L.H.; TRESE, A.T.; ARAGUNDI, J. Proof of pathogenicity of Crinipellis perniciosa to Theobroma cacao by using basidiospores production in vitro culture. Revista Thebroma, v.13, p.157-163,1983.

RAEDER, U.; BRODA, P. Rapid preparation of DNA from filamentous fungi. Letters in Apllied Microbiology, v.1, p.17-20, 1985.

REIS, E.M.; FORCELINI, C.A.; REIS, A.C. Classificação dos fungicidas. In: MOURA, N.R. (Ed). Manual de fungicidas. Florianópolis: Insular, 2001. Cap. 5, p.25-52.

RESENDE, M.L.; NOJOSA, G.B.A.; AGUILAR, M.G.; SILVA, L.H.C.P.; NIELLA, G.R.; CARVAlHO, G.A.; GIOVANINI, G.R.; CASTRO, R.M. Crinipellis perniciosa proveniente de um novo hospedeiro, Heteropterys acutifolia, é patogênico ao cacaueiro. Fitopatologia Brasileira, v.25, n.1, p.88-91, 2000.

ROCHA, H.M.; WHEELER, B.E.J. Factors influencing the prodution of basidiocarps and deposition and germination of basidiospores of Crinipellis perniciosa, the causal fungus of witches' broom on cocoa (Theobroma cacao). Plant Pathology, v.34, p.319-328, 1985.

ROUMAS, E.N. Produção de celulases e fusão de protoplastos em Humicula sp. Piracicaba, 1988. 168p. Tese (Doutotado) - Escola Superior de Agricultura 'Luiz de Queiroz', Universidade de São Paulo.

RUDGARD, S.A. Witches' broom disease on cocoa in Rondonia, Brazil: infection of vegetative flushes and flower cushions in relation to host phenology. Plant Patholology, v.36, p.523-530, 1987. 
RYU, D.D.; MANDELS, M. Cellulases: biosynthesis and applications. Enzyme and Microbiology Technology, v.2, p.91-102, 1980.

SAMBROOK, J.; FRITSCH, E.F.; MANIATIS, T. Molecular cloning: a laboratory manual. 2.ed. New York: Cold Spring Harbor Laboratory Press, 1989, 1v.

SAIKKONEN, K.; FAETH, S.H.; HELANDER, M.; SULLIVAN, T.J. Fungal endophytes: A continum of interactions with host plants. Annual Review of Ecology and Systematics, v.29, p.319-343, 1998.

SAS. Institute SAS/STAT. User's Guide 8.0. Cary, N.C.: SAS Institute Inc., 1999.

SCHULTHESS, F.; CARDWELL, K.F.; Gounou, S. The effect of endophytic Fusarium verticillioides on infestation of two maize varieties by lepidopterous stemborers and coleopteran grain feeders. Phytopathology, v.92, n.2, 2002.

SGRILLO, R.B.; ARAUJO, M.R.P. Modelo de simulação da evolução da vassoura-debruxa do cacaueiro na Bahia. Agrotrópica, v.6, n.3, p.73-84, 1994.

SILVA, S.D.V. M.; MATSUOKA, K. Histologia da interação Crinipellis perniciosa em cacaueiros susceptíveis e resistentes á vassoura-de-bruxa. Fitopatologia Brasileira, v.24, n.1, p.54-59, 1999.

SILVA, A.C. Isolamento de fungos endofíticos de milho (Zea mays). Piracicaba, 1997.

56p. Dissertação (Mestrado) - Escola Superior de Agricultura 'Luiz de Queiroz', Universidade de São Paulo.

SILVA, S.D.V.M.; GRAMADO, K.P.; ALMEIDA, O.C. Solanum paniculatum , hospedeiro de Crinipellis perniciosa na região sul da Bahia. Agrotrópica, v.10, n.4, p.17-20, 1992.

SINCLAIR, J.B. Latent infection of soybean plants and seeds by fungi. Plant Disease, v.75, p.220-224, 1991.

SINCLAIR, J.B.; CERKAUSKAS, R.F. Latent infection vs. endophytic colonization by fungi. In: SCOTT, C.; CARRIS, L.M. (Ed.) Endophytic fungi in grasses and woody plants - Systematics, ecology, and evolution. Minnesota: APS Press. 1996, p.3-29. 
SOBERANIS, W.; RIOS, R.; ARÉVALO, E.; ZÚÑIGA, L.; CABEZAS,O.; KRAUSS, U. Increased frequency of phytosanitary pod removal in cacao (Theobroma cacao L.) increases yied economically in eastern Peru. Crop Protection, v.18, p.667-685, 2000 .

SREENIVASAN, T.N.; DABYDEEN, S. Modes of penetration of young cocoa leaves by Crinipellis perniciosa. Plant Disease, v. 73, p.478-484, 1989.

STAMFORD, T.L.M.; ARAÚJO, J.M.; STAMFORD, N.P. Atividade enzimática de microrganismos isolados do Jacatupé (Pachyrhizus erosus L. Urban). Ciência e Tecnolologia de Alimentos, v.18, n.4, p.382-385, 1998.

STIERLE, A.; STROBEL, G.; STIERLE, D. Taxol and taxane production by Taxomyces andreane, an endophytic fungus of Pacific Yew. Science, v.260, p.214216, 1993.

STROBEL, G.A.; HESS, W.; FORD, E.; SIDHU, R.S. YANG, X. Taxol from fungal endophytes and the issue of biodiversity. Journal of Industrial Microbiology v.17, p.413-423, 1996.

TEDFORD, G.A.; JAFFEE, B.A.; MULDOON, A.E. Variabilility nematophagous fungus Hirsutella rhossiliensis. Mycologycal Research, v.98, p.1127-1136, 1994.

TOVAR, G. LA escoba de bruja del cacao Crinipellis perniciosa (Stahel) Singer: descripción de síntomas de la enfermedade. Agronomia Colombiana, v.8, n.1, p.227-239, 1991.

VARGAS, L.R.B.; ROSSATO, M.; RIBEIRO, R.T.S.; DE BARROS, N.M. Characterization of Nomuraea rileyi strains using polymorphic DNA, virulence and enzyme activity. Brazilian Archives of Biology and Technology, v.46, n.1, p.13-18, 2003.

VIANA JUNIOR, C.A.C. Compatibilidade somática e patogenicidade de Crinipellis sp. Lavras, 2001. 61p. Dissertação (Mestrado), Universidade Federal de Lavras.

VICENTE, V.A. Isolamento e caracterização de fungos da cromoblastomicose. Piracicaba, 2000. 181p. Tese (Doutorado). Escola Superior de Agricultura 'Luiz de Queiroz', Universidade de São Paulo. 
YAMADA, M.M.; ANDEBRHAN, T.; FURTEK, D.B. Genetic variability among isolates or Crinipellis perniciosa from solanaceous host and their relationship to isolates from Theobroma cacao. Agrotrópica, v.10, p.123-126, 1998.

YAP I., NELSON, R.J. WinBoot: a program for performing bootstrap analysis of binary data to determine the confidence limits of UPGMA-based dendrograms. IRRI Discussion Paper Series, v. 14, 1996.

WHEELER, B.E.J. Plant pathology in a developing world. Plant Patholology, v.36, p.430-437, 1987.

WHEELER, B.E.J; MEPSTED, R. Patogenic variability amongst isolates of Crinipellis perniciosa from cocoa (Theobroma cacao L.). Plant Patholology, v.37, p.475-488, 1988.

WHITE Jr, J.F.;COLE, G.T. Endophyte host associations in forage grasses. I. Distribuition of fungal endophytes in some species of Lolium and Festuca. Mycological., v.77, p.323-327, 1985.

WILliAMS, J.G.; KUBELIK, A.R.; LIVAK, K.J.; RAFALSKI, J.A.; TINGEY, S.V. DNApolymorphisms amplifield by arbitrary primers are useful as genetic markers. Nucleic Acids Research, v.18, p.6531-6535, 1990.

WILLIAMS, J.G.; KUBELIK, A.R.; LIVAK, K.J.; RAFALSKI, J.A.; TINGEY, S.V. Genetic analysis using random amplified polymorphic DNA markers. Methods in Enzymology, v.218, p.706-740, 1993.

WULFF, N.A. Caracterização enzimática das celulases XF-810, XF-818 e XF-2708 de Xylella fastidiosa e purificação da proteína XF-818, expressas em Escherichia coli. Piracicaba, 2002. 196p. Tese (Doutorado), Escola Superior de Agricultura 'Luiz de Queiroz', Universidade de São Paulo. 
ANEXOS 
Anexo A - Seqüências de linhagens de C. perniciosa de regiões do rDNA utilizando-se os primers ITS 1 e ITS 4.

Isolado 1

GGGTAGTCCTACCTGATTTGAGGTCAAAATGATCTAAGTTCATTGTCCAGTAACTTTGGACGGTTCGAAGC AGATACCCCAGAGAGAGCAGGTCATTACAACTTGCAACCCTCCAAACCGAAGTGTTGAGACCTAATTAAAG AGCCACCAACATTCGAAAGCGTAGATAAACCCAATGGCGTAGATAATTATCACACCAATGTGGTCCACTAT AGCGGTTTCCACTAATGCATTTCAAGAGAGCCGACTCTTGTTCAAAGCCGGCAGCCCTCACATCCAATCCT GAAATGACAAGTCATTCAAGGTTGATAATTTAATGACACTCAAACAGGCATGCCTCTCGGAATACCAAGAG GCGCAAGGTGCGTTCAAAGATTCGATGATTCACTGAATTCTGCAATTCACATTACTTATCGCATTTCGCTG CGTTCTTCATCGATGCGAGAGCCAAGAGATCCGTTGCTGAAAGTTGTATAGTTTTAAAGGGTCAATTAAGT CCCAATAAAATACATTCTAAACATACCATTAAGTGTGTTAAAAAACAAACATAGTAGACTCCGTACTAAGA GAAACGCAAGCGCCTCCTATTCCAGAATCTGCTACAAAAAGGTTCACAGGTGGGATGAATATTGAAAGTCG GCGAGCACATGCCCTTACAAGAACCAGCTCAACCTTCT

Isolado 2

GGGTAGTCCTACCTGATTTGAGGTCAAAATGATCTAAGTTCATTGTCCAGTAACTTTGGACGGTTCGAAGC AGATACCCCAGAGAGAGCAGGTCATTACAACTTGCAACCCTCCAAACCGAAGTGTTGAGACCTAATTAAAG AGCCACCAACATTCGAAAGCGTAGATAAACCCAATGGCGTAGATAATTATCACACCAATGTGGTCCACTAT AGCGGTTTCCACTAATGCATTTCAAGAGAGCCGACTCTTGTTCAAAGCCGGCAGCCCTCACATCCAATCCT GAAATGACAAGTCATTCAAGGTTGATAATTTAATGACACTCAAACAGGCATGCCTCTCGGAATACCAAGAG GCGCAAGGTGCGTTCAAAGATTCGATGATTCACTGAATTCTGCAATTCACATTACTTATCGCATTTCGCTG CGTTCTTCATCGATGCGAGAGCCAAGAGATCCGTTGCTGAAAGTTGTATAGTTTTAAAGGGTCAATTAAGT CCCAATAAAATACATTCTAGACATACCATTAAGTGTGTTAAAAAACAAACATAGTAGACTCCGTACTAAGA GAAACGCAAGCGCCTCCCTATTCCAGAATCTGCTACAAAAGGTTCACAGGTGGATGAATATTGAAAGTCGG CGAGCACATGCCCTACAAGAGCCAGCTCAACCTCCTTTACAATGTTNTCAATAATGATCCTTCCGCAGGTT CAC

Isolado 3

GGGTAGTCCTACCTGATTTGAGGTCAAAATGATCTAAGTTCATTGTCCAGTAACTTTGGACGGTTCGAAGC AGATACCCCAGAGAGAGCAGGTCATTACAACTTGCAACCCTCCAAACCGAAGTGTTGAGACCTAATTAAAG AGCCACCAACATTCGAAAGCGTAGATAAACCCAATGGCGTAGATAATTATCACACCAATGTGGTCCACTAT AGCGGTTTCCACTAATGCATTTCAAGAGAGCCGACTCTTGTTCAAAGCCGGCAGCCCTCACATCCAATCCT GAAATGACAAGTCATTCAAGGTTGATAATTTAATGACACTCAAACAGGCATGCCTCTCGGAATACCAAGAG GCGCAAGGTGCGTTCAAAGATTCGATGATTCACTGAATTCTGCAATTCACATTACTTATCGCATTTCGCTG CGTTCTTCATCGATGCGAGAGCCAAGAGATCCGTTGCTGAAAGTTGTATAGTTTTAAAGGGTCAATTAAGT 
CCCAATAAAATACATTCTAAACATACCATTAAGTGTGTTAAAAAACAAACATAGTAGACTCCGTACTGAGA GAAACGCAAGCGCCTCCCTATTCCAGAATCTGCTACAAAAGGTTCACAGGTGGATGAATATTGAAAGTCGG CGAGCACATGCCCTACAAGAGCCAGCTCAACCTCCTTTACAATGTTTTCAATAATGATCCTTCCCGAAGTT CAC

Isolado 4 TTATTGATATGCTTAAGTTCAGCGGGTAGTCCTACCTGATTTGAGGTCAAAATGATCTAAGTTCATTGTCC AGTAACTTTGGACGGTTCGAAGCAGATACCCCAGAGAGAGCAGGTCATTACAACTTGCAACCCTCCAAACC GAAGTGTTGAGACCTAATTAAAGAGCCACCAACATTCGAAAGCGTAGATAAACCCAATGGCGTAGATAATT ATCACACCAATGTGGTCCACTATAGCGGTTTCCACTAATGCATTTCAAGAGAGCCGACTCTTGTTCAAAGC CGGCAGCCCTCACATCCAATCCTGAAATGACAAGTCATTCAAGGTTGATAATTTAATGACACTCAAACAGG CATGCCTCTCGGAATACCAAGAGGCGCAAGGTGCGTTCAAAGATTCGATGATTCACTGAATTCTGCAATTC ACATTACTTATCGCATTTCGCTGCGTTCTTCATCGATGCGAGAGCCAAGAGATCCGTTGCTGAAAGTTGTA TAGTTTTAAAGGGTCAATTAAGTCCCAATAAAATACATTCTAAACATACCATTAAGTGTGTTAAAAAACAA ACATAGTAGACTCCGTACTAAGAGAAACGCAAGCGCCTCCCTATTCCAGAATCTGCTACAAAAGGTTCACA GGTGGATGAATATTGAAAGTCGGCGAGCACATGCCCTACAAGAGCCAGCTCAACCTCCTTTACAATGTTCA ATGAATAATAGAG

Isolado 5

GGGTAGTCCTACCTGATTTGAGGTCAAAATGATCTAAGTTCATTGTCCAGTAACTTTGGACGGTTCGAAGC AGATACCCCAGAGAGAGCAGGTCATTACAACTTGCAACCCTCCAAACCGAAGTGTTGAGACCTAATTAAAG AGCCACCAACATTCGAAAGCGTAGATAAACCCAATGGCGTAGATAATTATCACACCAATGTGGTCCACTAT AGCGGTTTCCACTAATGCATTTCAAGAGAGCCGACTCTTGTTCAAAGCCGGCAGCCCTCACATCCAATCCT GAAATGACAAGTCATTCAAGGTTGATAATTTAATGACACTCAAACAGGCATGCCTCTCGGAATACCAAGAG GCGCAAGGTGCGTTCAAAGATTCGATGATTCACTGAATTCTGCAATTCACATTACTTATCGCATTTCGCTG CGTTCTTCATCGATGCGAGAGCCAAGAGATCCGTTGCTGAAAGTTGTATAGTTTTAAAGGGTCAATTAAGT CCCAATAAAATACATTCTAAACATACCATTAAAGTGTGTTAAAAAACAAAACATAGTAAGACTCCGTACTA AGAGAAACGCAAGCGCCTCCTTATTCCAGAATCTGCTACAAAAGGGTCACAGGTGGATGAATATTTGAAAG TCGGCGAGCACAATGCCCTTACAAGAGCCAGCTTNACCTT

Isolado 6 GGTAGTCCTACCTGATTTGAGGTCAAAATGATCTAAGTTCATTGTCCAGTAACTTTGGACGGTTCGAAGCA GATACCCCAGAGAGAGCAGGTCATTACAACTTGCAACCCTCCAAACCGAAGTGTTGAGACCTAATTAAAGA GCCACCAACATTCGAAAGCGTAGATAAACCCAATGGCGTAGATAATTATCACACCAATGTGGTCCACTATA GCGGTTTCCACTAATGCATTTCAAGAGAGCCGACTCTTGTTCAAAGCCGGCAGCCCTCACATCCAATCCTG AAATGACAAGTCATTCAAGGTTGATAATTTAATGACACTCAAACAGGCATGCCTCTCGGAATACCAAGAGG 
CGCAAGGTGCGTTCAAAGATTCGATGATTCACTGAATTCTGCAATTCACATTACTTATCGCATTTCGCTGC GTTCTTCATCGATGCGAGAGCCAAGAGATCCGTTGCTGAAAGTTGTATAGTTTTAAAGGGTCAATTAAGTC CCAATAAAATACATTCTAAACATACCATTAAGTGTGTTAAAAGACAAACATAGTAGACTCCGGACTAAGAG AAACGCAAGCGCCTTCCTATTCCAGAATCTGCTACAAAAGGTTCACAGGTGGATGAATATTTGAAAGTCGC GAGCACATGCCCTACAAGAGCCAGCTCAACCTNCTTTACAATGNTNTCAATAATGATCCTTTCGCA

Isolado 7

TTAAGTTCAGCGGGTAGTCCTACCTGATTTGAGGTCAAAATGATCTAAGTTCATTGTCCAGTAACTTTGGA CGGTTCGAAGCAGATACCCCAGAGAGAGCAGGTCATTACAACTTGCAACCCTCCAAACCGAAGTGTTGAGA CCTAATTAAAGAGCCACCAACATTCGAAAGCGTAGATAAACCCAATGGCGTAGATAATTATCACACCAATG TGGTCCACTATAGCGGTTTCCACTAATGCATTTCAAGAGAGCCGACTCTTGTTCAAAGCCGGCAGCCCTCA CATCCAATCCTGAAATGACAAGTCATTCAAGGTTGATAATTTAATGACACTCAAACAGGCATGCCTCTCGG AATACCAAGAGGCGCAAGGTGCGTTCAAAGATTCGATGATTCACTGAATTCTGCAATTCACATTACTTATC GCATTTCGCTGCGTTCTTCATCGATGCGAGAGCCAAGAGATCCGTTGCTGAAAGTTGTATAGTTTTAAAGG GTCAATTAAGTCCCAATAAAATACATTCTAAACATACATTAAGTGTGTTAAAAAACAAACATAGTAGACTC CGTACTAAGAGAAACGCAAGCGCCTCCCTATTCCAGAATCTGCTACAAAAGGTTCACAGGTGGATGAATAT TGAAAGTCGGCGAGCACATGCCCTACAAGAGCCAGCTCAACCTCCTTTACAATGTTTTCAATAATGNC

Isolado 8

GNCATTATTGAAAACATTGTAAAGGAGGTTGAGCTGGCTCTTGTAGGGCATGTGCTCGCCGACTTTCAATA TTCATCCACCTGTGAACCTTTTGTAGCAGATTCTGGAATAGGGAGGCGCTTGCGTTTCTCTTAGTACGGAG TCTACTATGTTTGTTTTTTAACACACTTAATGTATGTTTAGAATGTATTTTATTGGGACTTAATTGACCCT TTAAAACTATACAACTTTCAGCAACGGATCTCTTGGCTCTCGCATCGATGAAGAACGCAGCGAAATGCGAT AAGTAATGTGAATTGCAGAATTCAGTGAATCATCGAATCTTTGAACGCACCTTGCGCCTCTTGGTATTCCG AGAGGCATGCCTGTTTGAGTGTCATTAAATTATCAACCTTGAATGACTTGTCATTTCAGGATTGGATGTGA GGGCTGCCGGCTTTGAACAAGAGTCGGCTCTCTTGAAATGCATTAGTGGAAACCGCTATAGTGGACCACAT TGGTGTGATAATTATCTACGCCATTGGGTTTATCTACGCTTTCGAATGTTGGTGGCTCTTTAATTAGGTCT CAACACTTCGGTTTGGAGGGTTGCAAGTTGTAATGACCTGCTCTCTCTGGGGTATCTGCTTCGAACCGTCC AAAGTTACTGGACAATGAACTTAGATCATTTTGACCTCAAATCAGGTAGGACTACCCGTTGACTTAA

Isolado 9

CCTCNCCCNCNTTATTGATATGCTTAAGTTCAGCGGGTAGTCCTACTTGATTTGAGGTCAAAATGATCTAA GTTCATTGTCCAGTAACTTTGGCGGTTCGAAGCAGATACCCCAGAGAGAGCAGGTCATTACAACTTGCAAC CCTCCAAACCGAAGTGTTGAGACCTAATTAAAGAGCCACCAACATTCGAAAGCGTAGATAAACCCAATGGC GTAGATAATTATCACACCAATGTGGTCCACTATAGCGGTTTCCACTAATGCATTTCAAGAGAGCCGACTCT TGTTCAAAGCCGGCAGCCCTCACATCCAATCCTGAAATGACAAGTCATTCAAGGTTGATAATTTAATGACA 
CTCAAACAGGCATGCCTCTCGGAATACCAAGAGGCGCAAGGTGCGTTCAAAGATTCGATGATTCACTGAAT TCTGCAATTCACATTACTTATCGCATTTCGCTGCGTTCTTCATCGATGCGAGAGCCAAGAGATCCGTTGCT GAAAGTTGTATAGTTTTAAAGGGTCAATTAAGTCCCAATAAAATACATTCTAAACATACATTAAGTGTGTT AAAAAACAAACATAGTAGACTCCGTACTAAGAGAAACGCAAGCGCCTCCCTATTCCAGAATCTGCTACAAA AGGTTCACAGGTGGATGAATATTGAAAGTCGGCGAGCACATGCCCTACAAGAGCCAGCTCAACCTCCTTTA CAATGTTTTC

Isolado 10

GAAAACATTGTAAAGGAGGTTGAGCTGGCTCTTGTAGGGCATGTGCTCGCCGACTTTCAATATTCATCCAC CTGTGAACCTTTTGTAGCAGATTCTGGAATAGGGAGGCGCTTGCGTTTCTCTTAGTACGGAGTCTACTATG TTTGTTTTTTAACACACTTAATGTATGTTTAGAATGTATTTTATTGGGACTTAATTGACCCTTTAAAACTA TACAACTTTCAGCAACGGATCTCTTGGCTCTCGCATCGATGAAGAACGCAGCGAAATGCGATAAGTAATGT GAATTGCAGAATTCAGTGAATCATCGAATCTTTGAACGCACCTTGCGCCTCTTGGTATTCCGAGAGGCATG CCTGTTTGAGTGTCATTAAATTATCAACCTTGAATGACTTGTCATTTCAGGATTGGATGTGAGGGCTGCCG GCTTTGAACAAGAGTCGGCTCTCTTGAAATGCATTAGTGGAAACCGCTATAGTGGACCACATTGGTGTGAT AATTATCTACGCCATTGGGTTTATCTACGCTTTCGAATGTTGGTGGCTCTTTAATTAGGTCTCAACACTTC GGTTTGGAGGGTTGCAAGTTGTAATGACCTGCTCTCTCTGGGGTATCTGCTTCGAACCGTCCAAAGTTACT GGACAATGAACTTAGATCATTTTGACCTCAAATCAGGTAGGACTACCCGCTGAACTTAAGCATATCAATAA GCGCGGGAGG

Isolado 11 GATTTGAGGTCAAAATGATCTAAGTTCATTGTCCAGTAACTTTGGACGGTTCGAAGCAGATACCCCAGAGA GAGCAGGTCATTACAACTTGCAACCCTCCAAACCGAAGTGTTGAGACCTAATTAAAGAGCCACCAACATTC GAAAGCGTAGATAAACCCAATGGCGTAGATAATTATCACACCAATGTGGTCCACTATAGCGGTTTCCACTA ATGCATTTCAAGAGAGCCGACTCTTGTTCAAAGCCGGCAGCCCTCACATCCAATCCTGAAATGACAAGTCA TTCAAGGTTGATAATTTAATGACACTCAAACAGGCATGCCTCTCGGAATACCAAGAGGCGCAAGGTGCGTT CAAAGATTCGATGATTCACTGAATTCTGCAATTCACATTACTTATCGCATTTCGCTGCGTTCTTCATCGAT GCGAGAGCCAAGAGATCCGTTGCTGAAAGTTGTATAGTTTTAAAGGGTCAATTAAGTCCCAATAAAATACA TTCTAAACATACATTAAGTGTGTTAAAAAACAAACATAGTAGACTCCGTACTAAGAGAAACGCAAGCGCCT CCCTATTCCAGAATCTGCTACAAAAGGTTCACAGGTGGATGAATATTGAAAGTCGGCGAGCACATGCCCTA CAAGAGCCAGCTCAACCTCCTTTACAATGTTTTCAATAATGATCCTTCCGCAGGGTCACCTACGGAG

Isolado 12

TTATTGATAGGCTTAAGTTCAGCGGGTAGTCCTACCTAATTTAAGGTCAAAATGATCTAAGTTCATTGTCC AGTAACTTTGGACGGTTCGAAGCAGATACCCCAGAGAGAGCAGGTCATTACAACTTGCAACCCTCCAAACC GAAGTGTTGAGACCTAATTAAAGAGCCACCAACATTCGAAAGCGTAGATAAACCCAATGGCGTAGATAATT 
ATCACACCAATGTGGTCCACTATAGCGGTTTCCACTAATGCATTTCAAGAGAGCCGACTCTTGTTCAAAGC CGGCAGCCCTCACATCCAATCCTGAAATGACAAGTCATTCAAGGTTGATAATTTAATGACACTCAAACAGG CATGCCTCTCGGAATACCAAGAGGCGCAAGGTGCGTTCAAAGATTCGATGATTCACTGAATTCTGCAATTC ACATTACTTATCGCATTTCGCTGCGTTCTTCATCGATGCGAGAGCCAAGAGATCCGTTGCTGAAAGTTGTA TAGTTTTAAAGGGTCAATTAAGTCCCAATAAAATACATTCTAAACATACATTAAGTGTGTTAAAAAACAAA CATAGTAGACTCCGTACTAAGAGAAACGCAAGCGCCTCCCTATTCCAGAATCTGCTACAAAAGGTTCACAG GTGGATGAATATTGAAAGTCGGCGAGCACATGCCCTACAAGAGCCAGCTCAACCTCCTTTACAATGTTTCA ATAATAATAAA

Isolado 13 GGGTAGTCCTACCTGATTTGAGGTCAAAATGATCTAAGTTCATTGTCCAGTAACTTTGGACGGTTCGAAGC AGATACCCCAGAGAGAGCAGGTCATTACAACTTGCAACCCTCCAAACCGAAGTGTTGAGACCTAATTAAAG AGCCACCAACATTCGAAAGCGTAGATAAACCCAATGGCGTAGATAATTATCACACCAATGTGGTCCACTAT AGCGGTTTCCACTAATGCATTTCAAGAGAGCCGACTCTTGTTCAAAGCCGGCAGCCCTCACATCCAATCCT AAAATGACAAGTCATTCAAGGTTGATAATTTAATGACACTCAAACAGGCATGCCTCTCGGAATACCAAGAG GCGCAAGGTGCGTTCAAAGATTCGATGATTCACTGAATTCTGCAATTCACATTACTTATCGCATTTCGCTG CGTTCTTCATCGATGCGAGAGCCAAGAGATCCGGTGCTGAAAGGTGTATAGTTTTAAAGGGTCAATTAAGT CCCAATAAAATACATTCTAAACATACATTAAGTGTATTAAAAAAACATAGTAGACTCCGTACTAGGAGAAA ACGCAGCGCCTTCCTATTNCAGAATCTGCTACAAAAGGTTCAC

Isolado FA 23

TTAAGTTCAGCGGGTAGTCCTACCTGATTTGAGGTCAAAATGATCTAAGTTCATTGTCCAGTAACTTTGGA CGGTTCGAAGCAGATACCCCAGAGAGAGCAGGTCATTACAACTTGCAACCCTCCAAACCGAAGTGTTGAGA CCTAATTAAAGAGCCACCAACATTCGAAAGCGTAGATAAACCCAATGGCGTAGATAATTATCACACCAATG TGGTCCACTATAGCGGTTTCCACTAATGCATTTCAAGAGAGCCGACTCTTGTTCAAAGCCGGCAGCCCTCA CATCCAATCCTGAAATGACAAGTCATTCAAGGTTGATAATTTAATGACACTCAAACAGGCATGCCTCTCGG AATACCAAGAGGCGCAAGGTGCGTTCAAAGATTCGATGATTCACTGAATTCTGCAATTCACATTACTTATC GCATTTCGCTGCGTTCTTCATCGATGCGAGAGCCAAGAGATCCGTTGCTGAAAGTTGTATAGTTTTAAAGG GTCAATTAAGTCCCAATAAAATACATTCTAAACATACCATTAAGTGTGTTAAAAAACAAACATAGTAGACT CCGTACTAAGAGAAACGCAAGCGCCTCCCTATTCCAGAATCTGCTACAAAAGGTTCACAGGTGGATGAATA TTGAAAGTCGGCGAGCACATGCCCTACAAGAGCCAGCTCAACCTCCTTTACAATGTTTTCAATAATGTC

Isolado 31 GGTAGTCCTACCTGATTTGAGGTCAAAATGATCTAAGTTCATTGTCCAGTAACTTTGGACGGTTCGAAGCA GATACCCCAGAGAGAGCAGGTCATTACAACTTGCAACCCTCCAAACCGAAGTGTTGAGACCTAATTAAAGA GCCACCAACATTCGAAAGCGTAGATAAACCCAATGGCGTAGATAATTATCACACCAATGTGGTCCACTATA 
GCGGTTTCCACTAATGCATTTCAAGAGAGCCGACTCTTGTTCAAAGCCGGCAGCCCTCACATCCAATCCTG AAATGACAAGTCATTCAAGGTTGATAATTTAATGACACTGCAAACAGGCATGCCTCTCGGAATACCAAGAG GCGCAAGGTGCGTTCAAAGATTCGATGATTCACTGAATTCTGCAATTCACATTACTTATCGCATTTGGCTG CGTTCTTCATCGGATGCGAGAGCCAAGAGATCCGTGTGCTGAAAGTTGGATAGTTTTAAAGGGTCAATTAA GTCCCAATAAAATACATTCTAAACATACATTAAGTGTGTTAAAAACAAACATAGTAGACTCCGTGCTAAGA GAAACGCAAGCGCCTTCCTATTCCAGAATCTGCTACAAAAGGTTCACAGGTGGATGAATATTGAAAGTCGG CGAGCACATGCCCTACAAGAGCCAGCTCAACCTTCTTTACAATGTTTTCAATAATGATCCTTTCGCAGGTT TACCTAACGGAGGNNNNNNNGGNTTATTATTGGAAACATTGGAAAGGAGGTTGGCTGGCTCTTGTA

Isolado FA 35 GGGTAGCCCTACCTGATTTGAGGTCAAAATGATCTAAGTTCATTGTCCAGTAACTTTGGACGGTTCGAAGC AGATACCCCAGAGAGAGCAGGTCATTACAACTTGCAACCCTCCAAACCGAAGTGTTGAGACCTAATTAAAG AGCCACCAACATTCGAAAGCGTAGATAAACCCAATGGCGTAGATAATTATCACACCAATGTGGTCCACTAT AGCGGTTTCCACTAATGCATTTCAAGAGAGCCGACTCTTGTTCAAAGCCGGCAGCCCTCACATCCAATCCT GAAATGACAAGTCATTCAAGGTTGATAATTTAATGACACTCAAACAGGCATGCCTCTCGGAATACCAAGAG GCGCAAGGTGCGTTCAAAGATTCGATGATTCACTGAATTCTGCAATTCACATTACTTATCGCATTTCGCTG CGTTCTTCATCGATGCGAGAGCCAAGAGATCCGTTGCTGAAAGTTGTATAGTTTTAAAGGGTCAATTAAGT CCCAATAAAATACATTCTAAACATACATTAAAGTGTGTTAAAAAACAAACATTAGTANACTCCGTACTAAG AGAAACGCAGCGCCTTCCTATTTCAGAATCTGCTTCCAAAAGGTCACANGTTGGATGAATATTGAAAAGTC GGNGAGCACATGCCCTACAAGANCCCACTCAACCTCCTT

Isolado FA 42

TATTTATATGCTTAAGTTCAGCGGGGTAGTCTTACCTGATTTGAGGTCAAAATGATCTAAGTTCATTGTCC AGTAACTTTGGACGGTTCGAAGCAGATACCCCAGAGAGAGCAGGTCATTACAACTTGCAACCCTCCAAACC GAAGTGTTGAGACCTAATTAAAGAGCCACCAACATTCGAAAGCGTAGATAAACCCAATGGCGTAGATAATT ATCACACCAATGTGGTCCACTATAGCGGTTTCCACTAATGCATTTCAAGAGAGCCGACTCTTGTTCAAAGC CGGCAGCCCTCACATCCAATCCTGAAATGACAAGTCATTCAAGGTTGATAATTTAATGACACTCAAACAGG CATGCCTCTCGGAATACCAAGAGGCGCAAGGTGCGTTCAAAGATTCGATGATTCACTGAATTCTGCAATTC ACATTACTTATCGCATTTCGCTGCGTTCTTCATCGATGCGAGAGCCAAGAGATCCGTTGCTGAAAGTTGTA TAGTTTTAAAGGGTCAATTAAGTCCCAATAAAATACATTCTAAACATACATTAAGTGTGTTAAAAAACAAA CATAGTAGACTCCGTACTAAGAGAAACGCAAGCGCCTCCCTATTCCAGAATCTGCTACAAAAGGTTCACAG GTGGATGAATATTGAAAGTCGGCGAGCACATGCCCTACAAGAGCCAGCTCAACCTCCTTTACAATGTTCAA TAATAATCACA 
Isolado 54

GGGTAGTCCTACCTGATTTGAGGTCAAAATGATCTAAGTTCATTGTCCAGTAACTTTGGACGGTTCGAAGC AGATACCCCAGAGAGAGCAGGTCATTACAACTTGCAACCCTCCAAACCGAAGTGTTGAGACCTAATTAAAG AGCCACCAACATTCGAAAGCGTAGATAAACCCAATGGCGTAGATAATTATCACACCAATGTGGTCCACTAT AGCGGTTTCCACTAATGCATTTCAAGAGAGCCGACTCTTGTTCAAAGCCGGCAGCCCTCACATCCAATCCT GAAATGACAAGTCATTCAAGGTTGATAATTTAATGACACTCAAACAGGCATGCCTCTCGGAATACCAAGAG GCGCAAGGTGCGTTCAAAGATTCGATGATTCACTGAATTCTGCAATTCACATTACTTATCGCATTTGGCTG CGTTCTTCATCGATGCGAGAGCCAAGAGATCCGTTGCTGAAAGTTGTATAGTTTTAAAGGGTCAATTAAGT CCCAATAAAATACATTCTAAACATACATTAAGTGTGTTAAAAAACAAACATAGTAGACTCCGTACTAGAGA GAGACGCAAGCGCCTCCCTATTCCAGAATCTGCTACAAAAGGTTCACAGGTGGATGAATATTGAAAGTCGG CGAGCACATGCCCTACAAGAGCCAGCTCAACCTCCTTTACAATGTTTTCAATAATGATCCTTCCGCAGGTT CAC

Isolado 79

TTATTGATAGGCTTAAGTTCAGCGGGTAGTCCTACCTAATTTAAGGTCAAAATGATCTAAGTTCATTGTCC AGTAACTTTGGACGGTTCGAAGCAGATACCCCAGAGAGAGCAGGTCATTACAACTTGCAACCCTCCAAACC GAAGTGTTGAGACCTAATTAAAGAGCCACCAACATTCGAAAGCGTAGATAAACCCAATGGCGTAGATAATT ATCACACCAATGTGGTCCACTATAGCGGTTTCCACTAATGCATTTCAAGAGAGCCGACTCTTGTTCAAAGC CGGCAGCCCTCACATCCAATCCTGAAATGACAAGTCATTCAAGGTTGATAATTTAATGACACTCAAACAGG CATGCCTCTCGGAATACCAAGAGGCGCAAGGTGCGTTCAAAGATTCGATGATTCACTGAATTCTGCAATTC ACATTACTTATCGCATTTCGCTGCGTTCTTCATCGATGCGAGAGCCAAGAGATCCGTTGCTGAAAGTTGTA TAGTTTTAAAGGGTCAATTAAGTCCCAATAAAATACATTCTAAACATACATTAAGTGTGTTAAAAAACAAA CATAGTAGACTCCGTACTAAGAGAAACGCAAGCGCCTCCCTATTCCAGAATCTGCTACAAAAGGTTCACAG GTGGATGAATATTGAAAGTCGGCGAGCACATGCCCTACAAGAGCCAGCTCAACCTCCTTTACAATGTTTCA ATAATAATAAA

Isolado FA 104

TATTCCCGGTACATCCTACCTGATTNGAGGTCAAAATGATCTAAGTTCATTGTCCAGTAACTTTGGACGGT TCGAAGCAGATACCCCAGAGAGAGCAGGTCATTACAACTTGCAACCCTCCAAACCGAAGTGTTGAGACCTA ATTAAAGAGCCACCAACATTCGAAAGCGTAGATAAACCCAATGGCGTAGATAATTATCACACCAATGTGGT CCACTATAGCGGTTTCCACTCATGCATTTCAAGAGAGCCGACTCTTGTTCAAAGCCGGCAGCCCTCACATC CAATCCTAAAATGACAAGTCATTCAAGGTTGATAATTTAATGACACTCAAACAGGCATGCCTCTCGGAATA CCAAGAGGCGCAAGGTGCGTTCAAAGATTCGATGATTCACTGAATTCTGCAATTCACATTACTTATCGCAT TTCGCTGCGTTCTTCATCGATGCGAGAGCCAAGAGATCCGTTGCTGAAAGTTGTATAGTTTTAAAGGGTCA ATTAAGTCCCAATAAAATACATTCTAAACATACATTAAGTGTATTAAAAAAACATAGTAGACTCCGTACTA AGAGAAACGCAAGCGCCTNCCTATTNCAGAATCTGCTACAAAANGGTCACAGGTGGATGAATATTGAAAGT 
CGGCGAGCACATGCCCTACAAGAGCCAGTTCAACCTTCNTTTACAATGGTTTCAATAATGATCCTTTCCNA NGGTCACCCCCNAGGGGGN

Isolado FA 136

GGGTAGTCCTACCTGATTTGAGGTCAAAATGATCTAAATTCATTGTCCAGTAACTTGGGACGGTTCGAAGC AGATACCCCAGAGAGAGCAGGTCATTACAACTTGCAACCCTCCAAACCGAAGTGTTGAGACCTAATTAAAG AGCCGCCAACATTCGAAAGCGTAGATAAACCCAATGGCGTAGATAATTATCACACCAATATGGTCCACTAT AGCGGTGGTTTCCACTAATGCATTTCAAGAGAGCCGACTCTTGTTCAAAGCCGGCAGCCCTCACATCCAAT CCTAAAATGACAAGTCATTCAAGGTTGATAATTTAATGACACTCAAACAGGCATGCCTCTCGGAATACCAA GAGGCGCAAGGTGCGTTCAAAGATTCGATGATTCACTGAATTCTGCAATTCACATTACTTATCGCATTTCG CTGCGTTCTTCATCGATGCGAGAGCCAAGAGATCCGTTGCTGAAAGTTGTATAGTTTTAAAGGGTCAATTA AGTCCCAATAAAATACATTCTAAACATACAATTGTGTTAAAAAAAAAAAAAACATANTAAACTCCCTNCTA ANAAANACCCAAGCNCTCCCTTTTCCAAANTTTTGNTACAAAAGGTTCCAGGNGGGTGAATTTTGAAAGTC ANCGAGCCCNTGCCCTTTTAAAACCCANNTNACCNTCC

Isolado FA 152

AAGTTCAAGCGGGTAGTCCTACCTGATTTGAGGTCAAAATGATCTAAGTTCATTGTCCAGTAACTTTGGAC GGTTCGAAGCAGATACCCCAGAGAGAGCAGGTCATTACAACTTGCAACCCTCCAAACCGAAGTGTTGAGAC CTAATTAAAGAGCCACCAACATTCGAAAGCGTAGATAAACCCAATGGCGTAGATAATTATCACACCAATGT GGTCCACTATAGCGGTTTCCACTAATGCATTTCAAGAGAGCCGACTCTTGTTCAAAGCCGGCAGCCCTCAC ATCCAATCCTGAAATGACAAGTCATTCAAGGTTGATAATTTAATGACACTCAAACAGGCATGCCTCTCGGA ATACCAAGAGGCGCAAGGTGCGTTCAAAGATTCGATGATTCACTGAATTCTGCAATTCACATTACTTATCG CATTTCGCTGCGTTCTTCATCGATGCGAGAGCCAAGAGATCCGTTGCTGAAAGTTGTATAGTTTTAAAGGG TCAATTAAGTCCCAATAAAATACATTCTAAACATACATTAAGTGTGTTAAAAAACAAACATAGTAGACTCC GTACTAAGAGAAACGCAAGCGCCTCCCTATTCCAGAATCTGCTACAAAAGGTTCACAGGTGGATGAATATT GAAAGTCGGCGAGCACATGCCCTACAAGAGCCAGCTCAACCTCCTTTACAATGTTTTCAATNATGT

Isolado FA 154

TATTACGGGTAGTCCTACCTGATTTGAGGTCAAAATGATCTAAGTTCATTGTCCAGTAACTTTGGACGGTT CGAAGCAGATACCCCAGAGAGAGCAGGTCATTACAACTTGCAACCCTCCAAACCGAAGTGTTGAGACCTAA TTAAAGAGCCACCAACATTCGAAAGCGTAGATAAACCCAATGGCGTAGATAATTATCACACCAATGTGGTC CACTATAGCGGTTTCCACTAATGCATTTCAAGAGAGCCGACTCTTGTTCAAAGCCGGCAGCCCTCACATCC AATCCTGAAATGACAAGTCATTCAAGGTTGATAATTTAATGACACTCAAACAGGCATGCCTCTCGGAATAC CAAGAGGCGCAAGGTGCGTTCAAAGATTCGATGATTCACTGAATTCTGCAATTCACATTACTTATCGCATT TCGCTGCGTTCTTCATCGATGCGAGAGCCAAGAGATCCGTTGCTGAAAGTTGTATAGTTTTAAAGGGTCAA TTAAAGTCCCAATAAAATACATTCTAAACATACATTAAAGTGTGTTAAAAAACAAACATAGTAGACTTCCG 
TCTAAGAGAAACGCAAGCGCCTNCCTATTNCAGAATCTGNTACAAAANGGTTCACAGGGNGGATGAATATT GAAAGTCGGCGAGCACATGCCCTACAAGAACCCAGCTTAAACCTTCTTTACAATGGTTTCAATAATGGATC CTTCCCANGGTCCCCCCCTCNGGGGG

Isolado FA 276

GGGTAGTCCTACCTGATTTGAGGTCAAAATGATCTAAGTTCATTGTCCAGTAACTTTGGACGGTTCGAAGC AGATACCCCAGAGAGAGCAGGTCATTACAACTTGCAACCCTCCAAACCGAAGTGTTGAGACCTAATTAAAG AGCCACCAACATTCGAAAGCGTAGATAAACCCAATGGCGTAGATAATTATCACACCAATGTGGTCCACTAT AGCGGTTTCCACTAATGCATTTCAAGAGAGCCGACTCTTGTTCAAAGCCGGCAGCCCTCACATCCAATCCT GAAATGACAAGTCATTCAAGGTTGATAATTTAATGACACTCAAACAGGCATGCCTCTCGGAATACCAAGAG GCGCAAGGTGCGTTCAAAGATTCGATGATTCACTGAATTCTGCAATTCACATTACTTATCGCATTTCGCTG CGTTCTTCATCGATGCGAGAGCCAAGAGATCCGTTGCTGAAAGTTGTATAGTTTTAAAGGGTCAATTAAGT CCCAATAAAATACATTCTAAACATACATTAAGTGTGTTAAAAAACAAACATAGTAGACTCCGTACTAAAGA GAAACGCAAGCGCCCTCCTATTCAGAATCTGCTACAAAANGGTCACAGGGGGATGAATATTGNAAGTCGGC GAGCACATGCCCTACAAGANCCAGCTTAACCTNCTTACA

Isolado FA 277

GGNTANTCCTACCTGATTTGAGGTCAAAANGATCTAAGTTCATTGTCCAGTAACTTTGGACGGTTCGAAGC AGATACCCCAGAGAGAGCAGGTCATTACAACTTGCAACCCTCCAAACCGAAGTGTTGAGACCTAATTAAAG AGCCACCAACATTCGAAAGCGTAGATAAACCCAATGGCGTAGATAATTATCACACCAATGTGGTCCACTAT AGCGGTTTCCACTAATGCATTTCAAGAGAGCCGACTCTTGTTCAAAGCCGGCAGGCCTCACATCCAATCCT GAAATGCCAAGTCATTCAAGGTTGATAATTTAATGACACTCAAACAGGCATGCCTCTCGGAATCCCAAGAG GCGCAAGGTGCGTTCAAAGATTCGATGATTCACTGAATTCTGCAATTCACATTACTTATCGCATTTCGCTG CGTTCTTCATCGATGCGAGAGCCAAGAGATCCGTTGCTGAAAGTTGTATAGTTTTAAAGGGTCNATTAAGT CCCAATAAAATCCATTCTAAACATACCCATTAAGTGTGTTAAAAAAACAAACATAGTTAGACTCCGTACTT AAGAGAAACGCAAGCCNCTTCCTTATTNCAGAATTCNGNTACAAAAAGGTTCNCAAGNGGATGAATATTTG AAAGTCNGGCGANCCCCAT

Isolado FA 278

GGGTAGTCCTACCTGATTTGAGGTCAAAATGATCTAAGTTCATTGTCCAGTAACTTTGGACGGTTCGAAGC AGATACCCCAGAGAGAGCAGGTCATTACAACTTGCAACCCTCCAAACCGAAGTGTTGAGACCTAATTAAAG AGCCACCAACATTCGAAAGCGTAGATAAACCCAATGGCGTAGATAATTATCACACCAATGTGGTCCACTAT AGCGGTTTCCACTAATGCATTTCAAGAGAGCCGACTCTTGTTCAAAGCCGGCAGCCCTCACATCCAATCCT GAAATGACAAGTCATTCAAGGTTGATAATTTAATGACACTCAAACAGGCATGCCTCTCGGAATACCAAGAG GCGCAAGGTGCGTTCAAAGATTCGATGATTCACTGAATTCTGCAATTCACATTACTTATCGCATTTCGCTG CGTTCTTCATCGATGCGAGAGCCAAGAGATCCGTTGCTGAAAGTTGTATAGTTTTAAAGGGTCAATTAAGT 
CCCAATAAAATACATTCTAAACATACCATTAAGTGTGTTAAAAAACAAACATAGTAGACTCCGTACTAAGA GAAACGCAAGCGCCTCCTATTCCAGAATCTGCTACAAAANGTTCACAGGTGGATGAATATTGAAAGTCGGC GAGCACATGCCCTACAAAGAACCAGCTCAACCCTNCTTTACAA

Isolado FA 279

GGGTAGTCCTACCTGATTTGAGGTCAAAATGATCTAAGTTCATTGTCCAGTAACTTTGGACGGTTCGAAGC AGATACCCCAGAGAGAGCAGGTCATTACAACTTGCAACCCTCCAAACCGAAGTGTTGAGACCTAATTAAAG AGCCACCAACATTCGAAAGCGTAGATAAACCCAATGGCGTAGATAATTATCACACCAATGTGGTCCACTAT AGCGGTTTCCACTAATGCATTTCAAGAGAGCCGACTCTTGTTCAAAGCCGGCAGCCCTCACATCCAATCCT GAAATGACAAGTCATTCAAGGTTGATAATTTAATGACACTCAAACAGGCATGCCTCTCGGAATACCAAGAG GCGCAAGGTGCGTTCAAAGATTCGATGATTCACTGAATTCTGCAATTCACATTACTTATCGCATTTCGCTG CGTTCTTCATCGATGCGAGAGCCAAGAGATCCGTTGCTGAAAGTTGTATAGTTTTAAAGGGTCAATTAAGT CCCAATAAAATACATTCTAAACATACCATTAAGTGTGTTAAAAAACAAACATAGTAGACTCCGTACTAAGA GAAACGCAAGCGCCTCCTATTCCAGAATCTGCTACAAAANGGTCACAGGTGGGATGAATATTGAAAGTCGG CGAGCACATGCCCTACAAGAGCCAGCTCAACCTTCTT

Isolado FA 281

GGGTAGTCCTACCTGATTTGAGGTCAAAATGATCTAAGTTCATTGTCCAGTAACTTTGGACGGTTCGAAGC AGATACCCCAGAGAGAGCAGGTCATTACAACTTGCAACCCTCCAAACCGAAGTGTTGAGACCTAATTAAAG AGCCACCAACATTCGAAAGCGTAGATAAACCCAATGGCGTAGATAATTATCACACCAATGTGGTCCACTAT AGCGGTTTCCACTAATGCATTTCAAGAGAGCCGACTCTTGTTCAAAGCCGGCAGCCCTCACATCCAATCCT GAAATGACAAGTCATTCAAGGTTGATAATTTAATGACACTCAAACAGGCATGCCTCTCGGAATACCAAGAG GCGCAAGGTGCGTTCAAAGATTCGATGATTCACTGAATTCTGCAATTCACATTACTTATCGCATTTCGCTG CGTTCTTCATCGATGCGAGAGCCAAGAGATCCGTTGCTGAAAGTTGTATAGTTTTAAAGGGTCAATTAAGT CCCAATAAAATACATTCTAAACATACATTAAGTGTGTTAAAAAACAAACATAGTAGACTCCGTACTAAGAG AAACGCAAGCGCCTCCCTATTCCAGAATCTGCTACAAAAGGTTCACAGGTGGATGAATATTGAAAGTCGGC GAGCACATGCCCTACAAGAGCCAGCTCAACCTTCTTTACAATGG

Isolado FA 282

GATATGCGGTCAAAACGATCAAACCTCATTGTCCAGTTACTTNGGACGGGGGTGAGNAACACCNGNNAGAG AGCCCNTCATTACAACTTGCAACCCTCCAAACCGAAGTGTTGCCACCTAATTAAAGAGCCCCAACATTCGA AAGCGTAGATAAACCCAATGGCGTAGATAATTATCACACCAATGTGGTCCACTATAGCGGTTTCCACTAAT GCATTTCAAGAGAGCCGACTCTTGTTCAAAGCCGGCNGCCCTCNCATCCTTCNTGNAATNCAAGTCTNCAA GGTTGATAATTTAATGACACTCAAACAGGCATGCCTCTCNGAATACCAAGAGGCGCAANGTGCGTTCAAAG ATTCGATGATTCACTGTATTCTGCAATNNACATTACTTATCGCATTTCGCTGCGTTCTTCATCGATGCGAG AGCCAAGAGATCCGTTGCTGAAAGTTGTNTAGNTTTAAAGGGTCAATTAAGTCCCAATANAATACATTCTA 
AACATACCATTAAGTGTGTTAAAAAACANACATNGGTAGACTCCGTCNAANANAAACGCAAGCGCCTCCCT ATTNCANAATNTGCTCCAAAAGGGTCACNGGGTGGATGAATNTTGAAANGGCCGGCGAGCACATGCCCCTC AANGAGCCNNTTNANCCNTCTTTTCCACGGT

Isolado FA 283

CCTCGGGGNTTNATTGATATGCTTAAGTTCAGCGGGTAGTCCTACNTGATTTGAGGTCAAAATGATCTAAG TTCATNGTCCAGTAACTTTGGCGGGTTCGAAGCAGATACCCCAGAGAGAGCAGGTCATTACACCTTGCAAC CCTCCAAACCGAAGTGTTGAGACCTAATTAAAGAGCCACCAACATTCGAAAGCGTAGATAAACCCAATGGC GTAGATAATTATCACACCAATGTGGTCCACTATAGCGGTTTCCACTAATGCATTTCAAGAGAGCCGACTCT TGTTCAAAGCCGGCAGCCCTCACATCCAATCCTGAAATGACAAGTCATTCAAGGTTGATAATTTAATGACA CTCAAACAGGCATGCCTCTCGGAATACCAAGAGGCGCAAGGTGCGTTCAAAGATTCGATGATTCACTGAAT TCTGCAATTCACATTACTTATCGCATTTCGCTGCGTTCTTCATCGATGCGAGAGCCAAGAGATCCGTTGCT GAAAGTTGTATAGTTTTAAAGGGTCAATTAAGTCCCAATAAAATACATTCTAAACATACATTAAGTGTGTT AAAAAACAAACATAGTAGACTCCGTACTAAGAGAAACGCGAGCGCCTCCCTATTCCAGAATCTGCTACAAA AGGTTCACAGGTGGATGAATATTGAAAGTCGGTGAGCACATGCCCTACAAGAGCCAGCTCAACCTCCTTTA CAATGTTTNC

Isolado FA 284 GGGTAGTCCTACCTGATTTGAGGTCAAAATGATCTAAGTTCATTGTCCAGTAACTTTGGACGGTTCGAAGC AGATACCCCAGAGAGAGCAGGTCATTACAACTTGCAACCCTCCAAACCGAAGTGTTGAGACCTAATTAAAG AGCCACCAACATTCGAAAGCGTAGATAAACCCAATGGCGTAGATAATTATCACACCAATGTGGTCCACTAT AGCGGTTTCCACTAATGCATTTCAAGAGAGCCGACTCTTGTTCAAAGCCGGCAGCCCTCACATCCAATCCT GAAATGACAAGTCATTCAAGGTTGATAATTTAATGACACTCAAACAGGCATGCCTCTCGGAATACCAAGAG GCGCAAGGTGCGTTCAAAGATTCGATGATTCACTGAATTCTGCAATTCACATTACTTATCGCATTTCGCTG CGTTCTTCATCGATGCGAGAGCCAAGAGATCCGTTGCTGAAAGTTGTATAGTTTTAAAGGGTCAATTAAGT CCCAATAAAATACATTCTAAACATACATTAAGTGTGTTAAAAAACAAACATAGTAGACTCCGTACTAAGAG AAACGCAAGCGCCTCCTATTCCAGAATCTGCTACAAAANGGTCACAAGGTGGATGAATATTGAAAGTCGGC GAGCACATGCCCTACAAGAACCACTTCAACCTNCTTTAC

Isolado FA 286

GGGTAGTCCTACCTGATTTGAGGTCAAAATGATCTAAGTTCATTGTCCAGTAACTTTGGACGGTTCGAAGC AGATACCCCAGAGAGAGCAGGTCATTACAACTTGCAACCCTCCAAACCGAAGTGTTGAGACCTAATTAAAG AGCCACCAACATTCGAAAGCGTAGATAAACCCAATGGCGTAGATAATTATCACACCAATGTGGTCCACTAT AGCGGTTTCCACTAATGCATTTCAAGAGAGCCGACTCTTGTTCAAAGCCGGCAGCCCTCACATCCAATCCT GAAATGACAAGTCATTCAAGGTTGATAATTTAATGACACTCAAACAGGCATGCCTCTCGGAATACCAAGAG GCGCAAGGTGCGTTCAAAGATTCGATGATTCACTGAATTCTGCAATTCACATTACTTATCGCATTTCGCTG 
CGTTCTTCATCGATGCGAGAGCCAAGAGATCCGTTGCTGAAAGTTGTATAGTTTTAAAGGGTCAATTAAGT CCCAATAAAATACATTCTAAACATACCATTAAGTGTGTTAAAAAACAAACATAGTAGACTCCGTACTAAGA GAAACGCAAGCGCCTCCTATTCCAGAATCTGCTACAAAAGGGTCACAGGTGGATGAATATTGAAAGTCGGC GAGCACATGCCTACAAGACCAGCTNAACCTCCTTTACAATGGT

Isolado FA 287

GAAAACATTGTAAAGGAGGTTGAGCTGGCTCTTGTAGGGCATGTGCTCGCCGACTTTCAATATTCATCCAC CTGTGAACCTTTTGTAGCAGATTCTGGAATAGGGAGGCGCTTGCGTTTCTCTTAGTACGGAGTCTACTATG TTTGTTTTTTAACACACTTAATGTATGTTTAGAATGTATTTTATTGGGACTTAATTGACCCTTTAAAACTA TACAACTTTCAGCAACGGATCTCTTGGCTCTCGCATCGATGAAGAACGCAGCGAAATGCGATAAGTAATGT GAATTGCAGAATTCAGTGAATCATCGAATCTTTGAACGCACCTTGCGCCTCTTGGTATTCCGAGAGGCATG CCTGTTTGAGTGTCATTAAATTATCAACCTTGAATGACTTGTCATTTCAGGATTGGATGTGAGGGCTGCCG GCTTTGAACAAGAGTCGGCTCTCTTGAAATGCATTAGTGGAAACCGCTATAGTGGACCACATTGGTGTGAT AATTATCTACGCCATTGGGTTTATCTACGCTTTCGAATGTTGGTGGCTCTTTAATTAGGTCTCAACACTTC GGTTTGGAGGGTTGCAAGTTGTAATGACCTGCTCTCTCTGGGGTATCTGCTTCGAACCGTCCAAAGTTACT GGACAATGAACTTAGATCATTTTGACCTCAAATCANGTAGGACTACCCGCTGAACTTAAGCATATCAATAA AGNNGGGAGN

Isolado FA 292

CCCCCCCNATTTANTGTTATGTTTAAATTTAGCGGGTATTCCTTCCTGTTGGGGTCAAAATTATTTAAGTT CATCGGCCAGTAACTTTGGANGGTTCCAAGCANNNNCCCCANAGAGGGCNGTTTTTTTCAACCTGCCACCC TCCCAAACGAAGTGTTGAGACTTAATAAAAGAGCCCCCTATTTTGGAGGGGGTAGATAAACCCAAGGGGGT AGATATTTATCCCACCAATGTGGGCCAATATAGCGGTTTCCATTAATGCATTTCAAGAGAGCCGACTTTTG TTAAAAGCGGGCAGCCTTCACATCCAATCCTNAAATGACAAGTCATTCAGGGTTGATAATTTAATGACACT CAAACAGGCATGCCTCTCGGAATACCAAGAGGCGCAAGGTGCGTTCAAAGATTCGATGATTCACTGAATTC TGCAATTCACATTACTTATCGCATTTCGCTGCGTTCTTCATCGATGCGAGAGCCAAGAGATCCGTTGCTGA AAGTTGTATAGTTTTAAAGGGTCAATTAAGTCCCAATAAAATACATTCTAAACATACATTAAGTGTGTTAA AAAACAAACATAGTAGACTCCGTACTAAGAGAAACGCAAGCGCCTCCCTATTCCAGAATCTGCTACAAAAG GTTCACAGGTGGATGAATATTGAAAGTCGGCGAGCACATGCCCTACAAGAGCCAGCTCAACCTCCTTTACA ATGTTTTC

Isolado 322

GAAAACATTGTAAAGGAGGTTGAGCTGGCTCTTATAGGGCATGTGCTCGCCGACTTTCAATATTCATCCAC CTGTGAACCTTTTGTAGTAGATTCTGGAATAGGGAGGCGCTTGCGTTTCTCTTAGTACGGAGTCTACTATG TTTGTTTAACACACTTAATGTATGTTTAGAATGTATTTTATTGGGACTTAATTGACCCTTTAAAACTATAC AACTTTCAGCAACGGATCTCTTGGCTCTCGCATCGATGAAGAACGCAGCGAAATGCGATAAGTAATGTGAA 
TTGCAGAATTCAGTGAATCATCGAATCTTTGAACGCACCTTGCGCCTCTTGGTATTCCGAGAGGCATGCCT GTTTGAGTGTCATTAAATTATCAACCTTGAATGACTTGTCATTCTAGGATTGGATGTGAGGGCTGCCGGCT TTGAACAAGAGTCGGCTCTCTTGAAATGCATTAGTGGAAACCGCTATAGTGGACCATATTGGTGTGATAAT TATCTACGCCATTGGGTTTATCTACGCTTTCGAATGTTGTTGGCTCTTTAATTAGGTCTCAACACTTCGGT TTGGAGGGTTGCAAGTTGTAATGACCTGCTCTCTCTGGGGTATCTGCTTCGAACCGCCTAAGTTACTGGAC AATGAATTTAAATCATTTTGACCTCAAATCAGGTAGGACTACCCGCTTAACTTAAGCATTTCATAANNNGN GGGAGG 
Anexo B - Isolados de C. perniciosa estudados com grupos formados pela análise de RAPD, ITS e produção enzimática

\begin{tabular}{|c|c|c|c|c|c|c|c|}
\hline Linhagens & $\begin{array}{l}\text { Grupos } \\
\text { RAPD }\end{array}$ & $\begin{array}{c}\text { Grupos } \\
\text { ITS }\end{array}$ & Lip & Pect & Amil & Egl & Eegl \\
\hline 1 & G1 & R3 & $\mathrm{B}(2,49)$ & $\mathrm{B}(1,03)$ & $\mathrm{B}(0,95)$ & $\mathrm{B}(1,11)$ & $\mathrm{C}(14,30)$ \\
\hline 2 & G1 & R6 & $\mathrm{B}(1,82)$ & $\mathrm{A}(1,68)$ & $\mathrm{B}(0,93)$ & $\mathrm{C}(0,97)$ & $\mathrm{B}(46,00)$ \\
\hline 3 & G1 & $\mathrm{R} 4$ & $\mathrm{~B}(2,25)$ & $\mathrm{B}(1,18)$ & $\mathrm{B}(0,83)$ & $\mathrm{B}(1,13)$ & $\mathrm{B}(49,00)$ \\
\hline 4 & G1 & R6 & $\mathrm{B}(2,84)$ & $\mathrm{B}(1,14)$ & $\mathrm{B}(0,86)$ & $\mathrm{B}(1,09)$ & $\mathrm{B}(45,6)$ \\
\hline 5 & G1 & R5 & $\mathrm{B}(2,21)$ & $\mathrm{B}(1,26)$ & $\mathrm{B}(1,04)$ & $\mathrm{B}(1,25)$ & $\mathrm{C}(38,3)$ \\
\hline 6 & G1 & R3 & $\mathrm{B}(3,10)$ & $\mathrm{B}(0,93)$ & $\mathrm{B}(0,93)$ & $\mathrm{B}(1,11)$ & $C(41,6)$ \\
\hline 7 & G2 & R6 & $\mathrm{B}(3,45)$ & $\mathrm{B}(1,12)$ & $\mathrm{B}(1,18)$ & $\mathrm{B}(1,09)$ & $\mathrm{B}(46,00)$ \\
\hline 8 & G2 & R3 & $\mathrm{B}(1,75)$ & $\mathrm{B}(1,22)$ & $\mathrm{A}(2,45)$ & $\mathrm{B}(1,43)$ & $\mathrm{C}(31,6)$ \\
\hline 9 & G2 & R6 & $\mathrm{B}(2,54)$ & $\mathrm{B}(0,80)$ & $\mathrm{A}(1,67)$ & $\mathrm{B}(1,65)$ & $\mathrm{C}(32,00)$ \\
\hline 10 & $\mathrm{G} 2$ & R6 & $\mathrm{B}(2,84)$ & $\mathrm{C}(0,00)$ & $\mathrm{B}(0,86)$ & $\mathrm{B}(1,05)$ & $\mathrm{A}(65,6)$ \\
\hline 11 & G3 & R3 & $\mathrm{B}(1,78)$ & $\mathrm{B}(1,00)$ & $\mathrm{B}(0,74)$ & $\mathrm{B}(1,09)$ & $\mathrm{C}(35,00)$ \\
\hline 12 & G6 & R5 & $\mathrm{B}(3,51)$ & $\mathrm{A}(1,69)$ & $\mathrm{A}(4,60)$ & $\mathrm{B}(1,55)$ & $\mathrm{C}(13,30)$ \\
\hline 13 & G4 & R6 & $\mathrm{B}(2,93)$ & $\mathrm{B}(1,12)$ & $\mathrm{B}(0,79)$ & $\mathrm{B}(1,38)$ & $\mathrm{C}(12,00)$ \\
\hline FA 23 & G1 & R6 & $\mathrm{B}(2,68)$ & $\mathrm{B}(1,39)$ & $\mathrm{B}(1,25)$ & $\mathrm{B}(1,33)$ & $\mathrm{C}(39,00)$ \\
\hline 31 & $\mathrm{G} 2$ & R3 & $\mathrm{B}(2,03)$ & $\mathrm{B}(1,00)$ & $\mathrm{A}(1,73)$ & $\mathrm{B}(1,27)$ & $\mathrm{B}(47,30)$ \\
\hline FA 35 & G 1-1 & R5 & $\mathrm{B}(1,84)$ & $\mathrm{B}(0,73)$ & $\mathrm{B}(0,84)$ & $\mathrm{C}(0,98)$ & $\mathrm{B}(45,30)$ \\
\hline FA 42 & $\mathrm{G} 2$ & R6 & $\mathrm{B}(2,84)$ & $\mathrm{B}(1,05)$ & $\mathrm{B}(0,95)$ & $\mathrm{B}(1,43)$ & $\mathrm{B}(50,00)$ \\
\hline 54 & $\mathrm{G} 2$ & R6 & $\mathrm{B}(1,87)$ & $\mathrm{A}(0,93)$ & $\mathrm{A}(1,77)$ & $\mathrm{A}(2,26)$ & $\mathrm{C}(25,00)$ \\
\hline 79 & $\mathrm{G} 2$ & R6 & $\mathrm{B}(2,47)$ & $\mathrm{B}(1,23)$ & $\mathrm{A}(2,00)$ & $\mathrm{B}(1,21)$ & $\mathrm{B}(51,60)$ \\
\hline FA 104 & G5 & R5 & $\mathrm{B}(3,06)$ & $\mathrm{C}(0,00)$ & $\mathrm{B}(1,25)$ & $\mathrm{B}(1,53)$ & $\mathrm{C}(30,00)$ \\
\hline FA 136 & G7 & $\mathrm{R} 1$ & $\mathrm{~B}(4,13)$ & $\mathrm{C}(0,00)$ & $\mathrm{B}(0,95)$ & $\mathrm{B}(1,00)$ & $\mathrm{C}(40,00)$ \\
\hline FA 152 & G1-2 & R6 & $\mathrm{B}(2,30)$ & $\mathrm{B}(1,38)$ & $\mathrm{A}(1,96)$ & $\mathrm{B}(1,00)$ & $\mathrm{C}(10,30)$ \\
\hline FA 154 & G1 & R3 & $\mathrm{B}(3,39)$ & $\mathrm{B}(1,00)$ & $\mathrm{A}(1,32)$ & $\mathrm{B}(1,09)$ & $\mathrm{B}(45,00)$ \\
\hline FA 276 & G2 & R5 & $\mathrm{B}(3,01)$ & $\mathrm{A}(1,59)$ & $\mathrm{B}(1,14)$ & $\mathrm{B}(1,26)$ & $\mathrm{A}(57,30)$ \\
\hline FA 277 & G1 & R3 & $\mathrm{B}(2,92)$ & $\mathrm{B}(1,02)$ & $\mathrm{B}(1,00)$ & $\mathrm{B}(1,23)$ & $\mathrm{C}(41,60)$ \\
\hline FA 278 & G1 & R5 & $\mathrm{B}(3,07)$ & $\mathrm{C}(0,00)$ & $\mathrm{B}(0,83)$ & $\mathrm{B}(1,07)$ & $\mathrm{B}(49,30)$ \\
\hline FA 279 & G1 & R5 & $\mathrm{B}(2,82)$ & $\mathrm{B}(1,12)$ & $\mathrm{B}(0,94)$ & $\mathrm{B}(1,19)$ & $\mathrm{C}(35,60)$ \\
\hline FA 281 & $\mathrm{G} 2$ & R6 & $\mathrm{B}(3,00)$ & $\mathrm{C}(0,00)$ & $\mathrm{B}(0,88)$ & $\mathrm{B}(1,11)$ & $\mathrm{A}(59,30)$ \\
\hline FA 282 & G1 & $\mathrm{R} 2$ & $\mathrm{~B}(2,44)$ & $\mathrm{B}(1,22)$ & $\mathrm{B}(0,83)$ & $\mathrm{B}(1,48)$ & $\mathrm{C}(35,00)$ \\
\hline FA 283 & G1 & R6 & $\mathrm{B}(1,84)$ & $\mathrm{B}(1,26)$ & $\mathrm{B}(1,00)$ & $\mathrm{A}(2,14)$ & $\mathrm{C}(28,30)$ \\
\hline FA 284 & $\mathrm{G} 2$ & R5 & $\mathrm{B}(3,04)$ & $\mathrm{B}(1,29)$ & $\mathrm{B}(0,90)$ & $\mathrm{B}(1,31)$ & $\mathrm{B}(47,60)$ \\
\hline FA 286 & G1 & R5 & $\mathrm{B}(1,67)$ & $\mathrm{B}(1,27)$ & $\mathrm{A}(1,48)$ & $\mathrm{A}(1,90)$ & $\mathrm{C}(31,60)$ \\
\hline FA 287 & G1 & $\mathrm{R} 3$ & $\mathrm{~B}(3,21)$ & $\mathrm{B}(1,30)$ & $\mathrm{B}(1,04)$ & $\mathrm{B}(1,40)$ & $\mathrm{B}(45,00)$ \\
\hline FA 292 & G1 & $\mathrm{R} 2$ & $\mathrm{~B}(2,15)$ & $\mathrm{B}(1,19)$ & $\mathrm{B}(0,96)$ & $\mathrm{B}(1,27)$ & $\mathrm{C}(35,00)$ \\
\hline 322 & G8 & $\mathrm{R} 1$ & $\mathrm{~B}(2,66)$ & $\mathrm{C}(0,66)$ & $\mathrm{B}(0,66)$ & $\mathrm{A}(2,33)$ & $\mathrm{B}(46,00)$ \\
\hline
\end{tabular}

G: grupos de RAPD, R: grupos de ITS; A: Relação Halo/Colônia (H/C) maior que FA 42, B: H/C igual, C: menor; Lip: lipase, Pect: pectinase, Amil: amilase, Egl: endoglicanase, EEgl: endo e exoglicanase. 
Anexo C - Porcentagens de inibição de crescimento do fungo C. perniciosa na presença de fungicidas. Para os fungicidas Mancozeb, Óxido cuproso e Benomil a dose 1 representa a concentração de $100 \mathrm{ppm}$ e a dose 2 de $400 \mathrm{ppm}$. Para o fungicida tebuconazole a dose 1 representa a concentração de $1 \mathrm{ppm}$ e a dose 2 de $10 \mathrm{ppm}$

\begin{tabular}{|c|c|c|c|c|c|c|c|c|}
\hline \multirow{2}{*}{ Linhagens } & \multicolumn{2}{|c|}{ Mancozeb } & \multicolumn{2}{|c|}{ Óxido cuproso } & \multicolumn{2}{|c|}{ Tebuconazole } & \multicolumn{2}{|c|}{ Benomil } \\
\hline & Dose 1 & Dose 2 & Dose 1 & Dose 2 & Dose 1 & Dose 2 & Dose 1 & Dose 2 \\
\hline 1 & 2,0 & 44,7 & 27,0 & 84,0 & 68,7 & 100,0 & 27,0 & 19,0 \\
\hline 2 & 3,0 & 50,0 & 9,0 & 79,0 & 82,0 & 100,0 & 27,0 & 27,7 \\
\hline 3 & 4,3 & 91,0 & 1,3 & 75,3 & 72,0 & 97,3 & 21,6 & 31,7 \\
\hline 4 & 9,0 & 84,0 & 8,3 & 89,0 & 78,3 & 100,0 & 13,0 & 27,0 \\
\hline 5 & 3,6 & 83,0 & 19,0 & 76,3 & 74,7 & 96,0 & 18,3 & 1,7 \\
\hline 6 & 3,3 & 86,0 & 7,0 & 83,0 & 100,0 & 94,0 & 11,6 & 13,0 \\
\hline 7 & 4,3 & 78,3 & 15,0 & 24,7 & 96,7 & 96,0 & 39,0 & 11,0 \\
\hline 8 & 5,7 & 83,0 & 4,3 & 83,7 & 66,0 & 95,0 & 9,6 & 19,3 \\
\hline 9 & 4,7 & 84,0 & 17,0 & 86,0 & 87,3 & 97,3 & 32,3 & 16,7 \\
\hline 10 & 4,0 & 78,7 & 0,0 & 66,3 & 89,3 & 95,0 & 24,3 & 13,0 \\
\hline 11 & 4,3 & 63,3 & 0,7 & 33,7 & 87,7 & 96,0 & 22,7 & 27,3 \\
\hline 12 & 1,0 & 81,0 & 0,0 & 4,0 & 92,0 & 98,0 & 23,0 & 24,7 \\
\hline 13 & 7,0 & 79,0 & 30,7 & 66,6 & 100,0 & 100,0 & 19,7 & 31,7 \\
\hline FA 23 & 3,0 & 88,0 & 0,0 & 97,0 & 100,0 & 98,0 & 23,0 & 41,7 \\
\hline 31 & 4,7 & 87,0 & 22,0 & 32,0 & 88,0 & 95,0 & 18,0 & 36,7 \\
\hline FA 35 & 4,0 & 96,7 & 0,0 & 59,7 & 89,7 & 96,0 & 0,0 & 7,7 \\
\hline FA 42 & 7,0 & 85,3 & 0,0 & 86,0 & 88,0 & 100,0 & 8,6 & 10,7 \\
\hline 54 & 5,0 & 82,0 & 9,0 & 89,3 & 86,7 & 96,0 & 32,3 & 7,0 \\
\hline 79 & 5,7 & 88,0 & 21,3 & 62,3 & 84,7 & 97,7 & 26,3 & 46,7 \\
\hline FA 104 & 4,0 & 56,3 & 1,0 & 38,7 & 100,0 & 100,0 & 14,6 & 24,0 \\
\hline FA 136 & 2,0 & 75,7 & 33,3 & 85,0 & 100,0 & 100,0 & 28,0 & 8,3 \\
\hline FA 152 & 2,3 & 76,7 & 34,0 & 100,0 & 99,0 & 96,0 & 14,0 & 36,0 \\
\hline FA 154 & 3,3 & 84,7 & 10,0 & 26,0 & 89,3 & 100,0 & 10,3 & 31,0 \\
\hline FA 276 & 5,3 & 62,0 & 0,0 & 27,7 & 96,3 & 97,0 & 28,0 & 31,3 \\
\hline FA 277 & 4,0 & 92,3 & 5,0 & 32,0 & 70,0 & 98,0 & 21,6 & 29,0 \\
\hline FA 278 & 3,0 & 72,7 & 1,0 & 83,0 & 84,0 & 94,0 & 18,3 & 49,3 \\
\hline FA 279 & 4,7 & 89,3 & 5,3 & 45,0 & 78,0 & 100,0 & 0,0 & 32,0 \\
\hline FA 281 & 10,3 & 84,0 & 0,0 & 21,3 & 84,7 & 98,0 & 25,0 & 20,7 \\
\hline FA 282 & 3,0 & 85,0 & 24,7 & 41,7 & 83,0 & 93,7 & 16,3 & 21,0 \\
\hline FA 283 & 4,3 & 80,3 & 20,0 & 73,7 & 88,0 & 94,0 & 24,0 & 30,0 \\
\hline FA 284 & 8,7 & 87,3 & 2,7 & 23,0 & 90,7 & 98,0 & 18,0 & 36,0 \\
\hline FA 286 & 4,3 & 82,7 & 25,0 & 69,0 & 86,3 & 92,0 & 20,0 & 0,0 \\
\hline FA 287 & 2,0 & 89,0 & 43,7 & 60,3 & 85,7 & 96,0 & 18,3 & 25,0 \\
\hline FA 292 & 3,0 & 83,7 & 22,0 & 32,7 & 54,7 & 97,3 & 0,0 & 7,7 \\
\hline 322 & 7,0 & 73,3 & 0,0 & 0,0 & 77,3 & 94,0 & 23,0 & 29,7 \\
\hline
\end{tabular}

